\title{
Overview and Future Perspectives on Tumor-Targeted Positron Emission Tomography and Fluorescence Imaging of Pancreatic Cancer in the Era of Neoadjuvant Therapy
}

\author{
Martijn A. van Dam ${ }^{1, *(\mathbb{D})}$, Floris A. Vuijk ${ }^{1}{ }^{(D}$, Judith A. Stibbe ${ }^{1}$, Ruben D. Houvast ${ }^{1}$, $_{\text {, Saskia A. C. Luelmo }}{ }^{2}$, \\ Stijn Crobach $^{3}$, Shirin Shahbazi Feshtali ${ }^{4}$, Lioe-Fee de Geus-Oei ${ }^{5,6}{ }^{\mathbb{D}}$, Bert A. Bonsing ${ }^{1}$, Cornelis F. M. Sier ${ }^{1,7} \mathbb{D}$, \\ Peter J. K. Kuppen ${ }^{1}$ (D), Rutger-Jan Swijnenburg ${ }^{8}$, Albert D. Windhorst ${ }^{9}$, Jacobus Burggraaf ${ }^{1,10}{ }^{\mathbb{D}}$, \\ Alexander L. Vahrmeijer ${ }^{1}$ and J. Sven D. Mieog ${ }^{1}$
}

check fo updates

Citation: van Dam, M.A.; Vuijk, F.A. Stibbe, J.A.; Houvast, R.D.; Luelmo,

S.A.C.; Crobach, S.; Shahbazi Feshtali, S.; de Geus-Oei, L.-F.; Bonsing, B.A.; Sier, C.F.M.; et al. Overview and Future Perspectives on Tumor-Targeted Positron Emission Tomography and Fluorescence Imaging of Pancreatic Cancer in the Era of Neoadjuvant Therapy. Cancers 2021, 13, 6088. https://doi.org/ 10.3390/cancers13236088

Academic Editors: Atsushi Masamune and Ajay Pratap Singh

Received: 8 October 2021

Accepted: 28 November 2021

Published: 2 December 2021

Publisher's Note: MDPI stays neutral with regard to jurisdictional claims in published maps and institutional affiliations.

Copyright: (c) 2021 by the authors. Licensee MDPI, Basel, Switzerland. This article is an open access article distributed under the terms and conditions of the Creative Commons Attribution (CC BY) license (https:/ / creativecommons.org/licenses/by/ $4.0 /)$.
1 Department of Surgery, Leiden University Medical Center, 2333 ZA Leiden, The Netherlands; f.a.vuijk@lumc.nl (F.A.V.); J.A.stibbe@lumc.nl (J.A.S.); R.D.Houvast@lumc.nl (R.D.H.); b.a.bonsing@lumc.nl (B.A.B.); C.F.M.Sier@lumc.nl (C.F.M.S.); P.J.K.Kuppen@lumc.nl (P.J.K.K.); kb@chdr.nl (J.B.); a.l.vahrmeijer@lumc.nl (A.L.V.); J.S.D.Mieog@lumc.nl (J.S.D.M.)

2 Department of Medical Oncology, Leiden University Medical Center, 2333 ZA Leiden, The Netherlands; s.a.c.luelmo@lumc.nl

3 Department of Pathology, Leiden University Medical Center, 2333 ZA Leiden, The Netherlands; a.s.l.p.crobach@lumc.nl

4 Department of Radiology, Leiden University Medical Center, 2333 ZA Leiden, The Netherlands; S.Feshtali@lumc.nl

5 Department of Radiology, Section of Nuclear Medicine, University Medical Center Leiden, 2333 ZA Leiden, The Netherlands; 1.f.de_geus-oei@lumc.nl

6 Biomedical Photonic Imaging Group, University of Twente, 7522 NB Enschede, The Netherlands

7 Percuros B.V., 2333 CL Leiden, The Netherlands

8 Department of Surgery, Amsterdam UMC, Location AMC, 1105 AZ Amsterdam, The Netherlands; r.j.swijnenburg@amsterdamumc.nl

9 Department of Radiology, Section of Nuclear Medicine, Amsterdam UMC, Location VUmc, 1081 HV Amsterdam, The Netherlands; ad.windhorst@amsterdamumc.nl

10 Centre for Human Drug Research, 2333 CL Leiden, The Netherlands

* Correspondence: m.a.van_dam@lumc.nl; Tel.: +31-71-529-84-20

Simple Summary: Patients diagnosed with pancreatic cancer have a poor prognosis at time of diagnosis, with a 5 -year survival rate of merely $10 \%$. The only treatment with curative intent is surgical resection of the tumor and adjacent tumor-containing lymph nodes. To improve surgical outcome and survival, additional (imaging) tools are needed that support complete surgical tumor resection. Firstly, more accurate monitoring of tumor response to neoadjuvant treatment and subsequent determination of resectability is needed. Secondly, an imaging tool is needed for intraoperative guidance allowing accurate identification, delineation, and complete resection of the tumor and suspected lymph nodes. Therefore, both tumor-targeted PET/CT before surgery and real time fluorescence-guidance during surgery could be helpful to improve patient outcome. This review focusses on literature considering tumor-targeted PET/CT and near-infrared fluorescence (NIRF) imaging. Several tumor-targeted agents are under clinical evaluation, and several other promising agents are currently tested preclinically, both with promising results. Their additional diagnostic value and feasibility for future implementation in standard clinical care of PDAC has yet to be established in phase III clinical trials.

Abstract: Background: Despite recent advances in the multimodal treatment of pancreatic ductal adenocarcinoma (PDAC), overall survival remains poor with a 5-year cumulative survival of approximately $10 \%$. Neoadjuvant (chemo- and/or radio-) therapy is increasingly incorporated in treatment strategies for patients with (borderline) resectable and locally advanced disease. Neoadjuvant therapy aims to improve radical resection rates by reducing tumor mass and (partial) encasement of important vascular structures, as well as eradicating occult micrometastases. Results from recent multicenter clinical trials evaluating this approach demonstrate prolonged survival and increased complete 
surgical resection rates (R0). Currently, tumor response to neoadjuvant therapy is monitored using computed tomography (CT) following the RECIST 1.1 criteria. Accurate assessment of neoadjuvant treatment response and tumor resectability is considered a major challenge, as current conventional imaging modalities provide limited accuracy and specificity for discrimination between necrosis, fibrosis, and remaining vital tumor tissue. As a consequence, resections with tumor-positive margins and subsequent early locoregional tumor recurrences are observed in a substantial number of patients following surgical resection with curative intent. Of these patients, up to $80 \%$ are diagnosed with recurrent disease after a median disease-free interval of merely 8 months. These numbers underline the urgent need to improve imaging modalities for more accurate assessment of therapy response and subsequent re-staging of disease, thereby aiming to optimize individual patient's treatment strategy. In cases of curative intent resection, additional intra-operative real-time guidance could aid surgeons during complex procedures and potentially reduce the rate of incomplete resections and early (locoregional) tumor recurrences. In recent years intraoperative imaging in cancer has made a shift towards tumor-specific molecular targeting. Several important molecular targets have been identified that show overexpression in PDAC, for example: CA19.9, CEA, EGFR, VEGFR/VEGF-A, uPA/uPAR, and various integrins. Tumor-targeted PET/CT combined with intraoperative fluorescence imaging, could provide valuable information for tumor detection and staging, therapy response evaluation with re-staging of disease and intraoperative guidance during surgical resection of PDAC. Methods: A literature search in the PubMed database and (inter)national trial registers was conducted, focusing on studies published over the last 15 years. Data and information of eligible articles regarding PET/CT as well as fluorescence imaging in PDAC were reviewed. Areas covered: This review covers the current strategies, obstacles, challenges, and developments in targeted tumor imaging, focusing on the feasibility and value of PET/CT and fluorescence imaging for integration in the work-up and treatment of PDAC. An overview is given of identified targets and their characteristics, as well as the available literature of conducted and ongoing clinical and preclinical trials evaluating PDAC-targeted nuclear and fluorescent tracers.

Keywords: pancreatic ductal adenocarcinoma; targeted molecular imaging; positron emission tomography; near-infrared fluorescence imaging; neoadjuvant therapy; response monitoring; fluorescence guided surgery

\section{Introduction}

Pancreatic cancer is one of the most lethal cancer types and is the third leading cause of cancer-related death in Europe, which is expected to rise even further within the next decades [1,2]. Pancreatic ductal adenocarcinoma (PDAC) is the most common subtype of pancreatic cancer and accounts for $>90 \%$ of all pancreatic neoplasms [3]. Despite advances in surgical and systemic treatment, the 5-year overall survival (OS) rate remains approximately $10 \%$ [4]. This low survival rate is mostly caused by late detection of disease due to the late onset of symptoms [5]. Therefore, most patients are diagnosed with advanced stage disease, and only a minority (15-20\%) of patients are eligible for treatment with curative intent $[4,6,7]$.

The diagnostic workup for PDAC typically consists of a combination of CT for staging and endoscopic ultrasound with fine needle aspiration (EUS-FNA) or biopsy or endoscopic retrograde cholangiopancreatography (ERCP) to obtain histological confirmation of disease [8,9]. Recently, magnetic resonance imaging (MRI) has gained ground for the primary evaluation of local disease stage and vascular encasement by tumor tissue, as well as the characterization of distant metastases, especially in the peritoneal cavity and liver [10]. The role of ${ }^{18}$ F-FDG positron emission tomography (PET) combined with computed tomography $(\mathrm{PET} / \mathrm{CT})$ in the workup of pancreatic cancer remains controversial. The National Comprehensive Cancer Network (NCCN) consensus guideline states that FDG-PET/CT may be used per institutional preference; although, it is not a substitute for high-quality 
contrast-enhanced CT (ce-CT) [8]. The European Society for Medical Oncology (ESMO) states likewise and says the role of PET/CT should be further clarified [9]. The individual treatment plan is based on various clinical and radiological parameters, including tumor stage, the presence of metastatic disease, the extent of tumor invasion into major blood vessels, and the patient's physical condition.

Determination of resectability of a pancreatic tumor with clear surgical margins is crucial, as only complete surgical resection of the tumor can provide curative-intent treatment. Constantly developing surgical techniques (e.g., robot-assisted surgery) and the clinical introduction of (neo)adjuvant therapy have significantly improved patient outcomes in the past decade, resulting in a 30-40\% five-year OS after complete (R0) tumor resection, compared to $17.4 \%$ in 2011 [4,11,12]. The incomplete surgical resection rates (R1 or up) vary enormously in the available literature, between 20 and $70 \%$ of all pancreatic resections for malignant disease show positive surgical margins, which dramatically increase the rate of local and early recurrence of pancreatic cancer [6,13-16]. Aiming to increase the number of patients eligible for curative-intent resection and to further optimize surgical outcome, the combination of neoadjuvant induction therapy and adjuvant treatment has been under clinical investigation in the past years [4,17-20]. There are currently two combinations recommended as first-line (neo)adjuvant treatment regimens by the NCCN and ESMO: (modified) FOLFIRINOX (Folic acid, 5-Fluoruracil, Irinotecan, and Oxaliplatin) or gemcitabine plus nab-paclitaxel, the last is often combined with radiation therapy $[8,9,21]$. Since individual patient health status and morbidity highly influence the ability to receive (neo)adjuvant treatment, most well-considered multidisciplinary recommendations for duration and intensity of treatment are made within these standardized regimens or ongoing clinical trials for individual patients [4].

Focusing on neoadjuvant therapy (NT), the most clinical benefit could be gained within the borderline resectable and locally advanced patients; however, a standardized role in primary resectable disease should also be considered [22]. NT aims to slow disease progression, decrease tumor volume and local extensiveness, as well as eradication of potentially 'occult' micrometastases. NT, on one side, provides an extended time-window to detect rapid progressive disease, thereby potentially avoiding futile surgeries. On the other side, it provides a way to increase the eligibility for curative-intent resection, raise the percentage of radical resections (R0) and improve the surgical outcome $[4,23,24]$. The advantages of NT are underlined by the results of the recently published PREOPANC-1 trial. This trial compared clinical outcome and survival data of postoperative patients with resectable and borderline resectable disease who had received neoadjuvant or adjuvant therapy. Results showed improved survival and higher complete surgical resection (R0) rates in the neoadjuvant therapy arm, with a 30\% increase in R0 resections (71\% vs. 40\%) and a 2 -month prolonged median survival (16 vs. 14 months) [18]. More recently, the recruitment of patients for its successor, the PREOPANC-II trial (NTR7292) was completed. In this trial neoadjuvant treatment with FOLFIRINOX was compared to neoadjuvant Gemcitabine-Radiotherapy followed by adjuvant Gemcitabine in patients with (borderline) resectable disease [25].

To date, accurate assessment of response to (neo)adjuvant treatment remains challenging, which is a crucial step in re-staging and determination of resectability [26,27]. Currently, treatment response is monitored with CT-imaging, which is evaluated by radiologists using the internationally standardized RECIST 1.1 criteria [28,29]. These criteria focus on a percentual change in tumor dimensions (longest diameter), which are used to determine therapy response: a complete response (CR), partial response (PR), progressive disease (PD), or stable disease (SD) [28]. Although the role of this approach for assessment of response is limited, besides overestimation of tumor size on $\mathrm{CT}$, the change in tumor attenuation is of limited value in the prediction of resectability, due to the inability to differentiate treatment-related necrosis, therapy-induced fibrosis (TIF), and tumor-associated pancreatitis (TAP) from residual vital tumor tissue in the pancreas [26,30,31]. Cassinotto et al. concluded ce-CT lacks the sensitivity and performance for accurately monitoring 
treatment response, showing that the diagnostic performance of ce-CT to predict resectability decreased after neoadjuvant treatment (58\% vs. 83\%) [32]. Ferrone et al. showed similar results, stating that ce-CT after FOLFIRINOX treatment no longer adequately predicts resectability of the tumor [33]. These results underline the need for improved imaging methods for assessment of therapy response, since this is pivotal for accurate (re)staging and determination of tumor resectability [31,34,35]. In addition to conventional CT-imaging, molecular-based FDG-PET/CT-imaging has been evaluated for monitoring of (neo)adjuvant treatment response in various malignancies, including PDAC [36-38]. Despite some favorable results, the main disadvantage of FDG-based PET/CT-imaging of pancreatic tissue is the increased uptake seen in TAP, complicating adequate differentiation between the remaining tumor and adjacent benign tissue [39]. Molecular-targeted tumor imaging has the potential to overcome these challenges by selectively targeting tumor biomarkers overexpressed on or in close proximity to PDAC cells, resulting in high tumorspecific signals with minimal background accumulation in surrounding normal tissue.

Following induction treatment and restaging, the next vital steps for curative intent resection are: intraoperative visualization and delineation of the tumor to its anatomical demarcations and relations with vital structures, identification of suspect tumor-containing lymph nodes, as well as assessment of the surgical margins for residual vital tumor. However, the complex and heterogeneous tumor characteristics of PDAC with its extensive desmoplastic reaction and locoregional changes resulting from NT as well as its retroperitoneally anatomical location make this very challenging [31]. Near-infrared fluorescence (NIRF) imaging, also called fluorescence-guided surgery (FGS), a novel technique, can offer a solution by providing real-time intraoperative guidance by enhancing visual contrast for localization of the tumor and discrimination between malignant and benign tissue $[40,41]$. FGS uses a fluorescent dye conjugated to a molecular tracer designed to bind specific molecular features on (tumor)-target cells (i.e., tumor tissue, tumor stroma, etc.) [40]. Aiding a surgeon with a tool that enhances intraoperative surgical navigation to detect tumor, lymph node, and metastatic deposits in real-time, might eventually result in fewer incomplete surgical resections (R1) and improve surgical outcome and OS in the near future.

Multiple molecular targets, or biomarkers, expressed by PDAC, have been identified in previous studies. These biomarkers form the basis for tumor-targeted nuclear and fluorescence imaging in various malignancies, including PDAC [34,42-44]. Molecular imaging of oncological targets has been of particular interest in the past decade: multiple (pre)clinical trials have shown promising results for PDAC-targeted PET/CT and NIRimaging, for diagnostic as well as therapeutic purposes [45-48].

This review covers the current strategies, obstacles, and developments in moleculartargeted tumor imaging, focusing on the potentials and possibilities of integrating nuclear and fluorescence imaging in the work-up of PDAC (Figure 1). Previous and future (pre)clinical trials with tumor specific imaging agents, have been selected and presented to address the potential value of nuclear and fluorescence imaging in PDAC in the future.

A comprehensive literature search in the PubMed database and (inter)national clinical trial registers (clinicaltrials.gov; clinicaltrialsregister.eu; trialregister.nl) was performed to collect all relevant preclinical and clinical papers regarding either nuclear (PET/CT) or fluorescence imaging of PDAC from the past 15 years. Data of eligible articles were reviewed and summarized in text and tables. 


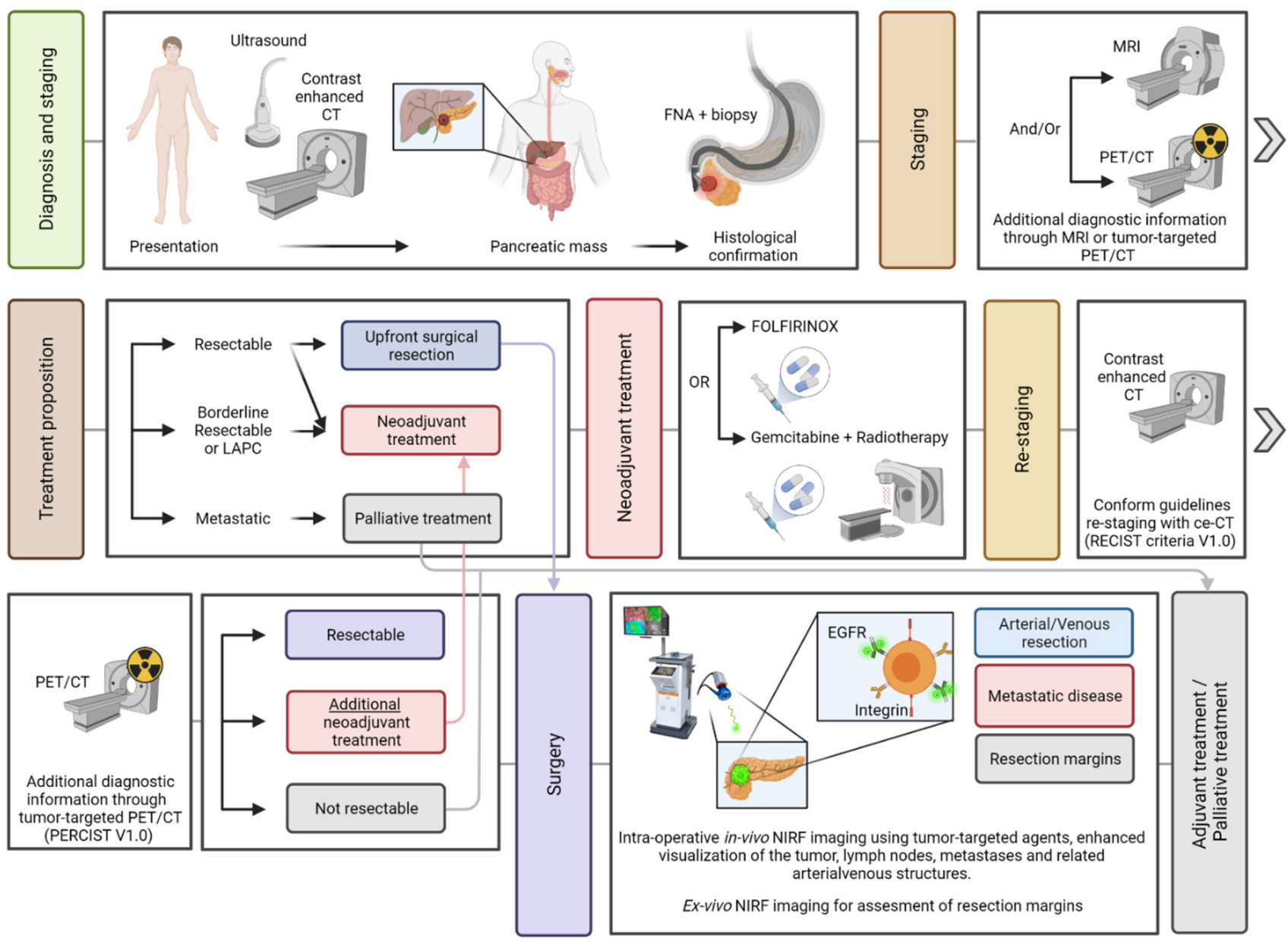

Figure 1. An overview is given of the patient journey from initial presentation to follow-up. Incorporation of molecular imaging in several stages of disease is presented. Abbreviations: CEA(CAM) $=$ Carcinoembryonic antigen; EGFR $=$ Epidermoid growth factor receptor; LAPC = Locally advanced pancreatic cancer; PDAC = Pancreatic ductal adenocarcinoma; RECIST $=$ Response Evaluation Criteria in Solid Tumors; PERCIST = Positron Emission Tomography (PET) Response Criteria in Solid Tumors; NIRF = Near-Infrared Fluorescence Imaging. Created with BioRender.com.

\section{Molecular Targets in Pancreatic Ductal Adenocarcinoma (PDAC)}

\subsection{Target Characteristics for PDAC Imaging}

Considering their pivotal roles in the onset and progression of cancer, the identification of tumor-specific molecular markers, located on tumor cells or within the tumor microenvironment (TME), for diagnostic or therapeutic targeting, has been a major focus in cancer research. A wide range of tumor-specific biomarkers for PDAC have been identified, which will be discussed in the following paragraphs, and are depicted in Table 1. The identified biomarkers are listed according to alphabetical coherence along with their molecular classification and associated function. An in-depth overview of the results of preclinical and clinical studies for each biomarker can be found in, respectively, Tables A1 and A2.

The 'ideal' target for tumor-targeted imaging has several characteristics, as described by van Oosten et al. [49]. An ideal target for PDAC imaging should be located on the cell membrane or within the extracellular matrix (ECM) in proximity of the tumor. Another category is intracellularly located targets, which possess enzymatic biological functions and are enzymatically activated. Furthermore, they should have a diffuse distribution and strong expression on the tumor cells, stroma, or on precursor lesions, including pancreatic intraepithelial neoplasia's (PanINs). In addition, an ideal target should have an absent or minimal expression on healthy pancreatic tissue as well as on tumor-associated pancreatitis (TAP), which is commonly present, proximate to, and hard to distinguish from PDAC [31,44]. Furthermore, enzymatic activity could be advantageous for application of 
locally activated imaging agents. Lastly, internalization of the target-tracer complex, which could facilitate intracellular tracer accumulation is a characteristic of interest as it could result in selective tumor cell uptake and enhanced signals.

\subsection{Overview of PDAC-Associated Molecular Targets for Imaging Purposes}

2.2.1. CA19.9

Carbohydrate antigen 19.9 (CA19.9) is a glycan attached to membrane-bound proteins and released by pancreatic (cancer) cells. CA19.9 plays a vital role in cell-to-cell recognition processes and high levels are associated with tumor progression, invasion, and metastasis [50]. Serum CA19.9 levels, which are increased in $>70 \%$ of PDAC patients, are clinically used as a biomarker for diagnosis and monitoring of PDAC. Moreover, serum CA19-9 levels are correlated with stage of disease and OS [51,52]. On a tissue level, CA19.9 is aberrantly expressed in 70-90\% of PDAC, and to a lesser extent in precursor lesions [53-55]. Nevertheless, elevated serum levels of CA19.9 and (over)expression are both observed in healthy pancreatic tissue, (chronic) pancreatitis, although, in varying levels of expression, as well as other hepatobiliary diseases, such as biliary tree obstruction [53-55]. This may potentially hamper adequate tumor identification and delineation. In addition to CA19-9, several CA19-9-related glycans are highly expressed on PDAC tissues, while expression on chronic pancreatitis and healthy pancreatic parenchyma is low or absent. Due to their amplified expression on the outermost layer of the tumor cell, tumor-associated glycans may provide several advantages for tumor targeting beyond proteins [56].

\subsubsection{Cathepsin-E}

Cathepsin-E (Cath-E) is an intracellular located aspartic proteolytic enzyme, belonging to a larger group of cathepsins, which recycle proteins for cellular homeostasis. It is assumed that Cath-E downregulates the body's immune response and promotes protein turnover [57]. Its carcinogenic function as well as the mechanism resulting in overexpression of Cath-E in PDAC and other cancer types is largely unknown [57]. Cath-E is expressed in $>90 \%$ of PDAC as well as in pancreatic precursor lesion, while its expression in healthy pancreatic tissue and pancreatitis is absent or low. [57-59]. Considering its high and diffuse expression in early pancreatic cancer lesions as well as PDAC, Cath-E is a potentially interesting target for early PDAC detection. A drawback of targeting cathepsins is its dependence on internalized, protease-activatable tracers, which are essential for adequate target visualization $[58,60,61]$.

\subsubsection{CDCP-1}

Cub-domain containing protein-1 (CDCP-1) is a transmembrane glycosylated receptor protein present on epithelial cells. CDCP-1 regulates cell-to-cell adhesion and interacts with carcinogenic pathways, which promote tumor invasiveness and metastasis. Overexpression of CDCP-1 in PDAC as well as various other cancers is correlated with poor prognosis [62] CDCP-1 is overexpressed in $>90 \%$ of PDAC [62]. Pancreatic precursor lesions express CDCP-1 low to moderately, making it a potentially interesting target for early PDAC detection. CDCP-1 has been a target of interest for targeted-imaging as well as therapy in various cancers $[63,64]$.

\subsubsection{CEA/CEACAM-5}

Carcinoembryonic antigen (CEA), or CEACAM-5 is a cell adhesion molecule anchored to the cell membrane and is involved in cellular ECM adhesion, motility, and inhibition of apoptosis [52]. Like CA19.9, CEA is clinically used as a serum biomarker for diagnosis and monitoring of PDAC. CEA serum levels are increased in 40-70\% of all PDAC patients, while CEA is overexpressed on the cell membrane in $70-85 \%$ of PDAC cases. Of note, CEA is virtually not expressed on healthy pancreatic tissue and moderately expressed in pancreatitis, strengthening its potential as a PDAC-specific target $[44,54,65]$. Anti-CEA targeted antibodies have been evaluated predominantly in PDAC-targeted fluorescence 
imaging and to a lesser extent in PET/CT-imaging, demonstrating tumor identification in both preclinical and clinical settings [66-71].

\subsubsection{EGFR}

Epidermal growth factor receptor (EGFR) is a transmembrane tyrosine-kinase receptor (TKR) for epidermal growth factor (EGF). EGFR is expressed on the cell membrane of various normal human tissues, while overexpression is observed in several types of cancer, including PDAC. EGFR plays a key role in the transition from normal epithelial to neoplastic epithelial cells and overexpression in cancerous tissues results in activation of pathways involved in cell proliferation, survival, invasion, and metastasis, as well as neoangiogenesis, which classifies EGFR overexpression as an indicator for advanced disease, poor OS, and presence of metastases [72,73]. Overexpression on the cell membrane of PDAC cells varies from $70-90 \%$, while EGFR has been detected to a lesser extent in pancreatic precursor lesions and is absent in normal pancreatic parenchyma [42,73]. Overexpression of EGFR expression in PDAC as well as its precursor lesions has made it a viable target for tumortargeted imaging and therapy. Although targeted therapy using anti-EGFR antibodies (cetuximab, and panitumumab) was moderately effective in PDAC, their employment as targeting vehicles for NIR-fluorescence imaging has allowed clear tumor delineation in both preclinical and clinical settings [42,44,72,74,75].

\subsubsection{Endoglin}

Endoglin is a component of the transforming growth factor-beta receptor complex (TGF- $\beta$ ) and is mainly expressed on the membrane of vascular endothelial cells. Endoglin, as a TGF- $\beta$ co-receptor, modulates the response to the signaling cascade upon binding of TGF- $\beta$, rather than initiating the signaling cascade like the TGF- $\beta$ receptor itself [76]. This signaling cascade mediates tumor invasiveness as well as metastatic spread through induction of (neo)angiogenesis, cell migration, and proliferation. Therefore, endoglin overexpression is related to significantly poorer OS [77]. Endoglin is diffusely upregulated in vascular endothelial PDAC cells, whereas vascular endothelial cells in healthy pancreatic tissue do not express endoglin $[77,78]$. Endoglin expression of vascular endothelial cells in pancreatitis is unknown. The applicability of targeting endoglin for molecular imaging of PDAC has to be demonstrated, since exact expression profiles of endoglin on PDAC precursor lesions as well as pancreatitis is not specifically studied, which could hamper its diagnostic value.

\subsection{7. ЕpCAM}

Epithelial cell adhesion molecule (EpCAM) is a transmembrane protein that mediates epithelial cell-to-cell adhesions. Its carcinogenic function is known to promote tumor growth, metastatic spread, and functions as an oncogenic signaling protein. EpCAM is expressed by the majority of healthy epithelial tissues while being overexpressed in a subset of human carcinomas, including PDAC. EpCAM overexpression is seen in roughly 56-78\% of all PDAC and to a lesser extent in pancreatic precursor lesions $[44,79,80]$. Overexpression of EpCAM in pancreatitis and healthy pancreatic tissue is varying, and conflicting profiles are seen in the literature, deemed minimal by Fong et al., whereas de Geus et al. demonstrate moderate expression profiles in healthy pancreatic tissue. Although EpCAM-targeted imaging tracers have been successfully evaluated for breast cancer delineation [81], their applicability for PDAC remains to be elucidated. 


\subsubsection{FAP}

Fibroblast Activation Protein- $\alpha$ (FAP) is a transmembrane protein, functioning as a serine protease and plays an important role in reactive fibroblasts, promoting angiogenesis and altering the extracellular matrix (ECM), which are crucial for tumor progression. FAP expression is only expressed by cancer-associated fibroblasts (CAF) present in the stromal compartment and in roughly $75 \%$ of the PDAC lesions. Moreover, low expression is seen in resting fibroblasts present in healthy pancreatic tissue, while moderate FAP expression is observed in patients with signs of pancreatitis [82]. Because PDAC is characterized by its prominent and dense stroma that mainly consists of CAFs, FAP is a high potential target for high-contrast tumor-targeted imaging of PDAC. Up until now, mainly applications for primary staging (PET/CT) have been investigated, showing promising results in late-stage clinical trials [83,84]. It is currently, one of the most promising targets for PDAC imaging and therapy.

\subsubsection{Fibronectin}

Fibronectin is a high-molecular weight protein of the ECM that interacts with fibrins, integrins, and collagens, through which it is involved in cell-to-cell adhesion. Fibronectin overexpression by cancer-associated fibroblasts (CAFs) has been correlated to promote angiogenesis, metastatic spread, and resistance to chemotherapy [85]. Overexpression is correlated to advanced stage of disease. Fibronectin is overexpressed in $>80 \%$ of PDAC, whereas no overexpression in normal pancreatic parenchyma is seen [86,87]. Expression profiles in precursor lesions and pancreatitis have not been evaluated. Assessment hereof, could support further evaluation of fibronectin as a target for PDAC imaging.

\subsubsection{GRP78}

Glucose-Regulated Protein-78 (GRP78) is a chaperone signaling protein normally located in the endoplasmic reticulum. In the case of neoplastic cells, it is translocated to the cell membrane, functioning as co-receptor for various proteins, including integrins. GRP78 has a dedicated function in engaging endogenous cytoprotective processes, thereby promoting tumor cell survival pathways [88]. Overexpression of GRP78 is correlated to increased tumor growth, therapeutic resistance, and metastases [89,90]. GRP78 expression is upregulated on the cell membrane of PDAC cells and to a lesser extent in precursor lesions, while it is located in the endoplasmic reticulum in normal pancreatic parenchyma, which makes it an interesting target for targeted PET/CT, since the translocation of this protein from the ER to the cell membrane is solely seen on malignant pancreatic cells. Targeting GRP78 has already been evaluated in a preclinical setting for the monitoring response of GRP78 targeted-NT using small animal PET, demonstrating its value for evaluating disease course and therapeutic efficacy at the earliest stages this treatment [91,92].

\subsubsection{Integrins}

Integrins are considered cell adhesion molecules and are the predominant receptors of the ECM, located on the cell membrane, binding various ligands, for example, RGDsequences, fibronectin, and laminin. Upon binding their ligands, they activate signal transduction pathways mediating cell-to-cell and cell-to-ECM adhesion as well as cell migration. Integrin overexpression could therefore promote tumor progression and metastatic spread. Overexpression of various integrins, including $\alpha v \beta 3, \alpha v \beta 5$, and $\alpha v \beta 6$, is seen in PDAC and correlates with more aggressive disease and decreased survival [93]. From the aforementioned PDAC-associated integrins, expression and function of integrins $\alpha v \beta 3$ and $\alpha v \beta 6$ have been most extensively evaluated. Integrin $\alpha v \beta 3$ is expressed on stromal and endothelial cells in $\sim 60 \%$ of PDAC, whereas integrin $\alpha v \beta 6$ is expressed on the epithelial cells of $80-90 \%$ of PDAC lesions [93-97]. Integrin $\alpha v \beta 3$ shows low to moderate expression on normal pancreatic tissue and moderate expression in pancreatitis [97]. Whereas integrin $\alpha \mathrm{v} \beta 6$ shows low expression on normal pancreatic tissue and moderate expression in pancreatitis $[42,44,96,98]$. Integrins possess favorable characteristics for tumor-targeted 
imaging, since targeting could take place with small-molecular sized peptides, which are easily modifiable and are able to pass biological and physical barriers essential for effective target binding $[99,100]$. Av $\beta 3 / \alpha \mathrm{v} \beta 6$ peptide sequences have been developed in different configurations, such as linear, cyclic, or cystine knotted, for optimization of specific target binding affinity and elimination pattern [101].

\subsubsection{Mesothelin}

Mesothelin is a GPI-anchored protein, present in the vast majority of mesothelial cells, in which it functions as an adhesion molecule and mediates cell-to-cell adhesion. Overexpression promotes cell proliferation, migration, and metastasis, while simultaneously interfering with pathways initiating cell apoptosis. Mesothelin is strongly and diffusely overexpressed in $>90 \%$ of PDAC, while it is minimally expressed in pancreatitis and normal pancreatic parenchyma [102,103]. Considering its expression profile, mesothelin possesses favorable characteristics for high-contrast targeted imaging of PDAC lesions, but to a lesser extent for early PDAC detection, given its minimal expression on precursor lesions [104,105].

\subsubsection{MT1-MMP/MMP-14}

Membrane type 1 matrix metalloproteinase (MT1-MMP, and MMP-14) is a cell membraneassociated endopeptidase involved in degradation of the ECM of stromal cells and facilitates cell migration, tumor invasiveness, and resistance to chemotherapy. Collagenmediated overexpression of MT1-MMP is observed in the extensive desmoplastic regions of PDAC [106,107]. MT1-MMP is overexpressed in 75\% of PDAC and to a lesser extent in precursor lesions and pancreatitis, while being absent in normal pancreatic parenchyma [108]. Since MT1-MMP plays a key role in establishing the desmoplastic reaction in pancreatic cancer, and subsequent tumor progression, it is of particular interest for investigation as a target for tumor-targeted diagnostic and therapeutic applications [109].

\subsubsection{Mucin-1}

Mucin-1 is a high-molecular weight, transmembrane glycoprotein, present on the epithelium of the pancreas, liver, breast, kidneys, lungs, and reproductive organs, on which it contributes to a protective mucus barrier. Mucin-1 overexpression in PDAC is associated with resistance to cytotoxic drugs, tumor invasiveness, metastasis, and increased cell proliferation. Mucin-1 is aberrantly expressed in its under-glycosylated form on the basolateral membrane in $90 \%$ of epithelial PDAC cells and, to a lesser extent, in precursor lesions. In normal pancreatic parenchyma, Mucin-1 is expressed in heavily glycosylated form on the apical surface of epithelial cells [110-112]. Targeting moieties that recognize the tumorassociated, under-glycosylated Mucin-1 form are of particular interest for high-contrast (early) diagnostic imaging and monitoring of PDAC [113].

\subsubsection{NTSR1}

Neurotensin receptor-1 (NTSR1) is a G-protein coupled receptor for neurotensin located on the cell membrane of cells of the upper-GI tract. In PDAC, NTSR1 is associated with activation of carcinogenic pathways resulting in cellular survival and inhibition of apoptosis. Therefore, NTSR1 overexpression in PDAC has shown to be correlated with more advanced disease [114]. NTSR1 is highly expressed in PDAC ( 79-88\%), with a low expression in normal pancreatic parenchyma and pancreatitis [115]. Since NTSR1 expression is selectively upregulated in PDAC, it possesses favorable characteristics for PDAC delineation. Several (pre)clinical trials have been conducted evaluating the performance of NTSR1 targeted peptides for tumor-targeted PET/CT as well as NIR-fluorescence imaging [115-118]. 


\subsubsection{PSMA}

Prostate-specific membrane antigen (PSMA) is a cell membrane-associated enzyme, functioning as carboxypeptidase, thereby degrading protein or peptide bonds. PSMA is believed to be involved in induction of tumor neoangiogenesis; however, the exact mechanism remains unclear [119]. PSMA is expressed in 68\% of the tumor-associated neovasculature in PDAC, and to a lesser extent on tumor cells, while no PSMA overexpression in healthy pancreatic tissue and pancreatitis is reported [119-121]. PSMA-targeted imaging has already shown promising results for diagnostic and therapeutic application in prostate cancer [122,123]. Given its tumor-specific abundance in PDAC, PSMA may be a high-potential target for high-contrast tumor-targeted imaging of PDAC [124-126].

\subsubsection{TF}

Tissue factor (TF) is a cytokine-receptor for factor VII and an initiator of the coagulation cascade through factor X. TF contributes to tumor growth, angiogenesis, metastatic spread, and thrombogenesis and is correlated with advanced disease stage, histological grade, and poor OS in PDAC [127-129]. TF overexpression in PDAC is observed in $50-90 \%$ of cases, while it is moderately expressed in pancreatic precursor lesions. Low/moderate expression is seen in pancreatitis, whereas normal pancreatic parenchyma does only minimally express TF [127]. Further evaluation with the available TF-targeted small molecule inhibitors is warranted to address the potential for early detection and monitoring of PDAC [130-132].

\subsubsection{TfR1}

Transferrin receptor-1 (TfR1) is an ion-channel coupled receptor for transferrin (Tf) that plays a key role in the cellular iron homeostasis of normal cells in the body and modulates cell growth. Overexpression of TfR1 is seen in various malignancies, since increased proliferation requires cell growth and, consequently, enhanced iron homeostasis. Overexpression of TfR 1 has been correlated with advanced tumor stage and poor prognosis $[133,134]$. TfR1 is overexpressed in $>90 \%$ of PDAC tissue, whereas expression in healthy pancreatic tissue is minimal [135]. Since TfR1 has been highly overexpressed in PDAC, it could be a target of interest for therapeutic and molecular imaging purposes. Nevertheless, more detailed information of TfR1 expression profiles in precursor lesions is warranted before evaluating its potential as a target for diagnostic PDAC imaging [136,137].

\subsubsection{9. uPA/uPAR System}

Urokinase-plasminogen activator receptor (uPAR) is a GPI-anchored receptor that localizes urokinase-plasminogen (uPA) to the cell. Activation of uPA promotes degradation of the ECM and initiates angiogenesis and metastatic spread. uPAR is correlated with more aggressive disease, poor prognosis, and decreased OS. uPAR is overexpressed on $67-80 \%$ of PDAC lesions, by neoplastic, endothelial, as well as stromal cells. Overexpression is to a lesser extent seen in precursor lesions, while expression in healthy pancreatic tissue is minimal [138-140]. Considering its expression profile on both epithelial and stromal cells, significant tumor uptake is observed, making the uPA/uPAR system a particularly interesting target for molecular imaging PDAC [42,44].

\subsubsection{VEGFR/VEGF-A}

Vascular endothelial growth factor receptors (VEGFR1 and VEGFR2) are TKRs present on vascular endothelial healthy and cancer cells. Their ligand, vascular endothelial growth factor-A (VEGF-A), is the most well-known angiogenic growth factor and abundantly present on vascular endothelial cells, in which it promotes neoangiogenesis. VEGF-A binds to VEGFR-2, which is overexpressed on the cell membrane of most gastro-intestinal cancers (GI), including PDAC [141]. Although PDAC is known as a hypovascular cancer type, angiogenesis is an essential process for supplying sufficient levels of oxygen and nutrients [142]. VEGFR-2 is overexpressed in $>70 \%$ of vascular endothelial cells in PDAC and moderately overexpressed in pancreatitis, whereas no overexpression of VEGFR-2 
expression is seen normal pancreatic parenchyma [143]. As VEGFR-2 expression is limited to the vascular endothelium and expression on pancreatitis is moderate, VEGFR-2 has less favorable characteristics for targeted PET/CT-imaging for primary diagnosis or response monitoring [34].

\subsection{The Effect of (Neo)Adjuvant Treatment on Target Expression}

A possible 'side-effect' of neoadjuvant treatment is the alteration of target expression on the tumor cells (differential expression), which may have direct consequences for the diagnostic performance of targeted imaging. Therefore, evaluation of the extent of this differential expression is a pivotal step to evaluate a tumor target. In a small cohort study, Tummers et al. demonstrated a significantly changed expression profile of CEA but not of $\alpha \mathrm{v} \beta 6$ in patients treated with neoadjuvant chemoradiation [42]. Vuijk et al. analyzed the differential expression pattern of neoadjuvant FOLFIRINOX treated PDAC tissue specimens on integrin $\alpha \mathrm{v} \beta 6, \mathrm{CEA}$, mesothelin, PSMA, uPAR, FAP, Integrin Subunit Alpha 5 (ITGA5), and EGFR [31]. Except for UPAR, FAP, ITGA5, and EGFR, which were excluded due to low expression profiles, all analyzed targets showed a significantly higher expression in PDAC compared to tumor associated pancreatitis (TAP) and normal surrounding pancreatic tissue, while therapy induced fibrosis (TIF) showed no expression of integrin $\alpha \mathrm{v} \beta 6, \mathrm{CEACAM} 5$, and mesothelin. Integrin $\alpha \mathrm{v} \beta 6, \mathrm{CEACAM} 5$, mesothelin, and PSMA have the potential to distinguish vital PDAC from surrounding fibrotic tissue after neoadjuvant FOLFIRINOX treatment, strengthening their high potential as targets for molecular imaging of PDAC in a clinical setting.

\subsection{Summary}

As shown in the abovementioned sections, twenty different PDAC (-associated) targets have been identified. Of these targets, the tumor cell targets: CEACAM, EGFR, integrin $\alpha \mathrm{v} \beta 6$, mesothelin, NTSR1, PSMA, TF, uPA/uPAR, and VEGFR/VEGF-A; and stromal targets: FAP, Fibronectin, MT1-MMP/MMP-14 and Integrin $\alpha \mathrm{v} \beta 3$ own most of the characteristics characterizing the 'ideal' imaging target, as compiled by Oosten et al. [49]. Furthermore, since PDAC is known for its extensive desmoplastic reaction, causing PDAC lesions to consist for $>90 \%$ of stromal tissue [144], targets expressed by the ECM (FAP, Fibronectin, MT1-MMP/MMP-14 and Integrin $\alpha \mathrm{v} \beta 3$ ) are of particular interest compared to epithelial markers (CDCP-1, EpCAM and Integrin $\alpha \mathrm{v} \beta 6$ ). Of these mentioned, a minority has been evaluated in clinical trials, which can mostly be attributed to the extensive, costly, and time-consuming preclinical research required for construction of suitable targeted tracers, which is followed by the preclinical validation and feasibility testing in animal models to assess the potential for further clinical translation. 
Table 1. Overview of (pre)clinical evaluated PDAC biomarkers for molecular imaging (PET/CT -NIR-fluorescence).

\begin{tabular}{|c|c|c|c|c|c|c|c|c|}
\hline Target & $\begin{array}{l}\text { Biological Function } \\
\text { (Subtype) }\end{array}$ & $\begin{array}{c}\text { Biological Effect } \\
\text { Related to Expression } \\
\text { by Tumor- } \\
\text { (Associated) Cells }\end{array}$ & $\begin{array}{c}\text { Location, } \\
\text { Expression on } \\
\text { Pancreatic } \\
\text { Cell-Type }\end{array}$ & $\begin{array}{c}\text { Target Expression } \\
\text { in PDAC } \\
(\% \text { of }+)\end{array}$ & $\begin{array}{l}\text { Advantages for PDAC } \\
\text { Imaging }\end{array}$ & $\begin{array}{l}\text { Disadvantages for } \\
\text { PDAC Imaging }\end{array}$ & $\begin{array}{l}\text { Expression } \\
\text { Profile } \\
(0 /-/+/++)\end{array}$ & Ref. \\
\hline CA19.9 & Glycan & $\begin{array}{l}\text { Cell-to-cell recognition } \\
\text { processes }\end{array}$ & $\begin{array}{l}\text { Cell membrane, } \\
\text { (neoplastic) } \\
\text { pancreatic cells }\end{array}$ & $70-90 \%$ & $\begin{array}{ll}\text { - } & \text { Diffuse, high } \\
\text { expression in PDAC } \\
\text { - } & \text { Moderate expression } \\
\text { in precursor lesions }\end{array}$ & $\begin{array}{ll}\text { - } & \text { High expression in } \\
\text { pancreatitis } \\
\text { - } & \text { Moderate } \\
\text { expression in } \\
\text { healthy pancreatic } \\
\text { tissue }\end{array}$ & $\begin{array}{l}\text { NPT: }+ \\
\text { Pancreatitis: }++ \\
\text { Precursor lesions: } \\
-/+ \\
\text { PDAC: }++\end{array}$ & [53-55] \\
\hline Cathepsin-E & $\begin{array}{l}\text { Hydrolytic aspartic } \\
\text { protease }\end{array}$ & $\begin{array}{l}\text { Regulation of immune } \\
\text { response, protein } \\
\text { turnover, induction of } \\
\text { apoptosis }\end{array}$ & $\begin{array}{l}\text { Intracellular, } \\
\text { (neoplastic) } \\
\text { pancreatic cells }\end{array}$ & $\sim 92 \%$ & $\begin{array}{ll}\text { - } & \text { Diffuse, high } \\
\text { expression in PDAC } \\
\text { - } & \text { Moderate expression } \\
\text { in Precursor lesions } \\
\text { - } & \text { No expression in } \\
\text { healthy pancreatic } \\
\text { tissue }\end{array}$ & $\begin{array}{l}\text { - Low expression in } \\
\text { pancreatitis }\end{array}$ & $\begin{array}{l}\text { NPT: } 0 \\
\text { Pancreatitis: }- \\
\text { Precursor lesions: } \\
+/++ \\
\text { PDAC: }++\end{array}$ & {$[57,59]$} \\
\hline CDCP-1 & $\begin{array}{l}\text { Glycosylated receptor } \\
\text { protein }\end{array}$ & $\begin{array}{l}\text { Cell proliferation, tumor } \\
\text { invasiveness, metastasis }\end{array}$ & $\begin{array}{l}\text { Cell membrane, } \\
\text { (neoplastic) } \\
\text { pancreatic } \\
\text { epithelial cells }\end{array}$ & $\sim 92 \%$ & $\begin{array}{ll}\text { - } & \text { Diffuse, varying } \\
\text { expression in PDAC } \\
\text { No expression in } \\
\text { healthy pancreatic } \\
\text { tissue } \\
\text { Low /Moderate } \\
\text { expression in } \\
\text { precursor lesions }\end{array}$ & $\begin{array}{l}\text { No data available } \\
\text { of expression } \\
\text { profile in } \\
\text { pancreatitis }\end{array}$ & $\begin{array}{l}\text { NPT: } 0 \\
\text { Pancreatitis: N/A } \\
\text { Precursor lesions: } \\
-/+ \\
\text { PDAC: }-/+/++\end{array}$ & {$[145,146]$} \\
\hline CEA & $\begin{array}{l}\text { Cell Adhesion } \\
\text { Molecule }\end{array}$ & $\begin{array}{l}\text { Oncogenic signaling } \\
\text { protein, inhibition of } \\
\text { apoptosis }\end{array}$ & $\begin{array}{l}\text { Cell membrane, } \\
\text { (neoplastic) } \\
\text { pancreatic cells }\end{array}$ & $70-85 \%$ & $\begin{array}{ll}\text { - } & \text { Diffuse, high } \\
\text { expression in PDAC } \\
\text { - } & \text { Moderate expression } \\
\text { in precursor lesions } \\
\text { - } & \text { No expression in } \\
\text { healthy pancreatic } \\
\text { tissue }\end{array}$ & 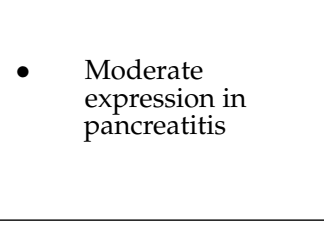 & $\begin{array}{c}\text { NPT: } 0 \\
\text { Pancreatitis }+ \\
\text { Precursor lesions: } \\
+ \\
\text { PDAC: }++\end{array}$ & {$[44,65,147]$} \\
\hline EGFR & $\begin{array}{l}\text { Tyrosine kinase } \\
\text { Receptor (TKR) }\end{array}$ & $\begin{array}{l}\text { Cell proliferation, } \\
\text { metastasis, tumor } \\
\text { angiogenesis }\end{array}$ & $\begin{array}{l}\text { Cell membrane, } \\
\text { (neoplastic) } \\
\text { pancreatic cells }\end{array}$ & $69-90 \%$ & $\begin{array}{ll}\text { - } & \text { Diffuse, high } \\
\text { expression in } \\
\text { PDAC> } \\
\text { - } \quad \text { Moderate expression } \\
\text { in precursor lesions } \\
\text { Low expression in } \\
\text { healthy pancreatic } \\
\text { tissue }\end{array}$ & $\begin{array}{l}\text { - No data available } \\
\text { of expression } \\
\text { profile in } \\
\text { pancreatitis }\end{array}$ & $\begin{array}{l}\text { NPT: }- \\
\text { Pancreatitis: N/A } \\
\text { Precursor lesions: } \\
+ \\
\text { PDAC: }++\end{array}$ & {$[42,44]$} \\
\hline
\end{tabular}


Table 1. Cont.

\begin{tabular}{|c|c|c|c|c|c|c|c|c|}
\hline Target & $\begin{array}{l}\text { Biological Function } \\
\text { (Subtype) }\end{array}$ & $\begin{array}{c}\text { Biological Effect } \\
\text { Related to Expression } \\
\text { by Tumor- } \\
\text { (Associated) Cells }\end{array}$ & $\begin{array}{c}\text { Location, } \\
\text { Expression on } \\
\text { Pancreatic } \\
\text { Cell-Type }\end{array}$ & $\begin{array}{c}\text { Target Expression } \\
\text { in PDAC } \\
(\% \text { of }+)\end{array}$ & $\begin{array}{l}\text { Advantages for PDAC } \\
\text { Imaging }\end{array}$ & $\begin{array}{l}\text { Disadvantages for } \\
\text { PDAC Imaging }\end{array}$ & $\begin{array}{l}\text { Expression } \\
\text { Profile } \\
(0 /-/+/++)\end{array}$ & Ref. \\
\hline Endoglin & Co-receptor for TGF- $\beta$ & $\begin{array}{l}\text { Tumor angiogenesis, } \\
\text { tumor growth, } \\
\text { metastasis }\end{array}$ & $\begin{array}{l}\text { Cell membrane, } \\
\text { (neoplastic) } \\
\text { pancreatic } \\
\text { vascular } \\
\text { endothelial cells }\end{array}$ & $\mathrm{N} / \mathrm{A}$ & $\begin{array}{l}\text { Diffuse, varying } \\
\text { expression in PDAC, } \\
\text { depending on tumor } \\
\text { aggressive- } \\
\text { ness/stage } \\
\text { Low expression in } \\
\text { precursor lesions } \\
\text { No expression in } \\
\text { healthy pancreatic } \\
\text { tissue }\end{array}$ & $\begin{array}{l}\text { - No data available } \\
\text { of expression } \\
\text { profile in } \\
\text { pancreatitis }\end{array}$ & $\begin{array}{l}\text { NPT: } 0 \\
\text { Pancreatitis: N/A } \\
\text { Precursor lesions: } \\
-/+ \\
\text { PDAC: }-/+/++\end{array}$ & {$[77,78]$} \\
\hline EрCAM & $\begin{array}{l}\text { Cell Adhesion } \\
\text { Molecule }\end{array}$ & $\begin{array}{l}\text { Cell proliferation, } \\
\text { metastasis, oncogenic } \\
\text { signaling protein }\end{array}$ & $\begin{array}{l}\text { Cell membrane, } \\
\text { (neoplastic) } \\
\text { pancreatic } \\
\text { epithelial cells }\end{array}$ & $56-78 \%$ & $\begin{array}{ll}\text { - } & \text { Diffuse, moderate } \\
\text { expression in PDAC } \\
\text { - } \\
\text { Low/Moderate } \\
\text { expression in } \\
\text { precursor lesions } \\
\text { - } \quad \text { Low /Moderate } \\
\text { expression in } \\
\text { pancreatitis }\end{array}$ & $\begin{array}{l}\text { Low / Moderate } \\
\text { expression in } \\
\text { healthy pancreatic } \\
\text { tissue }\end{array}$ & $\begin{array}{l}\text { NPT: }-/+ \\
\text { Pancreatitis: }-/+ \\
\text { Precursor lesions: } \\
-/+ \\
\text { PDAC: }+/++\end{array}$ & {$[44,80,148]$} \\
\hline FAP- $\alpha$ & $\begin{array}{c}\text { Cell membrane } \\
\text { associated enzyme }\end{array}$ & $\begin{array}{l}\text { Fibroblast activation, } \\
\text { promoting angiogenesis }\end{array}$ & $\begin{array}{l}\text { Cell membrane, } \\
\text { Cancer Associated } \\
\text { Fibroblasts (CAFs) } \\
\text { in stroma }\end{array}$ & $73-76 \%$ & $\begin{array}{l}\text { Diffuse, high } \\
\text { expression by CAFs } \\
\text { in PDAC } \\
\text { Low expression in } \\
\text { healthy pancreatic } \\
\text { tissue }\end{array}$ & $\begin{array}{ll}\text { - } & \text { Moderate } \\
\text { expression in } \\
\text { pancreatitis } \\
\text { - } \\
\text { No data available } \\
\text { of expression } \\
\text { profile in precursor } \\
\text { lesions }\end{array}$ & $\begin{array}{l}\text { NPT: - } \\
\text { Pancreatitis + } \\
\text { Precursor lesions: } \\
\text { N/A } \\
\text { PDAC: }++\end{array}$ & [82] \\
\hline $\begin{array}{l}\text { Fibronectin } \\
\quad \text { (FN) }\end{array}$ & Component of ECM & $\begin{array}{l}\text { Cell proliferation, } \\
\text { metastasis, resistance to } \\
\text { chemotherapy }\end{array}$ & $\begin{array}{l}\text { Cell membrane, } \\
\text { pancreatic } \\
\text { fibroblastic cells } \\
\text { and CAFs }\end{array}$ & $\sim 85 \%$ & 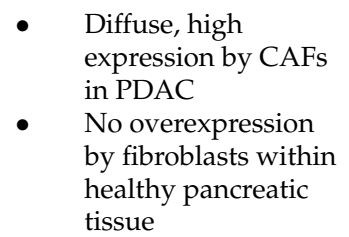 & $\begin{array}{l}\text { - No data available } \\
\text { of expression } \\
\text { profile in } \\
\text { pancreatitis and } \\
\text { precursor lesions }\end{array}$ & $\begin{array}{l}\text { NPT: } 0 \\
\text { Pancreatitis: N/A } \\
\text { Precursor lesions: } \\
\text { N/A } \\
\text { PDAC: ++ }\end{array}$ & {$[86,87]$} \\
\hline
\end{tabular}


Table 1. Cont.

\begin{tabular}{|c|c|c|c|c|c|c|c|c|}
\hline Target & $\begin{array}{l}\text { Biological Function } \\
\text { (Subtype) }\end{array}$ & $\begin{array}{c}\text { Biological Effect } \\
\text { Related to Expression } \\
\text { by Tumor- } \\
\text { (Associated) Cells } \\
\end{array}$ & $\begin{array}{c}\text { Location, } \\
\text { Expression on } \\
\text { Pancreatic } \\
\text { Cell-Type } \\
\end{array}$ & $\begin{array}{l}\text { Target Expression } \\
\text { in PDAC } \\
(\% \text { of }+)\end{array}$ & $\begin{array}{l}\text { Advantages for PDAC } \\
\text { Imaging }\end{array}$ & $\begin{array}{l}\text { Disadvantages for } \\
\text { PDAC Imaging }\end{array}$ & $\begin{array}{c}\text { Expression } \\
\text { Profile } \\
(0 /-/+/++)\end{array}$ & Ref. \\
\hline GRP78 & $\begin{array}{l}\text { Neoplastic cells: } \\
\text { Co-Receptor for } \\
\text { various proteins } \\
\text { Normal cells: } \\
\text { Chaperone protein } \\
\text { localized in ER }\end{array}$ & $\begin{array}{l}\text { Cell-to-cell and } \\
\text { cell-to-matrix } \\
\text { recognition processes, } \\
\text { induction of } \\
\text { endoplasmic reticulum } \\
\text { stress for cell aging, } \\
\text { survival, metastasis }\end{array}$ & $\begin{array}{l}\text { Cell membrane, } \\
\text { pancreatic } \\
\text { neoplastic cells (in } \\
\text { non-tumor cells } \\
\text { located in ER) }\end{array}$ & N/A & $\begin{array}{ll}\text { - } & \text { Diffuse and high } \\
\text { expression in PDAC } \\
\text { - } \quad \text { Low expression in } \\
\text { precursor lesions }\end{array}$ & $\begin{array}{l}\text { Low expression in } \\
\text { healthy pancreatic } \\
\text { tissue } \\
\text { No data available } \\
\text { of expression } \\
\text { profile in } \\
\text { pancreatitis }\end{array}$ & $\begin{array}{l}\text { NPT: }- \\
\text { Pancreatitis: N/A } \\
\text { Precursor lesions: } \\
- \\
\text { PDAC: }++\end{array}$ & {$[90,149]$} \\
\hline $\begin{array}{c}\text { Integrin } \\
\alpha v \beta 3\end{array}$ & $\begin{array}{l}\text { Cell Adhesion } \\
\text { Molecule }\end{array}$ & $\begin{array}{l}\text { Tumor angiogenesis, } \\
\text { tumor growth, } \\
\text { metastasis }\end{array}$ & $\begin{array}{l}\text { Cell membrane, } \\
\text { (neoplastic) } \\
\text { stromal and } \\
\text { endothelial } \\
\text { pancreatic cells }\end{array}$ & $\sim 68 \%$ & $\begin{array}{ll}\text { - } & \text { Diffuse, moderate } \\
\text { - } & \text { Modession in PDAC } \\
\text { in precursor lesions }\end{array}$ & $\begin{array}{ll}\text { - } & \text { Low } / \text { moderate } \\
\text { expression on } \\
\text { healthy pancreatic } \\
\text { tissue } \\
\text { Moderate } \\
\text { expression in } \\
\text { pancreatitis }\end{array}$ & $\begin{array}{l}\text { NPT: }- \text { to }-/+ \\
\text { Pancreatitis }-/+ \\
\text { Precursor lesions: } \\
-/+ \\
\text { PDAC: }+/++\end{array}$ & {$[93,97]$} \\
\hline $\begin{array}{c}\text { Integrin } \\
\alpha v \beta 6\end{array}$ & $\begin{array}{l}\text { Cell Adhesion } \\
\text { Molecule }\end{array}$ & $\begin{array}{l}\text { Tumor growth, } \\
\text { metastasis }\end{array}$ & $\begin{array}{l}\text { Cell membrane, } \\
\text { (neoplastic) } \\
\text { epithelial cells }\end{array}$ & $80-88 \%$ & $\begin{array}{ll}\text { - } & \text { Diffuse, high } \\
\text { - } & \text { Modession in PDAC } \\
\text { in precursor lesions }\end{array}$ & $\begin{array}{l}\text { Low expression on } \\
\text { healthy pancreatic } \\
\text { tissue } \\
\text { Moderate } \\
\text { expression in } \\
\text { pancreatitis }\end{array}$ & $\begin{array}{l}\text { NPT: }-/+ \\
\text { Pancreatitis }-/+ \\
\text { Precursor lesions: } \\
-/+ \\
\text { PDAC: }++\end{array}$ & {$[44,96,98]$} \\
\hline Mesothelin & $\begin{array}{l}\text { GPI-anchored protein } \\
\text { (Adhesion molecule) }\end{array}$ & $\begin{array}{l}\text { Cell proliferation, } \\
\text { migration, metastasis, } \\
\text { inhibition of apoptosis }\end{array}$ & $\begin{array}{l}\text { Cell membrane of } \\
\text { pancreatic } \\
\text { (neoplastic) } \\
\text { mesothelial cells }\end{array}$ & $>90 \%$ & $\begin{array}{l}\text { - Diffuse, high } \\
\text { expression in PDAC } \\
\text { No expression in } \\
\text { healthy pancreatic } \\
\text { tissue and in } \\
\text { pancreatitis }\end{array}$ & $\begin{array}{ll}\text { - } & \text { Minimal } \\
\text { - } & \text { expression in } \\
\text { most precursor } \\
\text { lesions }\end{array}$ & $\begin{array}{l}\text { NPT: } 0 \\
\text { Pancreatitis: } 0 \\
\text { Precursor lesions: } \\
\text { 0/- } \\
\text { PDAC: }++\end{array}$ & {$[102,103]$} \\
\hline $\begin{array}{c}\text { MT1- } \\
\text { MMP/MMP- } \\
14\end{array}$ & $\begin{array}{l}\text { Cell membrane } \\
\text { associated enzyme }\end{array}$ & $\begin{array}{l}\text { Tumor growth, } \\
\text { invasiveness, resistance } \\
\text { to chemotherapy }\end{array}$ & $\begin{array}{l}\text { Cell membrane, } \\
\text { (neoplastic) } \\
\text { pancreatic stromal } \\
\text { cells }\end{array}$ & $\sim 75 \%$ & $\begin{array}{ll}\text { - } & \text { Diffuse, high } \\
\text { expression in PDAC } \\
\text { - } \quad \text { Low expression in } \\
\text { pancreatitis }\end{array}$ & $\begin{array}{l}\text { Low expression in } \\
\text { healthy pancreatic } \\
\text { tissue } \\
\text { Low expression in } \\
\text { precursor lesions }\end{array}$ & $\begin{array}{l}\text { NPT: }- \\
\text { Pancreatitis: }-/+ \\
\text { Precursor lesions: } \\
-/+ \\
\text { PDAC: }++\end{array}$ & {$[108,150]$} \\
\hline
\end{tabular}


Table 1. Cont.

\begin{tabular}{|c|c|c|c|c|c|c|c|c|}
\hline Target & $\begin{array}{l}\text { Biological Function } \\
\text { (Subtype) }\end{array}$ & $\begin{array}{c}\text { Biological Effect } \\
\text { Related to Expression } \\
\text { by Tumor- } \\
\text { (Associated) Cells } \\
\end{array}$ & $\begin{array}{c}\text { Location, } \\
\text { Expression on } \\
\text { Pancreatic } \\
\text { Cell-Type } \\
\end{array}$ & $\begin{array}{c}\text { Target Expression } \\
\text { in PDAC } \\
(\% \text { of }+)\end{array}$ & $\begin{array}{l}\text { Advantages for PDAC } \\
\text { Imaging }\end{array}$ & $\begin{array}{l}\text { Disadvantages for } \\
\text { PDAC Imaging }\end{array}$ & $\begin{array}{l}\text { Expression } \\
\text { Profile } \\
(0 /-/+/++)\end{array}$ & Ref. \\
\hline Mucin-1 & Protective cell coating & $\begin{array}{l}\text { Cell proliferation, tumor } \\
\text { invasiveness due to } \\
\text { upregulated cell motility, } \\
\text { metastasis }\end{array}$ & $\begin{array}{l}\text { Cell membrane, } \\
\text { (neoplastic) } \\
\text { pancreatic } \\
\text { epithelial cells }\end{array}$ & $\sim 90 \%$ & $\begin{array}{ll}\text { - } & \text { Diffuse, high } \\
\text { expression in PDAC } \\
\text { - } \quad \text { Low /moderate } \\
\text { expression in } \\
\text { precursor lesions }\end{array}$ & $\begin{array}{ll}\text { - } & \text { Low expression } \\
\text { healthy pancreatic } \\
\text { tissue } \\
\text { No data available } \\
\text { of expression } \\
\text { profile in } \\
\text { pancreatitis }\end{array}$ & $\begin{array}{l}\text { NPT: }- \\
\text { Pancreatitis: N/A } \\
\text { Precursor lesions: } \\
-/+,+ \\
\text { PDAC: }++\end{array}$ & {$[112,151]$} \\
\hline NTSR1 & $\begin{array}{l}\text { G-protein-coupled } \\
\text { Receptor (GPCR) }\end{array}$ & $\begin{array}{l}\text { Cell proliferation, } \\
\text { inhibition of apoptosis. }\end{array}$ & $\begin{array}{l}\text { Cell membrane, } \\
\text { (neoplastic) } \\
\text { pancreatic cells }\end{array}$ & $79-88 \%$ & $\begin{array}{ll}\text { - } & \text { Diffuse and high } \\
\text { expression in PDAC } \\
\text { - } \quad \text { Low expression in } \\
\text { healthy pancreatic } \\
\text { tissue }\end{array}$ & $\begin{array}{l}\text { Low expression } \\
\text { pancreatitis } \\
\text { No data available } \\
\text { of expression } \\
\text { profile in precursor } \\
\text { lesions }\end{array}$ & $\begin{array}{l}\text { NPT: }- \\
\text { Pancreatitis: + } \\
\text { Precursor lesions: } \\
\text { N/A } \\
\text { PDAC: ++ }\end{array}$ & {$[114,115]$} \\
\hline PSMA & $\begin{array}{l}\text { Cell membrane } \\
\text { associated enzyme }\end{array}$ & Tumor angiogenesis & $\begin{array}{l}\text { Cell membrane, } \\
\text { neovascular } \\
\text { associated cells } \\
\text { and tumor cells }\end{array}$ & $\sim 68 \%$ & $\begin{array}{ll}\text { - } & \text { Diffuse, } \\
\text { moderate/high } \\
\text { expression in PDAC } \\
\text { No expression in } \\
\text { healthy pancreatic } \\
\text { tissue and in } \\
\text { pancreatitis }\end{array}$ & $\begin{array}{l}\text { No data available } \\
\text { of expression } \\
\text { profile precursor } \\
\text { lesions }\end{array}$ & $\begin{array}{l}\text { NPT: } 0 \\
\text { Pancreatitis: } 0 \\
\text { Precursor lesions: } \\
\text { N/A } \\
\text { PDAC: }+/++\end{array}$ & {$[119,120]$} \\
\hline $\begin{array}{l}\text { Tissue Factor } \\
\text { (TF) }\end{array}$ & Cytokine-receptor & $\begin{array}{l}\text { Initiating blood } \\
\text { coagulation cascades, } \\
\text { metastasis }\end{array}$ & $\begin{array}{l}\text { Cell membrane, } \\
\text { (neoplastic) } \\
\text { pancreatic cells }\end{array}$ & $50-90 \%$ & $\begin{array}{ll}\text { - } & \text { Diffuse, high } \\
\text { expression in PDAC } \\
\text { - } \\
\text { Moderate/high } \\
\text { expression in } \\
\text { precursor lesions } \\
\text { - } \quad \text { Low expression } \\
\text { healthy pancreatic } \\
\text { tissue }\end{array}$ & $\begin{array}{l}\text { Low expression in } \\
\text { pancreatitis }\end{array}$ & $\begin{array}{l}\text { NPT: }- \\
\text { Pancreatitis }-/+ \\
\text { Precursor lesions: } \\
+/++ \\
\text { PDAC: }++\end{array}$ & [127-129] \\
\hline TfR1 & $\begin{array}{l}\text { Ion-channel coupled } \\
\text { Receptor }\end{array}$ & $\begin{array}{l}\text { Cell proliferation, } \\
\text { regulation of iron } \\
\text { uptake/release. }\end{array}$ & $\begin{array}{l}\text { Cell membrane, } \\
\text { (neoplastic) } \\
\text { pancreatic cells }\end{array}$ & $>90 \%$ & $\begin{array}{ll}\text { - } & \text { Diffuse, high } \\
\text { expression in PDAC } \\
\text { - } \quad \text { No expression in } \\
\text { healthy pancreatic } \\
\text { tissue }\end{array}$ & $\begin{array}{l}\text { - No data available } \\
\text { of expression } \\
\text { profile in } \\
\text { pancreatitis and } \\
\text { precursor lesions }\end{array}$ & $\begin{array}{l}\text { NPT: } 0 \\
\text { Pancreatitis: N/A } \\
\text { Precursor lesions: } \\
\text { N/A } \\
\text { PDAC: ++ }\end{array}$ & {$[135,136]$} \\
\hline
\end{tabular}


Table 1. Cont.

\begin{tabular}{|c|c|c|c|c|c|c|c|c|}
\hline Target & $\begin{array}{l}\text { Biological Function } \\
\text { (Subtype) }\end{array}$ & $\begin{array}{c}\text { Biological Effect } \\
\text { Related to Expression } \\
\text { by Tumor- } \\
\text { (Associated) Cells }\end{array}$ & $\begin{array}{c}\text { Location, } \\
\text { Expression on } \\
\text { Pancreatic } \\
\text { Cell-Type }\end{array}$ & $\begin{array}{l}\text { Target Expression } \\
\text { in PDAC } \\
(\% \text { of }+)\end{array}$ & $\begin{array}{l}\text { Advantages for PDAC } \\
\text { Imaging }\end{array}$ & $\begin{array}{l}\text { Disadvantages for } \\
\text { PDAC Imaging }\end{array}$ & $\begin{array}{l}\text { Expression } \\
\text { Profile } \\
(0 /-/+/++)\end{array}$ & Ref. \\
\hline $\begin{array}{l}\text { uPAR/uPA } \\
\text { system }\end{array}$ & GPI-anchored receptor & $\begin{array}{l}\text { Degradation of ECM, } \\
\text { tumor angiogenesis, } \\
\text { metastasis }\end{array}$ & $\begin{array}{l}\text { Cell membrane, } \\
\text { stromal } \\
\text { (neoplastic) cells } \\
\text { Cell membrane, } \\
\text { endothelial } \\
\text { (neoplastic) } \\
\text { pancreatic cells }\end{array}$ & $\begin{array}{l}\sim 80 \% \\
\sim 67 \%\end{array}$ & $\begin{array}{ll}\text { - } & \text { Diffuse, moderate } \\
\text { expression PDAC } \\
\text { and surrounding } \\
\text { stroma } \\
\text { Moderate expression } \\
\text { in precursor lesions } \\
\text { - Low expression in } \\
\text { healthy pancreatic } \\
\text { tissue }\end{array}$ & 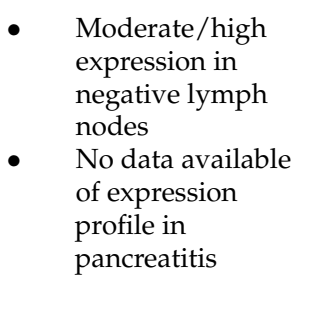 & $\begin{array}{l}\text { NPT: - } \\
\text { Pancreatitis: N/A } \\
\text { Precursor lesions: } \\
+ \\
\text { PDAC: }+/++\end{array}$ & {$[44,138,140]$} \\
\hline $\begin{array}{l}\text { VEGFR-2/ } \\
\text { VEGF-A }\end{array}$ & $\begin{array}{l}\text { Tyrosine kinase } \\
\text { Receptor (TKR) } \\
\text { Growth factor }\end{array}$ & Tumor angiogenesis & $\begin{array}{l}\text { Cell membrane, } \\
\text { pancreatic } \\
\text { vascular } \\
\text { endothelial cells }\end{array}$ & $>70 \%$ & $\begin{array}{l}\text { Diffuse and high } \\
\text { - } \quad \text { Low expren in PDAC } \\
\text { healthy pancreatic in } \\
\text { tissue }\end{array}$ & $\begin{array}{l}\text { Low expression in } \\
\text { pancreatitis } \\
\text { No data available } \\
\text { of expression } \\
\text { profile in precursor } \\
\text { lesions }\end{array}$ & $\begin{array}{l}\text { NPT: }- \\
\text { Pancreatitis: }- \\
\text { Precursor lesions: } \\
\text { N/A } \\
\text { PDAC: }++\end{array}$ & {$[143,152]$} \\
\hline
\end{tabular}

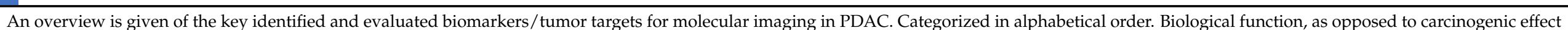

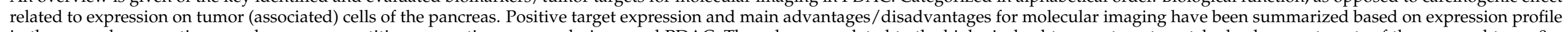

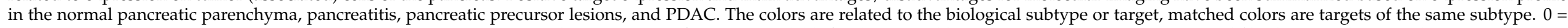

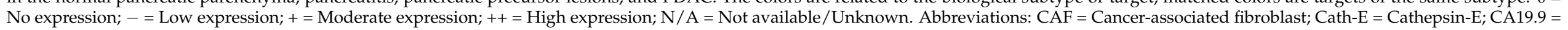

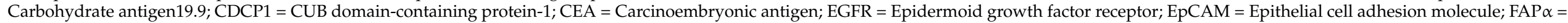

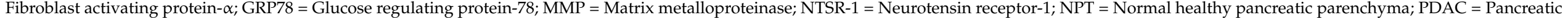

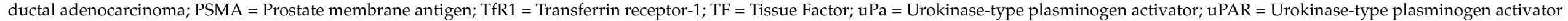
Receptor; VEGFR(2) = Vascular endothelial growth factor receptor; VEGF- $\alpha=$ Vascular endothelial growth factor $\alpha$. 


\section{Positron Emission Tomography—Computed Tomography (PET/CT)}

PET/CT has the unique ability to provide information on biochemical activity of cancer tissue. In the last decade, several PDAC-targeted PET-tracers have been evaluated in (pre)clinical studies for their potential to provide valuable diagnostic information in various stages of disease.

\subsection{Primary Diagnostic Work-Up and Monitoring Response to Neoadjuvant Treatment}

Currently, the diagnostic work-up of suspected pancreatic lesions is ce-CT. Current guidelines are indifferent on the role and diagnostic value of FDG-PET/CT [8]; however, this might change in the future based on recent literature as discussed in Section 4.2. Furthermore, with the implementation of neoadjuvant treatment schedules as standard of care for borderline resectable tumors, accurate treatment response monitoring and determination of resectability is important. As the current imaging methods are insufficient to predict response to NT, additional diagnostic tools are needed [32,33]. PET/CT could potentially contribute to this by visualizing and predicting changes in biochemical activity and tumor volume before and after NT. Treatment response monitoring using PET/CT has only been evaluated in clinical trials using radiolabeled glucose $\left({ }^{18} \mathrm{~F}-\mathrm{FDG}\right)$, which is one of the few clinically approved PET-tracers. PDAC-targeted PET-radiotracers are currently still in the early phases of (pre)clinical development and research is mainly focused on feasibility and performance during primary diagnostic work-up. Until now, no reports have been published on the clinical use of molecular targeted PET-imaging for treatment response monitoring in PDAC.

\subsection{Clinically Available PET-Tracers for PDAC Imaging}

\subsection{1. ${ }^{18} \mathrm{~F}-\mathrm{FDG}$}

${ }^{18} \mathrm{~F}$-FDG is currently the most widely used PET-tracer in cancer imaging and shows uptake in tissues with increased metabolic activity such as cancer or infection. The major drawback of ${ }^{18} \mathrm{~F}$-FDG PET/CT imaging for visualizing a suspected pancreatic mass is the low specificity for accurate differentiation between malignant, pre-existent, and inflammatory tissue. However, recent studies demonstrated superior sensitivity for detecting distant metastatic disease, especially in the liver, when compared to ce-CT [153-155]. The PETPANC study, a large multicenter prospective study conducted in the United Kingdom, showed that in $11 \%$ of the patients with primary suspected pancreatic malignancies, the management and therapeutic strategy were changed based on PET/CT findings (including avoidance of futile surgeries in $20 \%$ of patients) [154]. Feasibility and performance of FDG-PET/CT for monitoring response in PDAC has been evaluated in several smaller trials with favorable results. Two prospective trials by Heinrich et al., and Zimmermann et al. together with three retrospective trials by Yokose et al., Dalah et al., and Panda et al. demonstrated that a decrease in ${ }^{18} \mathrm{~F}$-FDG-uptake in PDAC was associated with a histopathologic response to treatment and a decrease in tumor size [36,37,156-158]. Yoshioka et al., showed that ${ }^{18}$ F-FDG-PET/CT could add valuable diagnostic information by demonstrating that a decrease in tumoral metabolic FDG uptake after NT tends to precede anatomic changes in tumor size as seen on ce-CT and MRI [159]. These results suggest that response to treatment might be visualized earlier using ${ }^{18} \mathrm{~F}$-FDG-PET/CT than ce-CT and MRI. Following these results, additional prospective validation in larger studies is warranted and will possibly be provided by Dutch PANDIGIPET trial (NTR7442), which evaluated treatment response using digital ${ }^{18} \mathrm{~F}-\mathrm{FDG}$-PET/CT and compared the results to the initial CT scans. This trial was recently completed, and results are expected soon. 


\subsection{2. ${ }^{18}$ F-Fluorothymidine (FLT)}

${ }^{18} \mathrm{~F}-\mathrm{FLT}$ is a radiotracer that accumulates in active proliferating cells and indicates the activity of the enzyme thymidine kinase. Although known as highly proliferative, uptake in PDAC was poor and significantly less compared to ${ }^{18} \mathrm{~F}-\mathrm{FDG}$, resulting in visualization of PDAC in only $40 \%$ of six included patients. Tracer activity in the primary tumor could be accurately differentiated from background tracer activity in only two patients. [160]. However, Wieder et al. suggest ${ }^{18}$ F-FLT-PET/CT might serve a purpose in determining prognosis and survival, as increased proliferative rates are associated with more aggressive tumors and decreased OS [161].

\subsection{3. ${ }^{18}$ F-Fluoromisonidazole (FMISO) and ${ }^{18} \mathrm{~F}$-Fluoroazomycin Arabinoside (FAZA)}

${ }^{18} \mathrm{~F}$-FMISO and ${ }^{18} \mathrm{~F}$-FAZA are hypoxia-based radiotracers which, despite the favorable hypoxic condition in PDAC, showed minimal uptake in PDAC. Segard et al. showed ${ }^{18} \mathrm{~F}-$ FMISO resulted in tumor-to-background ratio's (TBR) ranging from 1.4 to 2.9. Yamane et al. used ${ }^{18}$ F-FMISO and identified in 9/25 (36\%) PDAC patients the primary tumor, peak TBRs of the negative cases were significantly lower than that of the positive cases. In conclusion, no significant correlation between tumor perfusion and hypoxia, nor an association between tumor volume and hypoxia, was observed in three conducted studies. [162-164].

\subsection{PDAC-Targeted PET-Tracers in Clinical Early Clinical Trials}

PDAC-targeted radiotracers, which have been evaluated in early phase clinical trials, will be discussed in more detail, an overview of all clinical studies is depicted in Table A1.

\subsubsection{CA19.9}

CA19.9 has been extensively evaluated as serum biomarker, since it is strongly correlated with disease stage. Therefore, using CA19.9 overexpression on PDAC cells was one of the early molecular targets of interest for targeted molecular imaging in PDAC. Lohrmann et al. demonstrated that ${ }^{89} \mathrm{Zr}$ labeled anti-CA19.9 human antibody HuMab-5B1 ( ${ }^{89} \mathrm{Zr}$ MVT-2163) was able to detect the primary pancreatic tumor, metastases, and suspected lymph and unsuspected (additional) nodes in 12 patients with an in vivo TBR > 18 [165]. The relatively long optimal window between administration and imaging ( 7 days) makes application of CA19.9 for primary diagnosis less suitable. A solution would be using a radioligand with a shorter half-life time, such as fluor-18 $(18 \mathrm{~F})$ and/or smaller molecular constructs such as peptide sequences. An interesting future application for CA19.9 targeted imaging was recently preclinically evaluated by Houghton et al. showing promising results for a dual-labeled anti-CA19.9 PET/fluorescence tracer $\left({ }^{89} \mathrm{Zr}-{ }^{\mathrm{ss}}\right.$ dual-5B1), which could be used for pre-operative staging and navigation with PET/CT followed by intraoperative guidance with NIR-fluorescence [166].

\subsubsection{Fibroblast Activating Protein (FAP)}

PET/CT imaging using radiolabeled FAP inhibitors (FAPI) has recently been investigated in PDAC patients by Kratochwil et al.; they demonstrated intermediate to high accumulation of ${ }^{68}$ Ga-FAPI-04 in 50 PDAC patients. With minimal accumulation in surrounding benign tissue (including the liver), this resulted in significant tumor uptake with a SUV max ranging from 6 to 12 [83]. A second study retrospectively compared ${ }^{68} \mathrm{Ga}$-FAPI $\mathrm{PET} / \mathrm{CT}$ to ce-CT in 19 patients with suspected PDAC, and found that the use of ${ }^{68} \mathrm{Ga}-\mathrm{FAPI}$ $\mathrm{PET} / \mathrm{CT}$ resulted in detection of additional metastases and subsequent upstaging of 1 out of 7 primary PDAC patients and 8 out of 12 recurrent/progressive PDAC patients [167]. In conclusion, the use of ${ }^{68} \mathrm{Ga}$-FAPI PET/CT showed promising results to improve diagnosis and (re)staging of PDAC, and might in the future be combined with FAP-targeted therapies (e.g., radionuclide therapy), which has already been evaluated in the preclinical setting by Lui et al., demonstrating a significant tumor suppressing effect using ${ }^{177}$ Lu-FAPI-46 and ${ }^{225}$ Ac-FAPI-46 in PANC-1 xenograft mouse models. [167-169]. 


\subsubsection{Integrin $\alpha v \beta 6$}

Visualizing tumor associated neoangiogenesis using integrin $\alpha \mathrm{v} \beta 6$ targeted PET/CT has been evaluated in several smaller (pre)clinical trials $[94,95,170]$. The first clinical results by Kimura et al. show that their cystine knotted peptide-based PET-tracer $\left({ }^{18} \mathrm{~F}-\mathrm{FP}-\mathrm{R}_{0} 1-\right.$ MG-F) is safe and resulted in high specific uptake in pancreatic lesions, with minimal background uptake in the liver [170]. Nakamoto et al., which published their preliminary results in an abstract, used a comparable integrin $\alpha v \beta 6$ targeted tracer ${ }^{18} \mathrm{~F}-\mathrm{FP}-\mathrm{R}_{0} 1-\mathrm{MG}-\mathrm{F} 2$ in a cohort of 14 PDAC patients, and accurately detected all known PDAC as well as metastatic lesions, with high tumor uptake [171]. Feng et al. evaluated a cyclic $\alpha \mathrm{v} \beta 6$ targeting radiolabeled peptide $\left({ }^{68} \mathrm{Ga}\right.$-cycratide) and showed high specificity for PDAC lesions, with low background signal in the surrounding organs [95]. Considering that the expression profile of $\alpha \mathrm{v} \beta 6$ is not altered after neoadjuvant therapy (FOLFIRINOX), evaluating $\alpha v \beta 6$-targeted PET/CT for treatment response monitoring is of particular interest [31]. Summarizing, these trials with integrin $\alpha v \beta 6$-targeted PET/CT showed significant sensitivity and specificity for accurate visualization of PDAC and its metastases. This warrants further evaluation in (multicenter) phase III trials for evaluation of the diagnostical value.

\subsubsection{PSMA}

Tumor-targeted PSMA PET/CT has established a vital role in staging and determining treatment strategy in prostate cancer. In addition to prostate cancer, PSMA is expressed related to tumor-associated neovasculature and tumor cells in several other malignancies, including PDAC. Krishnaraju et al. published the first clinical trial including 40 patients with suspected pancreatic lesions. ${ }^{68} \mathrm{Ga}$-PSMA-11 PET/CT outperformed ${ }^{18} \mathrm{~F}$-FDG PET/CT for detection of primary PDAC with increased sensitivity $(94.7 \%$ vs. $89.5 \%)$, specificity $(90.5 \%$ vs. $57.1 \%)$, negative predictive value ( $95 \%$ vs. $87.5 \%)$, and accuracy $(92.5 \%$ vs. $72.5 \%$ ). Furthermore, pancreatitis lesions mimicking PDAC showed false positive uptake on ${ }^{18}$ F-FDG PET/CT but showed no uptake on PSMA PET/CT [124]. Since PSMA expression in PDAC is not altered after neoadjuvant treatment (FOLFIRINOX), evaluating PSMA-targeted PET/CT for treatment response monitoring is of particular interest [31]. If successful, treatment might be combined with PSMA-targeted therapies (e.g., radionuclide therapy), which have already been investigated in prostate cancer [122,123].

\subsection{Preclinical Evaluation and Development of PDAC-Targeted PET-Tracers}

In addition to the previously mentioned radiotracers, there are several promising targets for PDAC targeted PET/CT or PET/MRI imaging currently evaluated in preclinical studies. These include integrin $\alpha \mathrm{v} \beta 3, \mathrm{CDCP}-1$, EGFR, NTSR1, Tissue Factor (TF), and $\mathrm{uPA} / \mathrm{uPAR}$ system. Details from all preclinical studies are depicted in Table A2.

Trajkovic-Arsic et al. developed a safe and effective RGD targeted peptide $\left({ }^{68} \mathrm{Ga}\right.$ NODAGA-RGD) specifically targeting integrin $\alpha \mathrm{v} \beta 3$. Which was tested in an orthotopic PDAC mouse model, showing accurate identification of PDAC with TBRs $>10$ and relatively low background signal in the liver [172].

Moroz et al. evaluated their CDCP-1 targeted tracer $\left({ }^{89} \mathrm{Zr}-\mathrm{DFO}-4 \mathrm{~A} 06\right)$ and showed high specific tumor uptake and favorable rapid renal clearance in a subcutaneous PDAC mouse model [63].

Boyle et al. constructed an EGFR targeting $\mathrm{F}\left(\mathrm{ab}^{\prime}\right)$-fragment $\left({ }^{64} \mathrm{Cu}\right.$-panitumumab), which showed significant tumor and minimal background uptake in PDAC from two patient derived cell lines, resulting in clear tumor visualization [173].

Prignon et al. constructed a NTSR1 targeted peptide-based PET-tracer $\left({ }^{68} \mathrm{Ga}\right.$-DOTANT-20.3) with PDAC TBRs $>3.5$ and low background in the liver and small intestines. They also showed that DOTA-NT-20.3 was able to distinguish PDAC from pancreatitis [116]. Hodolic et al. recently published the first clinical results from three PDAC patients, demonstrating identification of primary tumor in three out of three patients and distant metastatic disease in two out of two patients [118]. 
Nielsen et al. constructed and evaluated a TF targeted antibody PET-tracer $\left({ }^{64} \mathrm{Cu}\right.$ NOTA-FVIIai) in a subcutaneous PDAC mouse model. PET/MRI imaging resulted in adequate visualization of PDAC with a tumor-to-muscle ratio ( $\mathrm{T} / \mathrm{M}$ ratio) $>30$, intermediate/high tracer uptake in the liver was observed [131].

Last, a uPAR-targeted antibody $\left({ }^{89} \mathrm{Zr}\right.$-Df-ATN-291) was validated by Yang et al. in a subcutaneous tumor mouse model in various cancer types, including PDAC, resulting in favorable biodistribution and a tumor-to-muscle ratio $>7$ based on PET/CT-imaging $24 \mathrm{~h}$ after tracer administration [174].

\subsection{Summary}

In conclusion, previous research has shown FAPI, PSMA, integrins $\alpha v \beta 3 / \alpha v \beta 6$, and CA19.9 to hold the most potential for tumor-targeted PET-imaging of PDAC. However, most of these tracers are still in the early phases of clinical development and larger studies are needed. Within our own research group, two clinical trials have been initiated evaluating the diagnostic performance of ${ }^{18}$ F-DCFPyL-(PSMA)-PET/CT (Netherlands Trial Register NL8919) targeting PSMA, which has been closed for inclusion and analysis of results is pending. Second, patients have currently been recruited in a clinical trial evaluating ${ }^{18}$ F-Fluciclatide-(RGD)-PET/CT targeting integrins $\alpha \mathrm{v} \beta 3, \alpha \mathrm{v} \beta 5$ and $\alpha \mathrm{v} \beta 6$ (Netherlands Trial Register NL7605). Progress has been made in recent years evaluating PDAC-targeted PET-tracers, and early phase clinical trials have shown some favorable results and added value, but more data is needed before PET/CT imaging will be integrated in the workflow of PDAC.

\section{NIR-Fluorescence Imaging and Fluorescence-Guided Surgery}

Over the last decade, image-guided surgery with NIR-fluorescence (NIRF) has been studied and developed for various malignancies $[175,176]$. With improved neoadjuvant treatment strategies more patients suffering from PDAC have become eligible for surgical treatment. Considering that surgery is moving towards minimally invasive techniques (i.e., laparoscopic, and robotic surgery), procedures are becoming more complex for the surgeon. Although minimally invasive surgery offers benefits for the patient such as smaller incisions and a shorter hospital stay compared to conventional open surgery, an important drawback is the loss of tactile feedback for the surgeon, potentially hampering accurate identification of tumor margins and vital structures adjacent to the tumor, of which iatrogenic damage must be avoided. Accurate tumor visualization and demarcation is pivotal for performing safe and complete surgical resections, which emphasizes the importance of additional tools to compensate for the loss of tactile feedback. Fluorescence-guided surgery (FGS) using NIRF imaging, can potentially fulfill this role by providing surgeons with real-time intraoperative fluorescence-enhanced tumor visualization [40].

NIRF imaging uses a NIR-fluorescent tracer that has been administered intravenously. Most fluorescently labeled tracers emit light in the NIR-spectrum, mainly in the NIR-I (650-900 nm) window; although, experimental studies have been conducted with tracers emitting in the NIR-II window (1000-1700 nm), latter technique is still in the experimental phase due to difficulties with fluorophore stability and toxicity [177]. For the imaging procedure, an external light source is required, which emits photons at a certain wavelength in order to penetrate tissue and reach the fluorescently labeled tracer bound to the target tissue. Upon entering and passing through tissues, these photons will be either absorbed by the fluorophore, reflected by the surface of imaged tissue or refracted. Absorption leads to excitation of the fluorophore, which induces emission of NIR-light of a longer wavelength. This difference in peak excitation and emission wavelength is referred to as the Stokes shift [40]. A NIR-camera system transforms the emitted signal in real-time to fluorescent images that are projected on a monitor in the operation room [178]. NIRFtracers can roughly be divided into two categories: untargeted tracers that predominantly enhance lesions or structures by the enhanced permeability and retention effect (EPR effect) or perfusion (Indocyanine Green, ICG, $800 \mathrm{~nm}$ or methylene blue, $M B, 700 \mathrm{~nm}$ ), and 
targeted tracers that consist of a target-specific molecular probe conjugated to a fluorescent dye [179]. Until this moment, only ICG and MB are FDA approved for intraoperative NIRfluorescence imaging. Although ICG is an effective untargeted agent to visualize biliary structures during pancreaticobiliary reconstructions in order to avoid iatrogenic damage, the currently known untargeted fluorescent agents have demonstrated limited applicability for adequate tumor visualization during cancer surgery [180-182]. Therefore, the main focus in FGS (pancreatic) cancer surgery in recent years is identification and synthesis of effective and safe tumor-specific NIRF-tracers, which enable enhanced visualization of the primary tumor, metastasized lymph nodes, and distant metastases.

\subsection{Clinically Tested PDAC Targeted NIRF-Tracers}

The following sections will review several conducted clinical studies evaluating tumortargeted NIRF-imaging in PDAC. More detailed information regarding these studies is presented in Table A1.

\subsubsection{CEA}

After successful preclinical testing of fluorescent CEA-antibody constructs $[66,70,183]$, Hoogstins et al. performed the first in-human dose-escalation trial using SGM-101, a chimeric antibody to CEA conjugated to the fluorophore BM-104 $(700 \mathrm{~nm})$. In 11 patients with resectable PDAC, NIR-imaging identified all primary pancreatic tumors and metastatic lesions (3/3). A moderate level of autofluorescence of the background tissue was observed, probably related to the $700 \mathrm{~nm}$ wavelength, resulting in calculated TBRs of, respectively, 1.6 (tumor) and 1.7 (metastases) [68].

\subsubsection{EGFR}

EGFR-targeted NIRF imaging for PDAC has been evaluated in two clinical trials, with promising results. Preclinical research was conducted primarily in head and neck cancers [184]. Tummers et al. performed phase II clinical trial evaluating cetuximab conjugated to IRDye $800 \mathrm{CW}(800 \mathrm{~nm})$ in non-pretreated patients; intraoperative imaging was performed 2-5 days after administration. This study reported accurate identification of all tumors and metastatic lesions with a sensitivity of $96.1 \%$ and specificity of $67.0 \%$. NIRFguided resection of the tumor and/or metastatic lymph nodes (LN) was possible in four out of six patients with in vivo TBRs of, respectively, 2.3 and $>6$ [185]. Mean fluorescence intensity (MFI) was significantly different between PDAC, normal pancreatic parenchyma, and pancreatitis. This finding is particularly interesting since pancreatitis is known for its PDAC mimicking appearance on radiological imaging [185]. Tummers et al. used this same construct for evaluation of the feasibility for the detection of visually occult metastatic lymph nodes by ex vivo NIRF imaging. Cetuximab-IRDye800CW was able to accurately identify metastatic LN's macroscopically with a sensitivity and specificity of, respectively, $100 \%$ and $78 \%$, as well as occult tumor deposits $(<5 \mathrm{~mm})$ with a sensitivity of $88 \%$. Although these results are from ex vivo imaging, it shows proof for fluorescence identification of nodal metastases, which were not previously seen with CT-imaging [186]. Lu et al. performed a phase I trial, evaluating panitumumab-IRDye $800 \mathrm{CW}$ in 11 non pretreated PDAC patients. Intra-operative NIRF imaging was performed 2-5 days after administration, resulting in identification of the primary tumors, metastatic LNs, and small $(<2 \mathrm{~mm})$ peritoneal metastasis in all patients. With adequate TBRs of $>3$ in the $50 \mathrm{mg}$ dosing cohort. Furthermore, fluorescence signal delineating the tumor correlated with histopathology in all cases and significant higher MFIs in LN+ than LN- were observed [187]. 


\subsubsection{VEGF-A}

VEGF-A targeted NIR-imaging using bevacuzimab-IRDye800CW, a monoclonal antiVEGF antibody conjugated to IRDye $800 \mathrm{CW}(800 \mathrm{~nm})$, has been described in patients with breast cancer as well as with colorectal peritoneal metastases. $[188,189]$ Our medical center, together with University Medical Center Groningen (UMCG) performed a phase II feasibility trial in patients with pancreatic tumors. Although, intraoperative tumor identification was feasible and administration of bevacuzimab-IRDye $800 \mathrm{CW}$ was safe, the combination of moderate TBRs and indifferent fluorescence signals in residual healthy pancreatic parenchyma resulted in early termination of this study, further analyses are pending (NCT02743975).

\subsection{Preclinical Evaluation and Development of PDAC-Targeted NIRF-Tracers}

All clinically evaluated tracers to date are antibody-based, which may be less able to penetrate the dense PDAC stroma, compared to smaller-sized carrier molecules (e.g., peptides, Fab'-fragments, nanobodies, nanoparticles, and DARPins (Designed Ankyrin Repeat Proteins)) [45,46]. As suboptimal penetration could result in a suboptimal target binding and, consequently, an insufficient fluorescence signal. Development and evaluation of smaller-sized carriers, which, due to their size, will be less influenced by the TME, potentially possess superior and faster tumor penetration, resulting in improved signal intensity. Furthermore, a smaller interval between tracer-administration and imaging is likely to be achieved by using smaller-sized carriers. This section focuses on promising preclinical studies evaluating PDAC-targeted NIRF-tracers, of which the preclinical results might warrant future clinical translation. These include the following targets: CA19.9, integrin $\alpha v \beta 3 / \alpha v \beta 5 / \alpha v \beta 6$, NTSR1, and the uPA/uPAR system. An overview of all preclinical studies evaluating PDAC-targeted NIRF-imaging are listed in Table A2.

Houghton et al. constructed a dual-labeled anti-CA19.9 PET/Fluorescence tracer $\left({ }^{89} \mathrm{Zr}-{ }^{\mathrm{ss}}\right.$ dual-5B1), which was tested in a subcutaneous mouse model using small-animal PET/CT-imaging, followed fluorescence-guided resected with NIRF imaging [166]. Lwin et al. evaluated for the first time a humanized CEA-targeted antibody conjugated to a NIR-fluorophore in an orthotopic PDAC tumor mouse model showing accurate tumor identification with TBRs $>16$. This humanized antibody has already been tested in clinical trials in head and neck cancer $[66,184]$.

Integrin $\alpha v \beta 3 / \alpha v \beta 5 / \alpha v \beta 6$ targeting using a cyclic configured peptide, cRGD-ZW800$1(800 \mathrm{~nm})$, performed by Handgraaf et al., has shown some promising results in a preclinical study in orthotopic mouse models of breast, colorectal, and pancreatic cancer cell lines [190]. The first clinical trial using cRGD-ZW800-1 in healthy volunteers and patients with colorectal carcinoma was initiated shortly after these findings. cRGD-ZW800-1 was safe and allowed accurate NIRF imaging and intra-operative delineation of the colorectal tumors $2 \mathrm{~h}$ after intravenous (IV) administration, with TBRs $>1.5$ in the highest dosing cohort $(0.05 \mathrm{mg} / \mathrm{kg})$ [191]. Specific integrin targeting for $\alpha v \beta 6$ has been evaluated by Tummers et al., and they evaluated the cysteine knottin peptide $\mathrm{R}_{0} 1-\mathrm{MG}$, conjugated to IRDye $800 \mathrm{CW}(800 \mathrm{~nm})$. They showed specific $\alpha \mathrm{v} \beta 6$ binding and fluorescence signal in PDAC tumors in an orthotopic mouse model, TBRs ranged from 1.2 to 3.6; furthermore, using $\mathrm{R}_{0} 1$-MG-IRDye800CW, successful distinction between PDAC and peritumoral inflammation could be made [192]. Based on the $>90 \%$ overexpression of integrin $\alpha v \beta 6$ in PDAC combined with the limited affected expression profile after neoadjuvant therapy, targeting $\alpha \mathrm{v} \beta 6$ using this construct potentially has the 'ideal' characteristics for fluorescence imaging of PDAC after neoadjuvant treatment [31,192]. 
Yin et al. performed a study in a subcutaneous/orthotopic PDAC tumor mouse using their NTSR1 receptor-targeted linear peptide NT for construction of a targeted PET-tracer $\left({ }^{64} \mathrm{Cu}\right.$-AmBaSar-NT), as well as a NIRF-tracer (IRDye800-NT, $800 \mathrm{~nm}$ ). This resulted in adequate visualization of orthotopic mouse PDAC tumors against low background of the iver and small intestine, with TBRs of 8.1 and 6.7 after $30 \mathrm{~min}$ and $1 \mathrm{~h}$, respectively [115]. This demonstrates the potential advantages of smaller peptide structures over antibodies for clinical application, as shown by the short time between administration and imaging.

Juhl et al. constructed a uPA/uPAR system using a targeted linear peptide (AE105) conjugated to ICG $(800 \mathrm{~nm})$. They evaluated Glu-Glu-AE105-ICG in an orthotopic PDAC tumor mouse model, for identification of the primary pancreatic tumor and metastases 6-24 $\mathrm{h}$ after IV administration, resulting in TBRs in the primary tumor of 3.5 and in metastases of 3.4. Furthermore, they were able to identify and resect six additional metastases $(14 \%)$, not visualized with white light inspection (WLI), as small as $1 \mathrm{~mm}$ in four out of eight mice, using NIRF imaging guidance [193]. The abovementioned pre-clinical studies show some promising results, and clinical translation is necessary to assess the safety, performance, and value of these PDAC targeted imaging agents in the clinic.

\subsection{Summary}

The field of targeted NIRF imaging is expanding rapidly as demonstrated by the abovementioned studies and the search for suitable PDAC-targeted NIRF-tracers continues. In conclusion, three targets have been evaluated in smaller clinical pilot studies, of which EGFR-targeted NIRF imaging with cetuximab-IRDye800CW or panitumumabIRDye800CW demonstrated the most clinically relevant results, which warrants further evaluation in future trials for determination of the true impact on clinical/surgical management. CEA-targeted NIRF imaging using SGM-101 was feasible, although insufficient contrast in fluorescent signals (TBR's $<2$ ) could hamper adequate tumor delineation and assessment of resection margins. Based on the limited available information, VEGF-Atargeted bevacuzimab-IRDye $800 \mathrm{CW}$ demonstrated tumor visualization; although, it has proven insufficient for accurate tumoral delineation and real-time assessment of the resection margins. An important factor that needs to be taken into consideration when evaluating clinical suitability of current and future NIRF-tracers, is the potential influence of NT on the TME composition, which is currently underexplored due to the inclusion of only non-pretreated patients. As demonstrated on neoadjuvant treated resected tissue specimens by Vuijk et al. [31], differential expression of targets was observed, which could negatively influence the intensity of tumor signal and related TBRs. Based on available literature, peptide- and Fab'-based tracers are closest to clinical evaluation [173,190,192], whereas smaller-sized nanobodies and nanoparticles are still in the early preclinical research phase [61].

\section{Future Perspectives: Application of Improved Targeting Strategies, Technological Advances, and a Theranostic Approach}

Molecular targeting enables visualization of tissue-specific biomarkers present within or around tumor cells. Ideally, these targets possess the characteristics suitable for molecular imaging during different stages of disease: early detection, treatment response monitoring, (re)staging, intra-operative guidance, as well as surveillance and follow-up. Interesting concepts aiming to improve the clinical value and applicability of (PDAC-) targeted molecular imaging are dual-labeled PET/NIRF-tracers, dual-targeted-tracers for PET/CT or NIRF imaging, cocktails of two or more separate tumor-targeted tracers, as well as application of pre-targeting strategies to improve tumor-specific contrast. A dual-labeled PET/NIRFtracer has the potential to aid in pre-operative PET/CT (re)staging and the consecutive surgery by means of fluorescence guidance using a single systemic administration. Although, careful planning and choice of tracer combination based on half-life is important for effectively using dual-labeled tracers. Several dual-labeled PET/NIRF tracers have been described $[166,194]$. One example is the PDAC-targeted dual-labeled CA19.9 agent that has been evaluated in a preclinical stetting by Houghton et al. (Table A2), which 
demonstrated clear tumor visualization using small-animal PET/CT and NIRF guided resection of subcutaneous tumors in mice. [166]. Moreover, a dual-targeted tracer, which simultaneously targets two different targets within a heterogeneous tumor, or which targets two differentially expressed targets in heterogeneous patient populations, could enable improved sensitivity for tumor detectability [195]. An interesting strategy for application for PDAC could be a dual-labeled tracer targeting epithelial as well as stromal tissue. Within the preclinical field of PDAC research, Wang et al. (Table A2), have developed a bispecific NIRF-diabody (bi50-IRdye800) targeting VEGF-A/EGFR, which compared to uni-specific VEGF-A or EGFR single-chain variable fragments $(\mathrm{scFv})$ resulted in improved clear delineation of PDAC lesions in a mouse model in vasculature rich areas (VEGF overexpression) as well the parenchymal rich areas (EGFR overexpression) [196]. Furthermore, Luo et al. (Table A2) developed a dual-targeted PET/CT tracer, targeting TF and endoglin, which demonstrated a clear tumor visualization with a (orthotopic) tumor-to-muscle ratio $>70$ [197]. Additionally, for dual-targeted imaging, providing a cocktail of two or more separate tumor-targeted tracers is a strategy to improve tumor-signals, on the other hand targeting more than one target potentially results in more false-positive signals. Lastly, a strategy to enhance visual contrast and reduce time between tracer administration and imaging is pre-targeting. Pre-targeting is based on separate administration of the targeting vector and radioligand or NIRF-fluorophore, aiming to decrease the circulation time of the radioligand/fluorophore, reduce its uptake in healthy nontarget tissues, which in case of PET/CT enabled enabling developing tracers with shorter half-life rates $[198,199]$. Houghton et al. developed a CA19.9-targeted PET tracer, and demonstrated adequate tumor delineation in a mouse model with a $>25$-fold reduction in total body radiation exposure compared to the non-pre-targeted control group [200].

The TME of pancreatic tumors contains biological barriers which makes targeting these tumors, for either imaging or therapy, challenging [201,202]. Using smaller (molecularly) sized carriers could be a solution to this problem. The preclinical field focusses on development and validation of smaller-sized carrier based tracers: peptides, Fab'-fragments, nanobodies [203], nanoparticles [204,205], and DARPins [206,207]. Advantages over these in comparison to $\mathrm{mAbs}$ are a reduced immunogenic response and most are renally cleared, as opposed to hepatic clearance [46]. Although, some developmental challenges related to these smaller-sized carriers, such as molecular stability, effective carrier extravasation and possibly inferior binding affinity must be considered, these compounds show promise for application in future PDAC-targeted molecular imaging and therapy [203,204].

Photoacoustic imaging (PAI) is an interesting technique in development for molecular imaging. PAI is based on the photoacoustic effect that is exhibited by several NIRF dyes, including $800 \mathrm{CW}$ or endogenous (tumor) tissue [208]. The photoacoustic effect is based on the principle of acoustic wave formation following light absorption caused by transient thermoelastic expansion of the target tissue. These acoustic waves are detected and analyzed by ultrasonic transducers to produce 2D or 3D images. PAI compared to NIRF has an improved optical contrast and spatial resolution with increased tissue penetration depth (up to $5 \mathrm{~cm}$ ) [34,209]. While NIRF-imaging is suitable for detection of superficial lesions and assessment of surgical margins, PAI could be of complementary interest for deeper-seated tumors. Multimodal application of NIRF/PAI is an interesting future aspect, since both could use the same NIRF-dye. Tummers et al. demonstrated the applicability of PAI in a clinical trial using cetuximab-IRDy800 with multimodal molecular imaging including ex vivo PAI, resulting in an adequate photoacoustic signal of the tumor [185]. Available literature is scarce, since limited clinical or commercially available intra-operative systems are currently available [210].

In addition to diagnostic purposes, the advantages of tumor-targeting have also found their way to anti-cancer therapies and precision therapies, labelled as theranostics [211]. By substituting the radioisotope of targeted PET-tracer, the same vector molecule can be used for radionuclide treatment. Theranostics have opened new opportunities for the management of malignant lymphomas and various solid tumors, including PDAC. 
Various targeted PET-tracers can be conjugated to therapeutic radioisotopes, such as an $\alpha$-emitter $\left({ }^{225}\right.$ Actinium and ${ }^{213}$ Bismuth) or $\beta$-emitter $\left({ }^{177}\right.$ Lutatium and ${ }^{90}$ Yttrium). An in-depth review of the principles and current developments of theranostics in PDAC was recently published by Montemagno et al., which provides a clear overview of the current advances in theranostics for diagnosis and treatment of PDAC [212]. An example includes the preclinical evaluation of the anti-FAP targeting vehicle FAPI labeled with ${ }^{225}$ Actinium in a PDAC mouse model ( ${ }^{225} \mathrm{Ac}$-FAPI) by Watabe et al., which demonstrated a significant tumor growth suppression after 3 weeks compared to control mice [213]. Theranostics have already shown promising (pre)clinical results regarding precision medicine and hold potential for application in and further improvement of therapeutic management of PDAC.

\section{Conclusions}

Molecular imaging of PDAC using PET and NIRF-probes can provide valuable information on tumor location during preoperative work-up and in real-time during intraoperative visualization and demarcation (Figure 1), thereby providing pre-, peri-, and postoperative clinical decision making. Identification and evaluation of several potent PDAC targets has led to the development and evaluation of multiple targeted PET/CT and NIRF-tracers, which, as shown by the wide variety of preclinical evaluated PDAC imaging agents, demonstrate the lack of one clear biomarker or target suitable for PDAC imaging. The value of tumor targeted PET/CT, NIRF-imaging or both has proven their diagnostic or therapeutic efficacy in early phase studies, including several clinical trials with small patient cohorts. Further refinement and advances in tracer development could result in dual specific and/or multimodal tracers that can be employed for various diagnostic and therapeutic modalities, including NIRF-imaging, FGS, PET/CT, and PAI. Interesting opportunities lie in the theranostic field, where targeted probes can be used to treat cancer by highly specific drug delivery to the tumor targets, and to visualize these targets by PET/CT imaging, which allows for accurate patient selection, pre- and post-treatment dosimetry, monitoring of therapy efficacy, and tumor (re)staging. Integration of targeted molecular imaging in the diagnostic and therapeutic management of PDAC has the potential to contribute to improved patient outcome and survival.

Author Contributions: Conceptualization, J.S.D.M. and M.A.v.D.; writing-original draft preparation, M.A.v.D.; writing—review and editing, M.A.v.D., F.A.V., J.A.S., R.D.H., S.A.C.L., S.C., S.S.F., L.-F.d.G.-O., B.A.B., C.F.M.S., P.J.K.K., R.-J.S., A.D.W., J.B. and J.S.D.M.; figure preparation, M.A.v.D.; supervision, A.L.V. and J.S.D.M. All authors have read and agreed to the published version of the manuscript.

Funding: This research received funding from the Dutch Organization for Scientific Research (NWO; Veni grant 016.196.059), as well as the ITEA 3 ASSIST (20044) project. Furthermore, the role of C.F.M.S. was supported by the European Union's Horizon 2020 research and innovation program under the Marie Sklodowska Curie grant agreement No 734684 (CHARMED), 872391 (CONCRETE), and 872860 (PRISAR2).

Acknowledgments: Authors would like to acknowledge J.W.M. Plevier of the Walaeus library in the LUMC for her contribution to the composition of the literature searches for literature inclusion.

Conflicts of Interest: The authors declare no conflict of interest. 


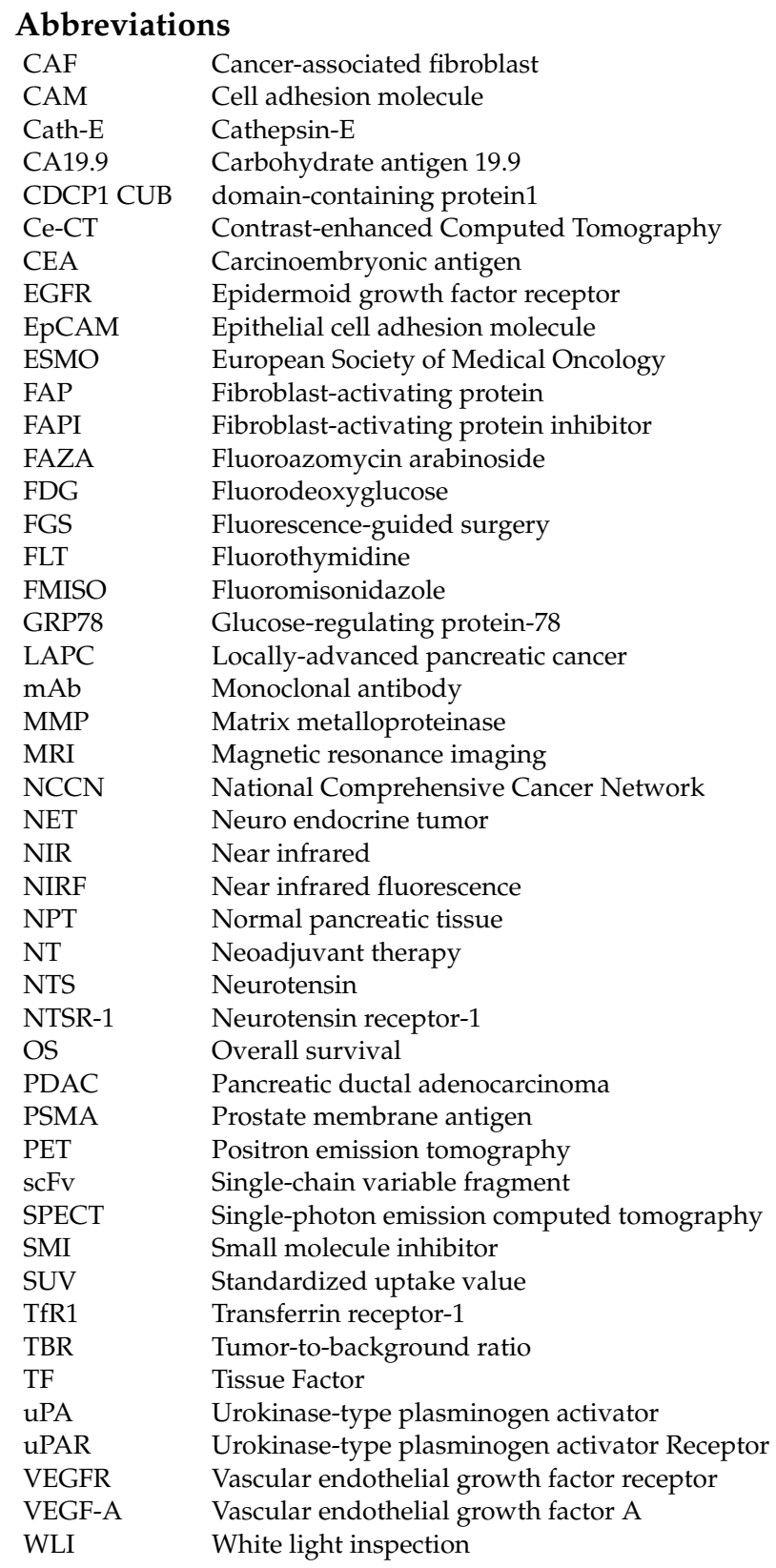




\section{Appendix A}

Table A1. Clinical studies evaluating targeted molecular imaging (PET/CT—fluorescence Imaging) of PDAC.

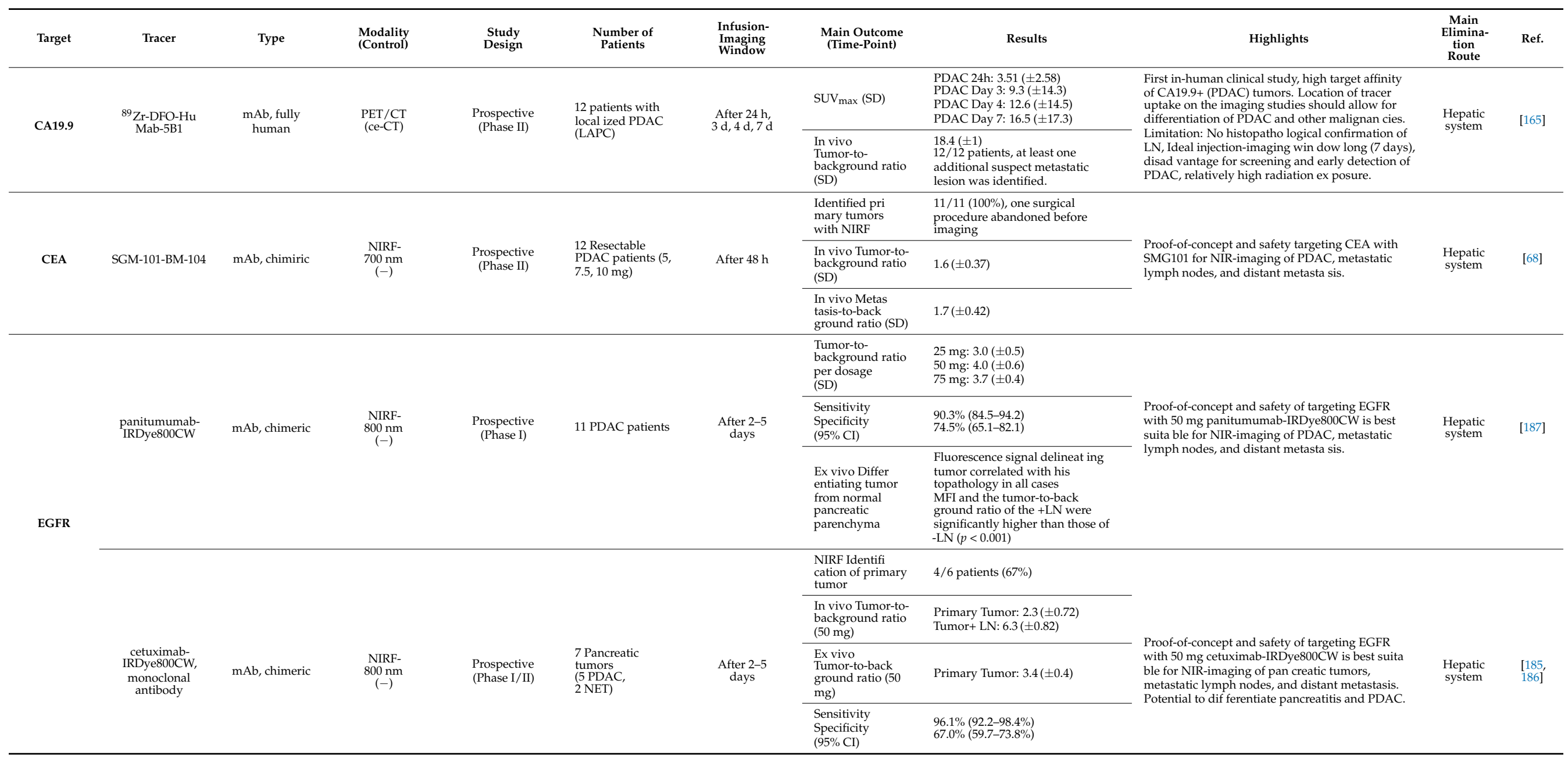


Table A1. Cont.

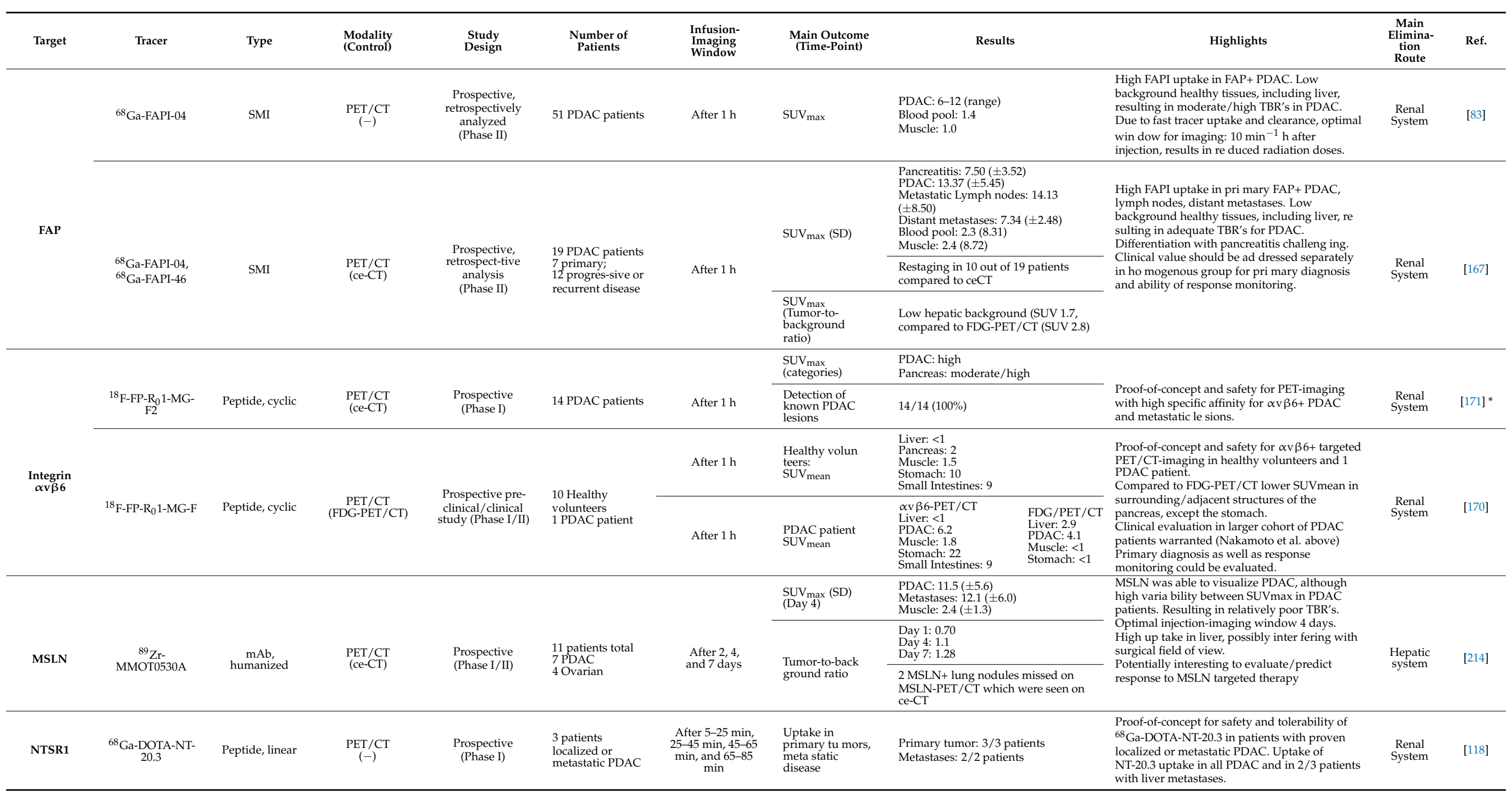


Table A1. Cont.

\begin{tabular}{|c|c|c|c|c|c|c|c|c|c|c|c|c|}
\hline Target & Tracer & Type & $\begin{array}{l}\text { Modality } \\
\text { (Control) }\end{array}$ & $\begin{array}{l}\text { Study } \\
\text { Design }\end{array}$ & $\begin{array}{c}\text { Number of } \\
\text { Patients }\end{array}$ & $\begin{array}{l}\text { Infusion- } \\
\text { Imaging } \\
\text { Window }\end{array}$ & $\begin{array}{c}\text { Main Outcome } \\
\text { (Time-Point) }\end{array}$ & Results & & Highlights & $\begin{array}{c}\text { Main } \\
\text { Elimina- } \\
\text { tion } \\
\text { Route }\end{array}$ & Ref. \\
\hline \multirow{3}{*}{ PSMA } & \multirow{3}{*}{${ }^{68}$ Ga-PSMA-11 } & \multirow{3}{*}{ Peptide, linear } & \multirow{3}{*}{$\begin{array}{c}\text { PET/CT } \\
\text { (FDG-PET/CT) }\end{array}$} & \multirow{3}{*}{$\begin{array}{l}\text { Prospective } \\
\text { (Phase II) }\end{array}$} & \multirow{3}{*}{$\begin{array}{l}\text { 19 PDAC } \\
21 \text { Benign } \\
\text { pancreatic lesions }\end{array}$} & \multirow{3}{*}{ After $1 \mathrm{~h}$} & \multirow{3}{*}{$\begin{array}{l}\mathrm{SUV}_{\max }(\mathrm{IQR}) \\
\\
\text { Sensitivity } \\
\text { Specificity } \\
\text { PPV } \\
\text { NPV } \\
\text { Accuracy }\end{array}$} & $\begin{array}{l}\text { PSMA- } \\
\text { PET/CT: }\end{array}$ & $\begin{array}{l}\text { FDG- } \\
\text { PET/CT: }\end{array}$ & \multirow{3}{*}{$\begin{array}{l}\text { PSMA-PET/CT out-performed FDG-PET/CT in } \\
\text { primary diagnosis of PSMA+ PDAC lesions. } \\
\text { Lesions with inflammatory origin were not } \\
\text { visualized with PSMA-PET/CT, in contrast to } \\
\text { FDG-PET/CT (false positive). } \\
\text { Promising results for PSMA-PET/CT, further } \\
\text { evaluation in a multicenter study will be able to } \\
\text { substantiate the diagnostic value of } \\
\text { PSMA-PET/CT in the primary diagnosis of } \\
\text { PDAC. }\end{array}$} & \multirow{3}{*}{$\begin{array}{l}\text { Renal } \\
\text { System }\end{array}$} & \multirow{3}{*}{ [124] } \\
\hline & & & & & & & & $\begin{array}{l}\text { Benign: } 3.9 \\
\text { (3.4) } \\
\text { Malignant: } 7.6 \text { (10.8) }\end{array}$ & $\begin{array}{l}\text { Benign: } \\
3.5 \\
(1.5) \\
\text { Malignant: } \\
7.4(4.5) \\
\end{array}$ & & & \\
\hline & & & & & & & & $\begin{array}{l}94.7 \% \\
90.5 \% \\
90 \% \% \\
95 \% \\
92.5 \% \\
\end{array}$ & $\begin{array}{l}89.5 \% \\
57.1 \% \\
65.4 \% \\
87.5 \% \\
72.5 \% \\
\end{array}$ & & & \\
\hline VEGF-A & $\begin{array}{c}\text { Bevacizu- } \\
\text { mabIRDye } \\
800 C W, \\
\text { monoclonal } \\
\text { antibody }\end{array}$ & $\begin{array}{c}\mathrm{mAb} \text {, } \\
\text { chime-ric }\end{array}$ & $\begin{array}{l}\text { NIRF- } \\
800 \text { nm } \\
(-)\end{array}$ & $\begin{array}{l}\text { Prospective } \\
\text { (Phase II) }\end{array}$ & $\begin{array}{l}10 \text { suspected } \\
\text { pancreatic } \\
\text { tumors (PDAC, } \\
\text { NET, } \\
\text { Periampul-lary, } \\
\text { IPMN) }\end{array}$ & $\begin{array}{l}\text { After } \\
3 \text { days }\end{array}$ & Detailed results $\mathrm{h}$ & not yet been published & & $\begin{array}{l}\text { Bevacizumab-800CW was safe without adverse } \\
\text { events related to the study drug although due to } \\
\text { residual in different fluorescent signals in } \\
\text { non-tumoral tissue after complete tumor resection } \\
\text { in the majority of included pa tients, this study } \\
\text { was termi nated early. } \\
\text { Feasibility for further clini cal translation of } \\
\text { VEGG-tar geted FGS of PDAC is based on these } \\
\text { results not proven. }\end{array}$ & $\begin{array}{l}\text { Hepatic } \\
\text { system }\end{array}$ & $\begin{array}{c}\text { Eudra- } \\
\text { CT } \\
2015- \\
004247- \\
39\end{array}$ \\
\hline
\end{tabular}

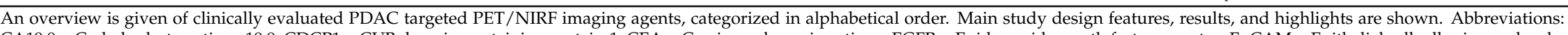

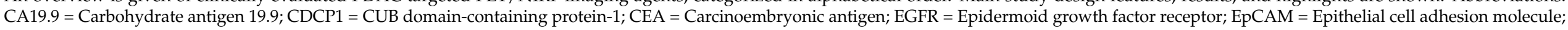

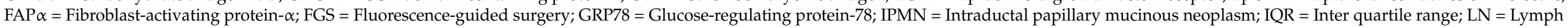

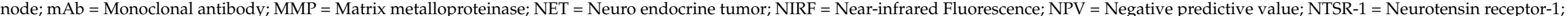

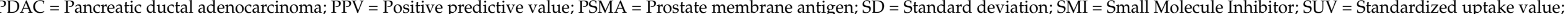

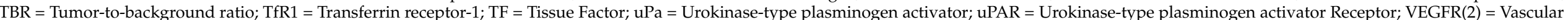
endothelial growth factor receptor; VEGF- $\alpha=$ Vascular endothelial growth factor $\alpha .{ }^{*}$ Only abstract available 
Table A2. Pre-clinical studies evaluating targeted molecular imaging (PET/CT_fluorescence Imaging) of PDAC.

\begin{tabular}{|c|c|c|c|c|c|c|c|c|c|c|}
\hline Target & Tracer & Type & Modality & Design & $\begin{array}{l}\text { Subjects } \\
\text { (Cell Line) }\end{array}$ & $\begin{array}{l}\text { Infusion- } \\
\text { Imaging } \\
\text { Window }\end{array}$ & Main Outcome & Results & Highlights & Ref. \\
\hline \multirow{10}{*}{ CA19.9 } & $\begin{array}{l}\text { Alexa Fluor } \\
\text { 488-anti- } \\
\text { CA19.9 }\end{array}$ & $\begin{array}{l}\mathrm{mAb}, \\
\text { hu } \\
\text { man- } \\
\text { ized }\end{array}$ & $\begin{array}{l}\text { Fluorescence } \\
\text { imaging- } \\
500 \mathrm{~nm}\end{array}$ & $\begin{array}{l}\text { In vitro/In vivo } \\
\text { Preclinical probe } \\
\text { construction and } \\
\text { target validation } \\
\text { in mouse model }\end{array}$ & $\begin{array}{c}\text { Orthotopic PDAC } \\
\text { mouse model } \\
\text { (CFPAC, } \\
\text { BxPC-3, } \\
\text { PANC-1) }\end{array}$ & $\begin{array}{l}\text { After } \\
24 \mathrm{~h}\end{array}$ & $\begin{array}{l}\text { Ability to visualize } \\
\text { CA19.9+ PDAC after } 24 \mathrm{~h}\end{array}$ & $\begin{array}{l}\text { Small tumors were virtually uni } \\
\text { dentifiable under standard bright-field } \\
\text { imaging but were clearly visible using } \\
\text { fluorescence imaging. Administration of } \\
\text { AlexaFluor } 488 \text {-anti-CA19.9 facilitated } \\
\text { visualization of experimental metastatic } \\
\text { implants in the spleen, liver, and } \\
\text { peritoneum at laparotomy. All metastatic } \\
\text { lesions in the spleen, liver, and } \\
\text { peritoneum were confirmed by histologic } \\
\text { evaluation following whole-body } \\
\text { imaging. }\end{array}$ & $\begin{array}{l}\text { Proof-of-concept of in vivo fluorescence } \\
\text { imaging of CA19.9+ PDAC with } \\
\text { fluorescence imaging. } \\
\text { Low expression/fluorescence on } \\
\text { surrounding stromal tissue. Low } \\
\text { background due to low CA19.9 } \\
\text { expression in normal tissue. } \\
\text { Additional evaluation is war ranted to } \\
\text { address imaging characteristics and } \\
\text { validate fluorescence signals. }\end{array}$ & [215] \\
\hline & \multirow{3}{*}{$\begin{array}{l}{ }^{124} \text { I-anti- } \\
\text { CA19-9 }\end{array}$} & \multirow{3}{*}{ Diabody } & \multirow{3}{*}{$\mathrm{PET} / \mathrm{CT}$} & \multirow{3}{*}{$\begin{array}{l}\text { In vitro/In vivo } \\
\text { Preclinical probe } \\
\text { construction and } \\
\text { target validation } \\
\text { in mouse model }\end{array}$} & \multirow{3}{*}{$\begin{array}{c}\text { Subcutaneous PDAC } \\
\text { mouse model (BxPC3: } \\
\text { CA19.9+ } \\
\text { Capan-2: CA19.9+ } \\
\text { MiaPaCa-2: Ca19.9-) }\end{array}$} & \multirow{3}{*}{$\begin{array}{l}\text { After } 4 \mathrm{~h} \text { and } \\
\quad 20 \mathrm{~h}\end{array}$} & $\begin{array}{l}\text { Tumor-to-background } \\
\text { ratio (blood pool) }\end{array}$ & $\begin{array}{l}\text { All cell lines: } 3.0 \\
\text { BxPC3: } 5.0 \\
\text { Capan-2: } 2.0 \\
\text { BxPC3: } 11.0\end{array}$ & \multirow{3}{*}{$\begin{array}{l}\text { Proof-of-concept PET/CT-imaging of } \\
\text { CA19.9+ PDAC. The cys-diabody } \\
\text { demonstrates target-specific binding of } \\
\text { human pancreatic cancer cells allowing } \\
\text { tumor visualization, and with the } \\
\text { potential to deliver targeted treatment. } \\
\text { Relative high uptake in the liver, which } \\
\text { could interfere with imaging of the } \\
\text { pancreas. }\end{array}$} & \multirow{3}{*}{216} \\
\hline & & & & & & & $\begin{array}{l}\text { Positive-to-negative } \\
\text { tumor ratio }\end{array}$ & $\begin{array}{l}\text { Capan-2: } 6.0 \\
\text { BxPC3 (tumor+): } 1.1(0.5-1.8)\end{array}$ & & \\
\hline & & & & & & & $\begin{array}{l}\text { Tumor } \\
\text { uptake/biodistribution in } \\
\text { \% of injected dosage/g } \\
\text { BW (range) }\end{array}$ & $\begin{array}{l}\text { BxPC3 (tumor-): } 0.1(0.03-0.2) \\
\text { Capan-2 (tumor+): } 0.5(0.3-0.1) \\
\text { Capan-2 (tumor-): } 0.1(0.06-0.1)\end{array}$ & & \\
\hline & \multirow{2}{*}{$\begin{array}{l}{ }^{124} \mathrm{I}-\mathrm{anti-} \\
\text { CA19-9 }\end{array}$} & \multirow{2}{*}{$\begin{array}{l}\text { Cysteine- } \\
\text { modified } \\
\text { dia- } \\
\text { body }\end{array}$} & \multirow{2}{*}{$\mathrm{PET} / \mathrm{CT}$} & \multirow{2}{*}{$\begin{array}{l}\text { In vitro/In vivo } \\
\text { Preclinical probe } \\
\text { construction and } \\
\text { target validation } \\
\text { in mouse model }\end{array}$} & \multirow{2}{*}{$\begin{array}{c}\text { Subcutaneous PDAC } \\
\text { mouse model (BxPC3: } \\
\text { CA19.9+ } \\
\text { MiaPaCa-2: Ca19.9-) }\end{array}$} & \multirow{2}{*}{$\begin{array}{l}\text { After } 4 \mathrm{~h} \text { and } \\
\quad 20 \mathrm{~h}\end{array}$} & $\begin{array}{l}\text { Positive-to-negative } \\
\text { tumor ratio }\end{array}$ & BxPC3 (tumor+): $1.1(0.4-1.7)$ & \multirow{2}{*}{$\begin{array}{l}\text { Proof-of-concept PET/CT-imaging of } \\
\text { CA19.9+ PDAC. High target binding } \\
\text { affinity for CA19.9 allowing tumor } \\
\text { visualization. } \\
\text { Shorter half-life-time than diabody in } \\
\text { comparison with study from Girgis } \\
\text { et al. above. }\end{array}$} & \multirow{2}{*}{217} \\
\hline & & & & & & & $\begin{array}{l}\text { Tumor } \\
\text { uptake/biodistribution in } \\
\text { \% of injected dosage/g } \\
\text { BW (range) }\end{array}$ & BxPC3 (tumor-): $0.2(0.1-0.3)$ & & \\
\hline & \multirow[t]{2}{*}{$\begin{array}{l}{ }^{89} \mathrm{Zr}(\mathrm{ss}) \mathrm{DFO}- \\
\quad 5 \mathrm{~B} 1\end{array}$} & \multirow{4}{*}{$\begin{array}{l}\mathrm{mAb}, \\
\text { fully } \\
\text { hu } \\
\text { man }\end{array}$} & \multirow{4}{*}{$\begin{array}{l}\text { PET/CT, } \\
\text { NIRF- } \\
800 \mathrm{~nm} \\
\text { (dual- } \\
\text { labeled) }\end{array}$} & \multirow{4}{*}{$\begin{array}{l}\text { In vitro/In vivo } \\
\text { preclinical probe } \\
\text { construction and } \\
\text { target validation } \\
\text { in mouse model }\end{array}$} & \multirow{2}{*}{$\begin{array}{c}\text { Subcutaneous PDAC } \\
\text { mouse model (BxPC3: } \\
\text { CA19.9+ } \\
\text { MiaPaca-2: Ca19.9-) }\end{array}$} & \multirow{2}{*}{$\begin{array}{l}\text { After } 48 \mathrm{~h} \\
\text { and } 120 \mathrm{~h} \\
(\mathrm{PET} / \mathrm{CT})\end{array}$} & \multirow{2}{*}{$\begin{array}{l}\text { Tumor } \\
\text { uptake/biodistribution in } \\
\% \text { of injected dosage/g } \\
\text { BW (After } 48 \text { h; after } 120 \\
\text { h) }\end{array}$} & $\begin{array}{l}\text { DFO-5B1 } \\
\text { BxPC3 (tumor+): } 32 ; 40 \\
\text { MiaPaCa-2 (control): } 8 ; 7 \\
\end{array}$ & \multirow{4}{*}{$\begin{array}{l}\text { Proof-of-concept with combined } \\
\text { PET/NIRF imaging of CA19.9+ PDAC } \\
\text { lesions with 89Zr-ssdual-5B1 to } \\
\text { delineate the pancreatic tumor, distant } \\
\text { metastases and positive lymph nodes } \\
\text { using PET/CT and NIRF imaging. } \\
\text { Dual-labeled imaging of CA19.9 with } \\
{ }^{89} \mathrm{Zr}(\mathrm{ss}) \text { dual-5B1 could serve as a guide } \\
\text { for the staging, treatment planning, and } \\
\text { resection of PDAC }\end{array}$} & \multirow{4}{*}{ [166] } \\
\hline & & & & & & & & $\begin{array}{l}\text { Dual-5B1 } \\
\text { BxPC3 (tumor+): } 36 ; 45 \\
\text { MiaPaCa-2 (control): } 5 ; 4\end{array}$ & & \\
\hline & $\begin{array}{l}{ }^{89} \mathrm{Zr}(\mathrm{ss}) \mathrm{FL}- \\
\mathrm{BB} 1\end{array}$ & & & & Subcutaneous PDAC & After $120 \mathrm{~h}$ & Feasibility of in vivo & With NIRF-imaging, the tumor, & & \\
\hline & $\begin{array}{l}{ }^{89} \mathrm{Zr} \text { (ss)dual- } \\
5 \mathrm{~B} 1 \\
\end{array}$ & & & & mouse model (SUIT-2) & $\begin{array}{l}\text { (single and } \\
\text { dual-labeled) }\end{array}$ & $\begin{array}{l}\text { NIRF-guided resection of } \\
\text { tumor, metastases, and } \\
\text { suspected lymph nodes }\end{array}$ & $\begin{array}{l}\text { (micro)metastases, and lymph nodes were } \\
\text { clearly visible, due to extensive disease no } \\
\text { complete resection could be achieved. }\end{array}$ & & \\
\hline
\end{tabular}


Table A2. Cont.

\begin{tabular}{|c|c|c|c|c|c|c|c|c|c|c|}
\hline Target & Tracer & Type & Modality & Design & $\begin{array}{l}\text { Subjects } \\
\text { (Cell Line) }\end{array}$ & $\begin{array}{l}\text { Infusion- } \\
\text { Imaging } \\
\text { Window }\end{array}$ & Main Outcome & Results & Highlights & Ref. \\
\hline \multirow[b]{3}{*}{$\begin{array}{l}\text { Cathep- } \\
\text { sin-E }\end{array}$} & \multirow{2}{*}{$\begin{array}{l}\text { Ala-Gly-Phe- } \\
\text { Ser-Leu-Pro- } \\
\text { Ala-Gly-Cys- } \\
\text { CONH } 2^{-} \\
\text {Cy5.5 }\end{array}$} & \multirow[t]{2}{*}{$\begin{array}{l}\text { Peptide, } \\
\text { linear }\end{array}$} & \multirow[t]{2}{*}{$\begin{array}{l}\text { NIRF- } \\
700 \mathrm{~nm}\end{array}$} & \multirow{2}{*}{$\begin{array}{l}\text { In vitro/In vivo } \\
\text { Preclinical activatable } \\
\text { probe construction and } \\
\text { target validation in } \\
\text { mouse model }\end{array}$} & \multirow{2}{*}{$\begin{array}{l}\text { Subcutaneous PDAC } \\
\text { mouse model } \\
\text { (MPanc96-E, CTSE+) }\end{array}$} & \multirow[t]{2}{*}{$\begin{array}{l}\text { After } 24 \mathrm{~h}, 48 \\
\quad \mathrm{~h}, 72 \mathrm{~h}\end{array}$} & $\begin{array}{l}\text { In vivo } \\
\text { Tumor-to-background } \\
\text { (SD) }\end{array}$ & $\begin{array}{l}24 \mathrm{~h}: \pm 2 \\
48 \mathrm{~h}: \pm 2.5 \\
72 \mathrm{~h}: \pm 3\end{array}$ & \multirow{2}{*}{$\begin{array}{l}\text { Proof-of-concept of an activable } \\
\text { NIRF-probe targeting cathepsin-E. } \\
\text { Cathepsin-E+ PDAC showed } \\
\text { fluorescent signals with subsequent } \\
\text { TBR's }(>2) \text { from } 24-72 \text { h post-injection. }\end{array}$} & \multirow[t]{2}{*}{ [60] } \\
\hline & & & & & & & Ex vivo Tumor-to-muscle & 16 & & \\
\hline & $\begin{array}{l}\text { Ala-Gly-Phe- } \\
\text { Ser-Leu-Pro- } \\
\text { Ala-Gly-Cys- } \\
\text { CONHH } \\
\text { Cy5.5 }\end{array}$ & $\begin{array}{l}\text { Peptide, } \\
\text { linear }\end{array}$ & $\begin{array}{l}\text { NIRF- } \\
700 \mathrm{~nm}\end{array}$ & $\begin{array}{l}\text { In vitro/Ex vivo } \\
\text { Preclinical activatable } \\
\text { probe construction and } \\
\text { target expression in } \\
\text { mouse model }\end{array}$ & $\begin{array}{l}\text { Orthotopic PDAC } \\
\text { mouse model } \\
\text { (MDA PATC-3, } \\
\text { MPanc96-E) }\end{array}$ & $\begin{array}{l}\text { After } \\
48 \mathrm{~h}\end{array}$ & Ex vivo Tumor-to-muscle & 5.5 & $\begin{array}{l}\text { Proof-of-concept of an activable } \\
\text { NIRF-probe targeting cathepsin-E. } \\
\text { Cathepsin-E+ PDAC. Only Ex vivo } \\
\text { quantification has been carried out. } \\
\text { Abd-Elgaliel et al. [60] performed } \\
\text { additional analysis of the same } \\
\text { tracer/probe combination. Adequate } \\
\text { signals with TBR's }(>2) \text { from } 24-72 \mathrm{~h} \\
\text { post-injection. }\end{array}$ & [58] \\
\hline \multirow{3}{*}{$\begin{array}{c}\text { CDCP- } \\
1\end{array}$} & \multirow{2}{*}{$\begin{array}{l}{ }^{89} \mathrm{Zr}-\mathrm{DFO}- \\
4 \mathrm{~A} 06\end{array}$} & \multirow{2}{*}{$\begin{array}{l}\mathrm{mAb}, \\
\text { hu } \\
\text { man- } \\
\text { ized }\end{array}$} & \multirow{2}{*}{$\mathrm{PET} / \mathrm{CT}$} & \multirow{2}{*}{$\begin{array}{l}\text { In vivo } \\
\text { Preclinical probe } \\
\text { construction and target } \\
\text { validation in mouse } \\
\text { model }\end{array}$} & \multirow{2}{*}{$\begin{array}{l}\text { Subcutaneous PDAC } \\
\text { mouse model } \\
\text { (HPAC, HPAF II, } \\
\text { Capan-1, Panc10.05, } \\
\text { Panc2.03) }\end{array}$} & \multirow{2}{*}{$\begin{array}{l}\text { After } \\
72 \mathrm{~h}\end{array}$} & $\begin{array}{l}\text { Tumor } \\
\text { uptake/biodistribution in } \\
\% \text { of injected dosage/g } \\
\text { BW (SD) }\end{array}$ & $\begin{array}{l}\text { HPAC: } 15.21( \pm 2.2) \\
\text { HPAF II: } 7.78( \pm 4.8) \\
\text { Capan-1: } 6.81( \pm 1.2) \\
\text { Panc10.05: } 6.09( \pm 0.5) \\
\text { Panc2.03: } 5.25( \pm 1.2)\end{array}$ & \multirow{2}{*}{$\begin{array}{l}\text { Proof-of-concept, for in vivo } \\
\text { PET/CT-imaging of CDCP-1+ PDAC in } \\
\text { mice. }\end{array}$} & \multirow{2}{*}{ [63] } \\
\hline & & & & & & & $\begin{array}{l}\text { Biodistribution in \% of } \\
\text { injected dosage/g BW } \\
\text { (range) }\end{array}$ & $\begin{array}{l}\text { Blood: } 2-2.5 \\
\text { Muscle: } 0.75-1.0\end{array}$ & & \\
\hline & $\begin{array}{l}{ }^{89} \mathrm{Zr} \text {-DFO- } \\
10 \mathrm{D} 7\end{array}$ & $\begin{array}{l}\text { mAb, } \\
\text { mouse }\end{array}$ & $\mathrm{PET} / \mathrm{CT}$ & $\begin{array}{c}\text { In vivo } \\
\text { Preclinical probe } \\
\text { construction and target } \\
\text { validation in mouse } \\
\text { model }\end{array}$ & $\begin{array}{l}\text { Subcutaneous/Orthotopic } \\
\text { PDAC mouse model } \\
\text { (TKCC05) }\end{array}$ & $\begin{array}{l}\text { After } 24 \mathrm{~h}, 48 \\
\mathrm{~h}, 72 \mathrm{~h}, 144 \mathrm{~h}\end{array}$ & $\begin{array}{l}\text { Biodistribution in \% of } \\
\text { injected dosage/g BW } \\
\text { (range) }\end{array}$ & $\begin{array}{l}\text { Blood: } 2-2.5 \\
\text { Muscle: } 0.75-1.0\end{array}$ & $\begin{array}{l}\text { Proof-of-concept, for in vivo } \\
\text { PET/CT-imaging of CDCP-1+ PDAC in } \\
\text { mice. }\end{array}$ & {$[146$} \\
\hline \multirow[t]{3}{*}{ CEA } & $\begin{array}{l}{ }^{124} \mathrm{I}-\text { anti-CEA } \\
\text { scFv- } \\
\mathrm{Fc}(\mathrm{H} 310 \mathrm{~A})\end{array}$ & $\begin{array}{l}\text { Single- } \\
\text { chain } \\
\text { vari- } \\
\text { able } \\
\text { frag- } \\
\text { ment } \\
\text { (scFv- } \\
\text { Fc) }\end{array}$ & $\mathrm{PET} / \mathrm{CT}$ & $\begin{array}{l}\text { In vitro/In vivo } \\
\text { Preclinical probe } \\
\text { construction and target } \\
\text { validation in mouse } \\
\text { model }\end{array}$ & $\begin{array}{l}\text { Subcutaneous PDAC } \\
\text { mouse model (Capan-1, } \\
\text { HPAF-II, and BxPC3) }\end{array}$ & $\begin{array}{l}\text { After } 4 \mathrm{~h} \text { and } \\
\quad 20 \mathrm{~h}\end{array}$ & $\begin{array}{l}\text { Tumor-to-background } \\
\text { ratio (blood pool) }\end{array}$ & $\begin{array}{l}\text { All cell-lines: } 4.0 \\
\text { CEA+Capan-1: } 3.7 \\
\text { CEA+ HPAF--II: } 3.2 \\
\text { CEA+ BXPC3:5.2 }\end{array}$ & $\begin{array}{l}\text { Proof-of-concept of in vivo } \\
\text { PET/CT-imaging with a targeted } \\
\text { anti-CEA-probe, high specific target } \\
\text { binding. }\end{array}$ & [183] \\
\hline & \multirow[t]{2}{*}{$\begin{array}{l}\text { Alexa Fluor } \\
\text { 488-anti-CEA }\end{array}$} & \multirow{2}{*}{$\begin{array}{l}\mathrm{mAb}, \\
\text { hu } \\
\text { man- } \\
\text { ized }\end{array}$} & \multirow{2}{*}{$\begin{array}{l}\text { Fluorescence } \\
\text { imaging- } \\
500 \mathrm{~nm}\end{array}$} & \multirow{2}{*}{$\begin{array}{l}\text { In vivo } \\
\text { Preclinical target } \\
\text { validation in mouse } \\
\text { model }\end{array}$} & $\begin{array}{l}\text { Subcutaneous PDAC } \\
\text { mouse model (ASPC-1, } \\
\text { BxPC-3, CFPAC, } \\
\text { Panc-1, and Capan-1) }\end{array}$ & \multirow{2}{*}{$\begin{array}{l}\text { After } 30 \mathrm{~min}, \\
1 \mathrm{~h}, 2 \mathrm{~h}, 6 \mathrm{~h}, 8 \\
\mathrm{~h}, 24 \mathrm{~h}, 48 \mathrm{~h}, \\
192 \mathrm{~h}, 360 \mathrm{~h}\end{array}$} & \multirow{2}{*}{$\begin{array}{l}\text { Ability to visualize } \\
\text { orthotopic CEA+ } \\
\text { pancreatic tumors after } \\
24 \mathrm{~h}\end{array}$} & \multirow{2}{*}{$\begin{array}{l}\text { In vivo fluorescence-imaging re } \\
\text { vealed very small pancreatic tu mors } \\
\text { which were difficult to visualize } \\
\text { using standard brightfield } \\
\text { illumination, furthermore extent of } \\
\text { tumor invasion could be assessed. }\end{array}$} & \multirow{2}{*}{$\begin{array}{l}\text { Proof-of-concept of in vivo fluorescence } \\
\text { imaging of CEA+ PDAC. } \\
\text { Low background due to low CEA } \\
\text { expression in normal parenchyma }\end{array}$} & \multirow{2}{*}{218} \\
\hline & & & & & $\begin{array}{l}\text { Orthotopic PDAC } \\
\text { mouse model (BxPC-3) }\end{array}$ & & & & & \\
\hline
\end{tabular}


Table A2. Cont.

\begin{tabular}{|c|c|c|c|c|c|c|c|c|c|c|}
\hline Target & Tracer & Type & Modality & Design & $\begin{array}{l}\text { Subjects } \\
\text { (Cell Line) }\end{array}$ & $\begin{array}{l}\text { Infusion- } \\
\text { Imaging } \\
\text { Window }\end{array}$ & Main Outcome & Results & Highlights & Ref. \\
\hline & \multirow{2}{*}{$\begin{array}{l}\text { Alexa Fluor } \\
\text { 488-anti- } \\
\text { CEA }\end{array}$} & \multirow[t]{2}{*}{$\begin{array}{l}\mathrm{mAb}, \\
\text { hu } \\
\text { man- } \\
\text { ized }\end{array}$} & \multirow{2}{*}{$\begin{array}{l}\text { Fluorescence } \\
\text { imaging- } \\
500 \mathrm{~nm}\end{array}$} & \multirow{2}{*}{$\begin{array}{l}\text { In vivo } \\
\text { Preclinical CEA+ } \\
\text { fluorescence- } \\
\text { guided surgery in } \\
\text { mouse model }\end{array}$} & \multirow[t]{2}{*}{$\begin{array}{l}\text { Orthotopic PDAC } \\
\text { mouse model (BxPC-3) }\end{array}$} & \multirow[t]{2}{*}{$\begin{array}{l}\text { After } \\
24 \mathrm{~h}\end{array}$} & $\begin{array}{l}\text { Ability to achieve } \\
\text { complete resection } \\
\text { compared to } \\
\text { bright-light-surgery } \\
\text { (BLS) }\end{array}$ & $\begin{array}{l}\text { NIRF: } 92 \%(23 / 25) \\
\text { BLS: } 45.5 \%(10 / 22)\end{array}$ & \multirow{2}{*}{$\begin{array}{l}\text { Proof-of-concept for fluorescence-guided surgery of } \\
\text { PDAC, improving complete resection rate and 1-year } \\
\text { survival. }\end{array}$} & \multirow[t]{2}{*}{ [71] } \\
\hline & & & & & & & $\begin{array}{l}\text { 1-year survival } \\
\text { (proportion) }\end{array}$ & $\begin{array}{l}\text { NIRF: } 0 \%(0 / 22) B L S: 28 \% \\
(7 / 25)\end{array}$ & & \\
\hline & \multirow{2}{*}{$\begin{array}{l}\text { hM5A- } \\
\text { IR800 }\end{array}$} & \multirow{2}{*}{$\begin{array}{l}\mathrm{mAb}, \\
\text { hu } \\
\text { man- } \\
\text { ized }\end{array}$} & \multirow{2}{*}{$\begin{array}{l}\text { NIRF- } \\
800 \mathrm{~nm}\end{array}$} & \multirow{2}{*}{$\begin{array}{l}\text { In vitro/In vivo } \\
\text { Preclinical probe } \\
\text { construction and } \\
\text { target validation } \\
\text { in mouse model }\end{array}$} & \multirow{2}{*}{$\begin{array}{l}\text { Orthotopic PDAC } \\
\text { mouse model (BxPC-3) }\end{array}$} & \multirow{2}{*}{$\begin{array}{l}\text { After } 6 \mathrm{~h}, 12 \\
\mathrm{~h}, 24 \mathrm{~h}, 48 \mathrm{~h} \\
\text { and } 72 \mathrm{~h}\end{array}$} & $\begin{array}{l}\text { Tumor-to-background } \\
\text { ratio (at all time points) }\end{array}$ & $>5.0$ & \multirow{2}{*}{$\begin{array}{l}\text { Proof-of-concept of in vivo NIRF-imaging of humanized } \\
\text { antibody targeting CEA+ PDAC in mice, optimal window } \\
\text { after } 48 \mathrm{~h} \text {. Low background fluorescence due to low CEA } \\
\text { expression in normal parenchyma. Except for the liver } \\
\text { parenchyma, possibly interfering with identification of } \\
\text { CEA-positive primary liver or metastatic lesions. }\end{array}$} & \multirow[b]{2}{*}{ [66] } \\
\hline & & & & & & & $\begin{array}{l}\text { Maximum } \\
\text { tumor-to-background } \\
\text { ratio (at } 48 \mathrm{~h} \text { ) }\end{array}$ & 16.6 & & \\
\hline \multirow{2}{*}{ EGFR } & \multirow{2}{*}{$\begin{array}{l}{ }^{64} \mathrm{Cu}- \\
\text { panitumumab- } \\
\mathrm{F}\left(\mathrm{ab}{ }^{\prime}\right)_{2}\end{array}$} & \multirow{2}{*}{$\begin{array}{l}\text { Antibody } \\
\text { frag- } \\
\text { ment } \\
\mathrm{F}\left(\mathrm{ab}^{\prime}\right) 2\end{array}$} & \multirow{2}{*}{$\mathrm{PET} / \mathrm{CT}$} & \multirow{2}{*}{$\begin{array}{l}\text { In vivo preclinical } \\
\text { probe construction } \\
\text { and target } \\
\text { validation in } \\
\text { mouse model }\end{array}$} & $\begin{array}{l}\text { Subcutaneous PDAC } \\
\text { mouse model (PANC-1, } \\
\text { OCIP23) }\end{array}$ & \multirow{2}{*}{$\begin{array}{l}\text { After } 24 \mathrm{~h}, 48 \\
\quad \mathrm{~h}, 72 \mathrm{~h}\end{array}$} & \multirow{2}{*}{$\begin{array}{l}\text { Tumor } \\
\text { uptake/biodistribution in } \\
\% \text { (SD) of injected } \\
\text { dosage/g BW (after } 24 \\
\text { h-72 h) }\end{array}$} & $\begin{array}{l}\text { PANC-1: } \\
\text { Subcutaneous: } 11.8( \pm 0.9) \\
\text { OCIP23: } \\
\text { Subcutaneous: } 12.0( \pm 0.9)\end{array}$ & \multirow{2}{*}{$\begin{array}{l}\text { Proof-of-concept, high target binding affinity using pani } \\
\text { tumumab-F(ab' })_{2} \text { fragments for EGFR+ PDAC allowing } \\
\text { tumor visualization during in vivo imaging. }\end{array}$} & \multirow[t]{2}{*}{ [173] } \\
\hline & & & & & $\begin{array}{l}\text { PDAC orthotopic } \\
\text { tumor bearing mice } \\
\text { (OCIP23) }\end{array}$ & & & $\begin{array}{l}\text { OCIP23 } \\
\text { Orthotopic: } 6.1( \pm 1.1) \\
\text { Blood: } 2.6( \pm 0.17) \\
\text { Muscle: } 0.3( \pm 0.02)\end{array}$ & & \\
\hline $\begin{array}{l}\text { EGFR/ } \\
\text { VEGF }_{165}\end{array}$ & $\begin{array}{c}\text { Bi50- } \\
65 \text { IRdye800 }\end{array}$ & Diabody & $\begin{array}{l}\text { NIRF- } \\
800 \mathrm{~nm}\end{array}$ & $\begin{array}{l}\text { In vitro/In vivo } \\
\text { preclinical probe } \\
\text { construction and } \\
\text { target validation } \\
\text { in mouse model }\end{array}$ & $\begin{array}{l}\text { Subcutaneous PDAC } \\
\text { mouse model } \\
(\text { BxPC-3) }\end{array}$ & $\begin{array}{l}\text { After } \\
8 \mathrm{~h}\end{array}$ & $\begin{array}{l}\text { Tumor-to-background } \\
\text { Ratio (SD) }\end{array}$ & $4.32( \pm 0.1)$ & $\begin{array}{l}\text { Proof-of-concept, simultane ous excellent target binding } \\
\text { capacity to VEGFR and EGFR. Clear delineation of tumor } \\
\text { and healthy tissue. Targeting tumor vasculature-rich areas } \\
\text { (overexpression of VEGFR), as well as largely bonded the } \\
\text { tumor parenchymal cells (EGFR overexpression) }\end{array}$ & [196] \\
\hline \multirow{5}{*}{ FAP } & \multirow{5}{*}{$\begin{array}{l}{ }^{18} \text { F-FAPI-74 } \\
{ }^{177} \text { Lu-FAPI- } \\
46 \\
{ }^{225} \text { Ac-FAPI- } \\
46\end{array}$} & \multirow{5}{*}{$\begin{array}{l}\text { SMI } \\
\text { SMI } \\
\text { SMI }\end{array}$} & \multirow{5}{*}{ РET/CT } & \multirow{5}{*}{$\begin{array}{l}\text { In vitro/In vivo } \\
\text { preclinical probe } \\
\text { construction and } \\
\text { target validation } \\
\text { in mouse model } \\
\text { In vivo preclinical } \\
\text { targeted } \alpha \text {-emitter } \\
\text { therapy efficacy } \\
\text { and monitoring } \\
\text { validation in } \\
\text { mouse model }\end{array}$} & \multirow{5}{*}{$\begin{array}{l}\text { Subcutaneous PDAC } \\
\text { mouse model } \\
\text { (PANC-1) }\end{array}$} & $\begin{array}{l}\text { After } \\
1 \mathrm{~h}\end{array}$ & SUVmean & $\begin{array}{l}\text { Tumor: } 0.24( \pm 0.04) \\
\text { Muscle: } 0.05( \pm 0.01) \\
\text { Kidneys: } 0.39( \pm 0.07)\end{array}$ & \multirow{5}{*}{$\begin{array}{l}\text { Proof-of-concept, demonstrating the effectiveness of } \\
\text { FAP-targeted PET-imaging and therapy in xenograft } \\
\text { PDAC mouse model, observing rapid clearance from } \\
\text { healthy tissue and high uptake in the tumors } 3 \text { h after } \\
\text { injection. } \\
\text { Tumor-suppressive effects were observed in both PANC-1 } \\
\text { xenograft mice treated with [177Lu]FAPI-46 as well as } \\
{ }^{225} \text { Ac-FAPI-46, although }{ }^{177} \text { Lu-FAPI- } 46 \text { showed a mild but } \\
\text { more prolonged therapeutic effects compared to } \\
{ }^{225} \text { Ac-FAPI-46. }\end{array}$} & \multirow{5}{*}{ [169] } \\
\hline & & & & & & After $3 \mathrm{~h}, 24 \mathrm{~h}$ & $\begin{array}{l}\text { Biodistribution in \% of } \\
\text { injected dosage/g BW }\end{array}$ & $\begin{array}{l}{ }^{177} \text { Lu-FAPI- } 46 \\
\text { Tumor: } 0.36 ; 0.10 \\
\text { Blood: } 0.08 ; 0.01\end{array}$ & & \\
\hline & & & & & & $\begin{array}{l}\text { After } \\
40 \mathrm{~d}\end{array}$ & $\begin{array}{l}\text { Therapy effect as relative } \\
\text { ratio of } \\
\text { tumor size }\end{array}$ & $\begin{array}{l}\text { 3 MBq: } 0.62 \\
\text { 10 MBq: } 0.56 \\
\text { 30 MBq: } 0.27 \\
\end{array}$ & & \\
\hline & & & & & & After $3 \mathrm{~h}, 24 \mathrm{~h}$ & $\begin{array}{l}\text { Biodistribution in \% of } \\
\text { injected dosage } / \mathrm{g} \text { BW }\end{array}$ & $\begin{array}{l}{ }^{225} \text { Ac-FAPI- } 46 \\
\text { Tumor: } 0.30 ; 0.10 \\
\text { Blood: } 0.07 ; 0.01\end{array}$ & & \\
\hline & & & & & & $\begin{array}{l}\text { After } \\
30 \mathrm{~d}\end{array}$ & $\begin{array}{l}\text { Tumor-suppressive-effect } \\
\text { versus control }\end{array}$ & $\begin{array}{l}\text { 3 MBq: mild } \\
10 \text { MBq: strong ( }(p=0.05) \\
\text { 30 MBq: strong }(p=0.05)\end{array}$ & & \\
\hline
\end{tabular}


Table A2. Cont.

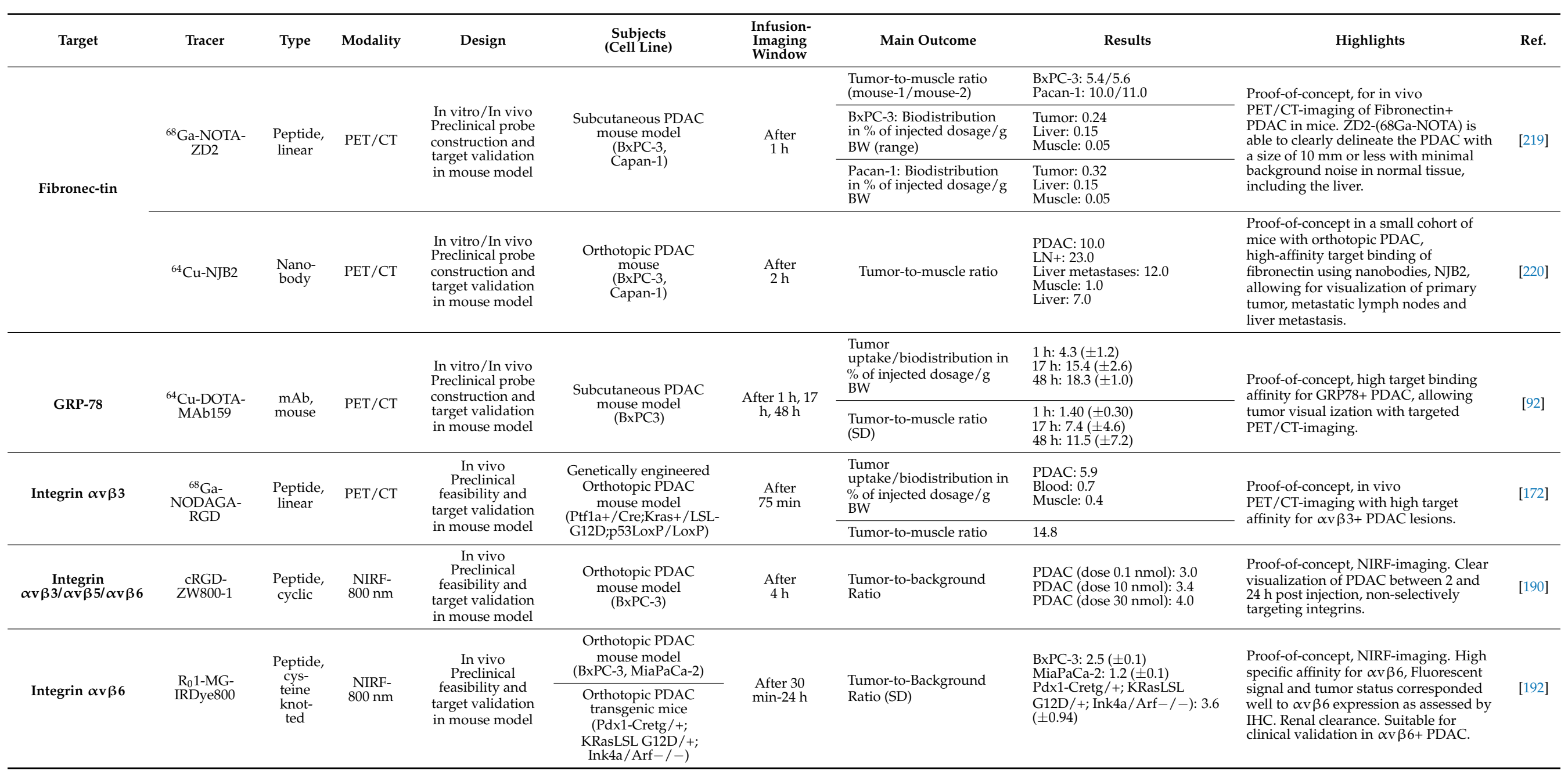


Table A2. Cont.

\begin{tabular}{|c|c|c|c|c|c|c|c|c|c|c|}
\hline Target & Tracer & Type & Modality & Design & $\begin{array}{l}\text { Subjects } \\
\text { (Cell Line) }\end{array}$ & $\begin{array}{l}\text { Infusion- } \\
\text { Imaging } \\
\text { Window }\end{array}$ & Main Outcome & Results & Highlights & Ref. \\
\hline & $\begin{array}{l}{ }^{68} \text { Ga-DOTA- } \\
\text { SFLAP3 }\end{array}$ & $\begin{array}{l}\text { Peptide, } \\
\text { cyclic }\end{array}$ & $\mathrm{PET} / \mathrm{CT}$ & $\begin{array}{l}\text { In vitro } \\
\text { Preclinical probe } \\
\text { construction and } \\
\text { target validation } \\
\text { in mouse model }\end{array}$ & $\begin{array}{l}\text { Orthotopic PDAC } \\
\text { mouse model } \\
\text { (Capan-2) }\end{array}$ & N/A & N/A & N/A & $\begin{array}{l}\text { High specific binding affinity to } \\
\text { integrin } \alpha \mathrm{v} \beta 6 \text { on pancreatic cancer cell } \\
\text { lines. No further data available. }\end{array}$ & $\begin{array}{c}{[221]^{*}} \\
\text { Only } \\
\text { ab- } \\
\text { stract } \\
\text { avail- } \\
\text { able }\end{array}$ \\
\hline & \multirow{3}{*}{${ }^{68}$ Ga-cycratide } & \multirow{3}{*}{$\begin{array}{l}\text { Peptide, } \\
\text { cyclic }\end{array}$} & \multirow{3}{*}{$\mathrm{PET} / \mathrm{CT}$} & \multirow{3}{*}{$\begin{array}{l}\text { Combined } \\
\text { pre-clinical probe } \\
\text { construction and } \\
\text { target valida- } \\
\text { tion/Experimental } \\
\text { clinical study } \\
\text { phase I }\end{array}$} & \multirow{3}{*}{$\begin{array}{l}2 \text { PDAC patients } \\
\text { Orthotopic PDAC } \\
\text { mouse model } \\
(\mathrm{BxPC}-3)\end{array}$} & After $30 \mathrm{~min}$ & SUVmax & $\begin{array}{l}\text { Patient 1: (diagnosis/staging): } 4.86, \\
\text { histological confirmation of PDAC. } \\
\text { Patient 2: (FU } 7 \mathrm{~m} \text { after surgery and } \\
\text { ChemoTx): } 1.6, \text { no relapse, inflammatory } \\
\text { response. }\end{array}$ & \multirow{3}{*}{$\begin{array}{l}\text { Proof-of-concept for }{ }^{68} \mathrm{Ga} \text {-cycratide as } \\
\text { effective and selective } \alpha \mathrm{v} \beta 6 \text { targeting } \\
\text { PET-probe and low-background signal } \\
\text { with exclusive renal clearance. } \\
\text { Although the clinical part of the study } \\
\text { had a small sample size, further } \\
\text { evaluation in a clinical setting is needed } \\
\text { for the potential of }{ }^{68} \mathrm{Ga} \text {-cycratide } \\
\text { imaging. }\end{array}$} & \multirow{3}{*}{ [95] } \\
\hline & & & & & & $\begin{array}{l}\text { After } \\
2 \mathrm{~h}\end{array}$ & $\begin{array}{l}\text { Tumor } \\
\text { uptake/biodistribution in } \\
\% \text { of injected dosage/g } \\
\text { BW (SD) }\end{array}$ & $2.15( \pm 0.46)$ & & \\
\hline & & & & & & After $30 \mathrm{~min}$ & $\begin{array}{l}\text { Tumor-to-muscle ratio } \\
\text { (SD) }\end{array}$ & $4.77( \pm 1.62)$ & & \\
\hline \multirow{2}{*}{$\begin{array}{l}\text { MT1- } \\
\text { MMP/MN }\end{array}$} & \multirow{2}{*}{$\begin{array}{l}{ }^{89} \mathrm{Zr}-\mathrm{DFO}- \\
\text { LEM2/15 } \\
\text { MP-68 Ga-DOTA- } \\
\text { AF7p }\end{array}$} & \multirow{2}{*}{$\begin{array}{l}\text { mAb, } \\
\text { mouse } \\
\text { Peptide, } \\
\text { linear }\end{array}$} & \multirow[b]{2}{*}{ PET/CT } & \multirow{2}{*}{$\begin{array}{l}\text { In vitro/In vivo } \\
\text { Preclinical probe } \\
\text { construction and } \\
\text { target validation } \\
\text { in mouse model }\end{array}$} & $\begin{array}{l}\text { Subcutaneous PDAC } \\
\text { mouse model, } \\
\text { (Capan-2) }\end{array}$ & $\begin{array}{l}\text { After } 5 \mathrm{~d} \text {, } \\
7 \text { days }\end{array}$ & $\begin{array}{l}\text { Tumor-to-background } \\
\text { (SD) of } \\
{ }^{80} \mathrm{Zr}-\mathrm{DFO}-\mathrm{LEM} 2 / 15\end{array}$ & $\begin{array}{l}5 \text { days: } 1.13( \pm 0.51) \\
7 \text { days: } 1.44( \pm 0.43)\end{array}$ & \multirow{3}{*}{$\begin{array}{l}\text { Proof-of-concept of in vivo } \\
\text { PET/CT-imaging of } \\
\text { MT1-MMP/MMP-14+ PDAC, with } \\
\text { high target specificity for } \\
{ }^{89} \text { Zr-DFO-LEM2/15. } \\
\text { Low/Moderate specificity for } \\
{ }^{68} \text { Ga-DOTA-AF7p. Further evaluation } \\
{ }^{89} \text { Zr-DFO-LEM2/15 is warranted to } \\
\text { address its potential in humans. } \\
\text { Proof-of-concept of in vivo } \\
\text { fluorescence-imaging of MUC-1+ } \\
\text { Subcutaneous/Orthotopic tumors. } \\
\text { Biodistribution and further evaluation } \\
\text { in pre-clinical is warranted before } \\
\text { clinical studies could be initiated, } \\
\text { furthermore humanized antibodies are } \\
\text { preferred over animal antibodies. }\end{array}$} & \multirow[b]{2}{*}{ [222] } \\
\hline & & & & & $\begin{array}{c}\text { Orthotopic PDX } \\
\text { PDAC mouse model }\end{array}$ & After $90 \mathrm{~min}$ & $\begin{array}{l}\text { Tumor-to-background of } \\
{ }^{68} \mathrm{Ga} \text {-DOTA-AF7p }\end{array}$ & 90 min: 0.5 & & \\
\hline$\underset{1}{\text { Mucin- }}$ & $\begin{array}{c}\text { Anti-MUC1 } \\
\text { (CT2)- } \\
\text { DyLight550/650 }\end{array}$ & $\begin{array}{l}\mathrm{mAb}, \\
\text { ham- } \\
\text { ster }\end{array}$ & $\begin{array}{l}\text { Fluorescence } \\
\text { imaging- } \\
600 \mathrm{~nm}\end{array}$ & $\begin{array}{l}\text { In vitro/In vivo } \\
\text { e Preclinical probe } \\
\text { construction and } \\
\text { target validation } \\
\text { in mouse model }\end{array}$ & $\begin{array}{l}\text { Subcutaneous/Orthotopic } \\
\text { PDAC mouse model } \\
\text { (PANC-1, } \\
\text { BxPC-3) }\end{array}$ & $\begin{array}{l}\text { After } 7-10 \\
\text { days }\end{array}$ & $\begin{array}{l}\text { In vivo } \\
\text { Tumor-to-background } \\
\text { (Orthotopic tumors) }\end{array}$ & $\begin{array}{l}\text { Panc-1: } 6.70 \\
\text { BxPC-3: } 2.39\end{array}$ & & [223] \\
\hline \multirow{2}{*}{ NTSR1 } & $\begin{array}{l}{ }^{64} \mathrm{Cu}-\mathrm{AmBaSar}- \\
\mathrm{NT}\end{array}$ & $\begin{array}{l}\text { Peptide, } \\
\text { linear }\end{array}$ & \multirow{2}{*}{$\begin{array}{l}\text { PET/CT } \\
\text { NIRF- } \\
800 \mathrm{~nm}\end{array}$} & \multirow{2}{*}{$\begin{array}{l}\text { In vivo preclinical } \\
\text { probe construction } \\
\text { and target } \\
\text { validation in } \\
\text { mouse model }\end{array}$} & $\begin{array}{l}\text { Subcutaneous PDAC } \\
\text { mouse model } \\
\text { (PANC-1, } \\
\text { AsPC-1) }\end{array}$ & \multirow{2}{*}{$\begin{array}{l}\text { After } \\
30 \mathrm{~min} \\
1 \mathrm{~h}, 4 \mathrm{~h}\end{array}$} & $\begin{array}{l}\text { PET/CT: } \\
\text { Tumor } \\
\text { uptake/biodistribution in } \\
\text { \% of injected dosage/g } \\
\text { BW (SD) }\end{array}$ & $\begin{array}{l}1 \text { h: } 3.76( \pm 1.45) \\
4 \text { h: } 2.29( \pm 0.10)\end{array}$ & \multirow{2}{*}{$\begin{array}{l}\text { Proof-of-concept, high target binding } \\
\text { affinity for NTSR+ PDAC, moderate } \\
\text { background in kidney uptake, low } \\
\text { background in liver and intestines. } \\
\text { Neurotensin peptide sequence could be } \\
\text { used for adequate PDAC visualization } \\
\text { with PET/CT and NIRF imaging. }\end{array}$} & \multirow{2}{*}{ [115] } \\
\hline & IRDye800-NT & $\begin{array}{l}\text { Peptide, } \\
\text { linear }\end{array}$ & & & $\begin{array}{l}\text { Orthotopic PDAC } \\
\text { mouse model } \\
\text { (PANC-1, } \\
\text { AsPC-1) }\end{array}$ & & $\begin{array}{l}\text { NIRF: } \\
\text { Tumor-to-background } \\
\text { Ratio (SD) }\end{array}$ & $\begin{array}{l}30 \min : 8.09( \pm 0.38) \\
1 \mathrm{h:} 6.67( \pm 0.43)\end{array}$ & & \\
\hline
\end{tabular}


Table A2. Cont.

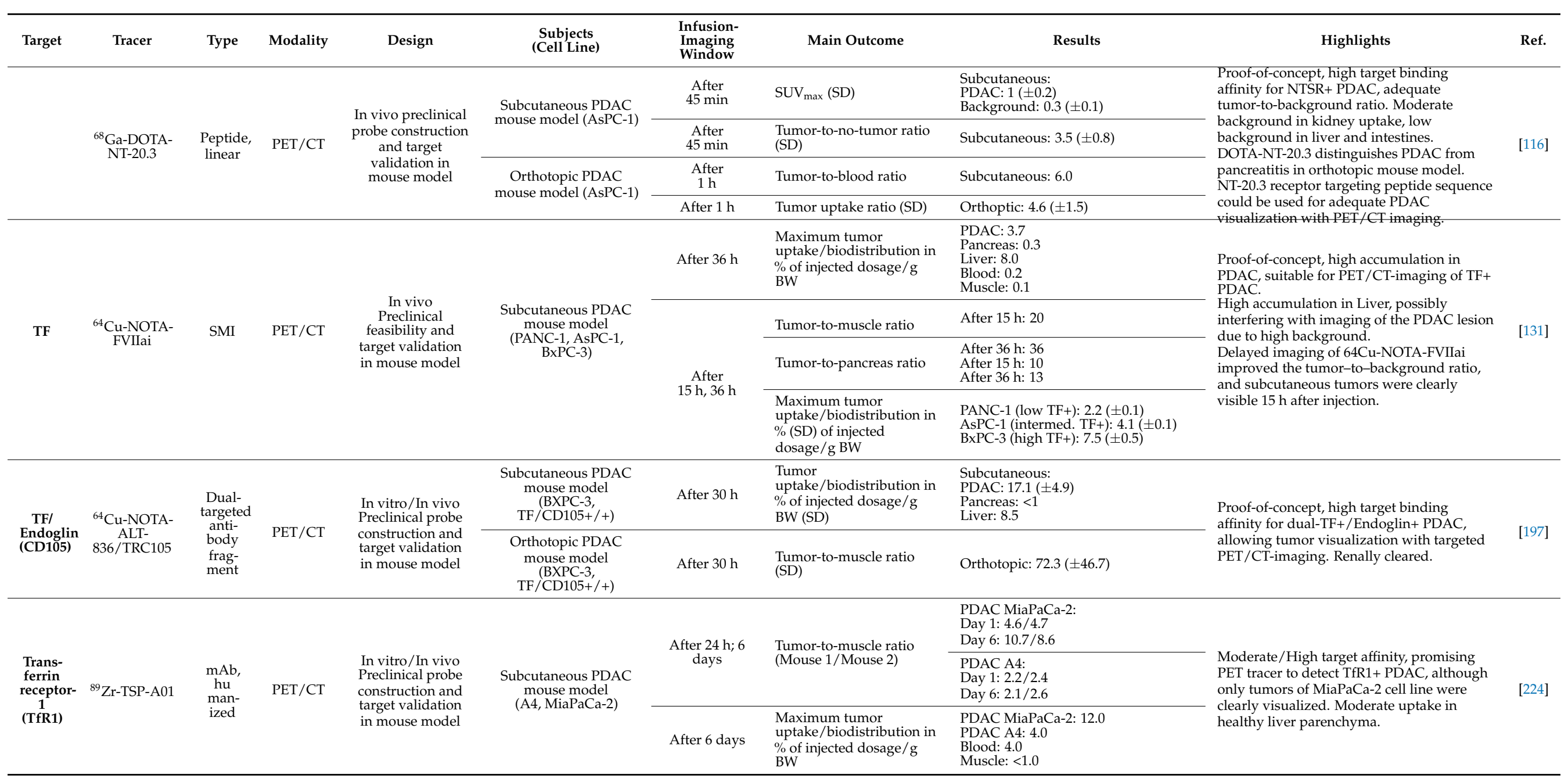


Table A2. Cont.

\begin{tabular}{|c|c|c|c|c|c|c|c|c|c|c|}
\hline Target & Tracer & Type & Modality & Design & $\begin{array}{l}\text { Subjects } \\
\text { (Cell Line) }\end{array}$ & $\begin{array}{l}\text { Infusion- } \\
\text { Imaging } \\
\text { Window }\end{array}$ & Main Outcome & Results & Highlights & Ref. \\
\hline \multirow{3}{*}{$\begin{array}{l}\text { uPA/ } \\
\text { uPAR } \\
\text { sys- } \\
\text { tem }\end{array}$} & \multirow[b]{2}{*}{$\begin{array}{l}{ }^{89} \text { Zr-Df-ATN- } \\
\quad 291\end{array}$} & \multirow[b]{2}{*}{$\begin{array}{l}\mathrm{mAb}, \\
\text { hu } \\
\text { man- } \\
\text { ized }\end{array}$} & \multirow[b]{2}{*}{$\mathrm{PET} / \mathrm{CT}$} & \multirow[b]{2}{*}{$\begin{array}{l}\text { In vitro/In vivo } \\
\text { preclinical probe } \\
\text { construction and } \\
\text { target validation } \\
\text { in mouse model }\end{array}$} & \multirow[b]{2}{*}{$\begin{array}{l}\text { Subcutaneous PDAC } \\
\text { mouse model } \\
(\text { BxPC-3) }\end{array}$} & \multirow[b]{2}{*}{$\begin{array}{l}\text { After 2, 24,72 } \\
\text { and } \\
120 \mathrm{~h}\end{array}$} & $\begin{array}{l}\text { Tumor-to-muscle Ratio } \\
\text { (after } 24,72 \mathrm{~h} \text { ) }\end{array}$ & PDAC: $7.4-21.3$ & \multirow[b]{2}{*}{$\begin{array}{l}\text { Proof-of-concept, high target affinity for } \\
\text { uPAR+ PDAC, useful imaging tool for } \\
\text { cancer (metastasis) detection and } \\
\text { evaluation of a given } \\
\text { uPA/uPAR-targeted treatment. }\end{array}$} & \multirow[b]{2}{*}{174} \\
\hline & & & & & & & $\begin{array}{l}\text { Tumor } \\
\text { uptake/biodistribution in } \\
\% \text { (SD) of injected } \\
\text { dosage/g BW (after } 24 \\
\text { h-72 h) }\end{array}$ & PDAC: $9.4( \pm 0.6)-18.9( \pm 1.9)$ & & \\
\hline & $\begin{array}{l}\text { Glu-Glu- } \\
\text { AE105-ICG }\end{array}$ & $\begin{array}{l}\text { Peptide, } \\
\text { linear }\end{array}$ & $\begin{array}{l}\text { NIRF- } \\
800 \mathrm{~nm}\end{array}$ & $\begin{array}{l}\text { In vivo preclinical } \\
\text { target validation } \\
\text { and NIRF-guided } \\
\text { surgery in mouse } \\
\text { model }\end{array}$ & $\begin{array}{l}\text { Orthotopic PDAC } \\
\text { mouse model } \\
(\text { BxPC-3) }\end{array}$ & After $15 \mathrm{~h}$ & $\begin{array}{l}\text { Tumor-to-background } \\
\text { Ratio }(95 \% \mathrm{CI})\end{array}$ & $\begin{array}{l}\text { PDAC: } 3.5(3.3-3.7) \\
\text { Metastases: } 3.4(3.1-4.0)\end{array}$ & $\begin{array}{l}\text { Clear localization of primary PDAC } \\
\text { and metastases with NIRF imaging } \\
\text { Glu-Glu-AE105-ICG. Identification of } \\
\text { additional fluorescent lesions, resulting } \\
\text { in resection. }\end{array}$ & {$[193$} \\
\hline
\end{tabular}

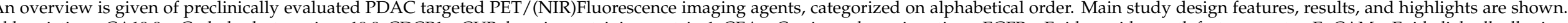

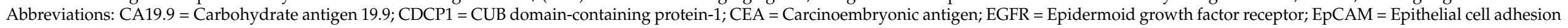

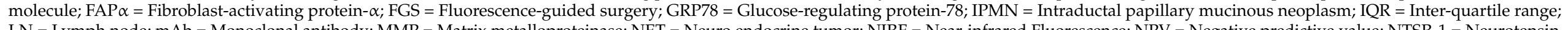

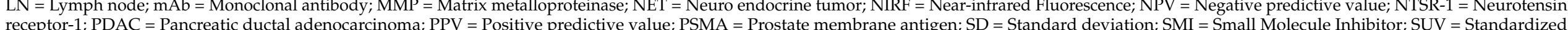

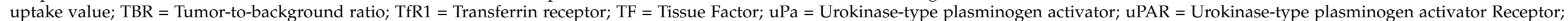
VEGFR(2) = Vascular endothelial growth factor receptor; VEGF- $\alpha=$ Vascular endothelial growth factor $\alpha$. 


\section{References}

1. Carioli, G.; Malvezzi, M.; Bertuccio, P.; Boffetta, P.; Levi, F.; La Vecchia, C.; Negri, E. European cancer mortality predictions for the year 2021 with focus on pancreatic and female lung cancer. Ann. Oncol. 2021, 32, 478-487. [CrossRef] [PubMed]

2. System, E.-E.C.I. Incidence and Mortality Estimates 2020. Available online: https://ecis.jrc.ec.europa.eu (accessed on 21 September 2021).

3. Adamska, A.; Domenichini, A.; Falasca, M. Pancreatic Ductal Adenocarcinoma: Current and Evolving Therapies. Int. J. Mol. Sci. 2017, 18, 1338. [CrossRef] [PubMed]

4. Mizrahi, J.D.; Surana, R.; Valle, J.W.; Shroff, R.T. Pancreatic cancer. Lancet 2020, 395, 2008-2020. [CrossRef]

5. Milan, M.; Diaferia, G.R.; Natoli, G. Tumor cell heterogeneity and its transcriptional bases in pancreatic cancer: A tale of two cell types and their many variants. EMBO J. 2021, 40, e107206. [CrossRef]

6. Tummers, W.S.; Groen, J.V.; Mulder, B.G.S.; Farina-Sarasqueta, A.; Morreau, J.; Putter, H.; Van De Velde, C.J.; Vahrmeijer, A.L.; Bonsing, B.A.; Mieog, J.S.; et al. Impact of resection margin status on recurrence and survival in pancreatic cancer surgery. BJS 2019, 106, 1055-1065. [CrossRef]

7. McGuigan, A.; Kelly, P.; Turkington, R.C.; Jones, C.; Coleman, H.G.; McCain, R.S. Pancreatic cancer: A review of clinical diagnosis, epidemiology, treatment and outcomes. World J. Gastroenterol. 2018, 24, 4846-4861. [CrossRef]

8. Tempero, M.A.; Malafa, M.P.; Al-Hawary, M.; Behrman, S.W.; Benson, A.B.; Cardin, D.B.; Chiorean, E.G.; Chung, V.; Czito, B.; Del Chiaro, M.; et al. Pancreatic Adenocarcinoma, Version 2.2021, NCCN Clinical Practice Guidelines in Oncology. J. Natl. Compr. Cancer Netw. 2021, 19, 439-457. [CrossRef]

9. Ducreux, M.; Cuhna, A.S.; Caramella, C.; Hollebecque, A.; Burtin, P.; Goéré, D.; Seufferlein, T.; Haustermans, K.; Van Laethem, J.L.; Conroy, T.; et al. Cancer of the pancreas: ESMO Clinical Practice Guidelines for diagnosis, treatment and follow-up. Ann. Oncol. 2015, 26 (Suppl. 5), v56-v68. [CrossRef]

10. Vachiranubhap, B.; Kim, Y.H.; Balci, N.C.; Semelka, R.C. Magnetic Resonance Imaging of Adenocarcinoma of the Pancreas. Top. Magn. Reson. Imaging 2009, 20, 3-9. [CrossRef]

11. Strobel, O.; Neoptolemos, J.; Jäger, D.; Büchler, M.W. Optimizing the outcomes of pancreatic cancer surgery. Nat. Rev. Clin. Oncol. 2019, 16, 11-26. [CrossRef]

12. Bengtsson, A.; Andersson, R.; Ansari, D. The actual 5-year survivors of pancreatic ductal adenocarcinoma based on real-world data. Sci. Rep. 2020, 10, 16425. [CrossRef]

13. Schmocker, R.K.; Delitto, D.; Wright, M.J.; Ding, D.; Cameron, J.L.; Lafaro, K.J.; Burns, W.R.; Wolfgang, C.L.; Burkhart, R.A.; He, J. Impact of Margin Status on Survival in Patients with Pancreatic Ductal Adenocarcinoma Receiving Neoadjuvant Chemotherapy. J. Am. Coll. Surg. 2020, 232, 405-413. [CrossRef]

14. Maeda, S.; Moore, A.M.; Yohanathan, L.; Hata, T.; Truty, M.J.; Smoot, R.L.; Cleary, S.; Nagorney, D.M.; Grotz, T.E.; Park, E.J.; et al. Impact of resection margin status on survival in pancreatic cancer patients after neoadjuvant treatment and pancreatoduodenectomy. Surgery 2020, 167, 803-811. [CrossRef]

15. Ghaneh, P.; Kleeff, J.; Halloran, C.M.; Raraty, M.; Jackson, R.; Melling, J.; Jones, O.; Palmer, D.H.; Cox, T.F.; Smith, C.J.; et al. The Impact of Positive Resection Margins on Survival and Recurrence Following Resection and Adjuvant Chemotherapy for Pancreatic Ductal Adenocarcinoma. Ann. Surg. 2019, 269, 520-529. [CrossRef]

16. Verbeke, C.S. Resection margins and R1 rates in pancreatic cancer-Are we there yet? Histopathology 2008, 52, 787-796. [CrossRef]

17. Do, Z.J.B.; Cloyd, J.M. Trends in the utilization of neoadjuvant therapy for pancreatic ductal adenocarcinoma. J. Surg. Oncol. 2021, 123, 1432-1440. [CrossRef]

18. Versteijne, E.; Suker, M.; Groothuis, K.; Akkermans-Vogelaar, J.M.; Besselink, M.G.; Bonsing, B.A.; Buijsen, J.; Busch, O.R.; Creemers, G.-J.M.; van Dam, R.M.; et al. Preoperative Chemoradiotherapy Versus Immediate Surgery for Resectable and Borderline Resectable Pancreatic Cancer: Results of the Dutch Randomized Phase III Preopanc Trial. J. Clin. Oncol. 2020, 38, 1763-1773. [CrossRef]

19. Murphy, J.E.; Wo, J.Y.; Ryan, D.P.; Jiang, W.; Yeap, B.Y.; Drapek, L.C.; Blaszkowsky, L.S.; Kwak, E.L.; Allen, J.N.; Clark, J.W.; et al. Total Neoadjuvant Therapy with Folfirinox Followed by Individualized Chemoradiotherapy for Borderline Resectable Pancreatic Adenocarcinoma: A Phase 2 Clinical Trial. JAMA Oncol. 2018, 4, 963-969. [CrossRef]

20. Jang, J.-Y.; Han, Y.; Lee, H.; Kim, S.-W.; Kwon, W.; Lee, K.-H.; Oh, D.-Y.; Chie, E.K.; Lee, J.M.; Heo, J.S.; et al. Oncological Benefits of Neoadjuvant Chemoradiation With Gemcitabine Versus Upfront Surgery in Patients With Borderline Resectable Pancreatic Cancer: A Prospective, Randomized, Open-label, Multicenter Phase 2/3 Trial. Ann. Surg. 2018, 268, 215-222. [CrossRef]

21. Pentheroudakis, G. Recent eUpdates to the ESMO Clinical Practice Guidelines on hepatocellular carcinoma, cancer of the pancreas, soft tissue and visceral sarcomas, cancer of the prostate and gastric cancer. Ann. Oncol. 2019, 30, 1395-1397. [CrossRef]

22. Xu, J.-Z.; Wang, W.-Q.; Zhang, S.-R.; Xu, H.-X.; Wu, C.-T.; Qi, Z.-H.; Gao, H.-L.; Li, S.; Ni, Q.-X.; Yu, X.-J.; et al. Neoadjuvant Therapy is Essential for Resectable Pancreatic Cancer. Curr. Med. Chem. 2020, 26, 7196-7211. [CrossRef]

23. Truty, M.J.; Kendrick, M.L.; Nagorney, D.M.; Smoot, R.L.; Cleary, S.; Graham, R.; Goenka, A.H.; Hallemeier, C.L.; Haddock, M.G.; Harmsen, W.S.; et al. Factors Predicting Response, Perioperative Outcomes, and Survival Following Total Neoadjuvant Therapy for Borderline/Locally Advanced Pancreatic Cancer. Ann. Surg. 2019, 273, 341-349. [CrossRef] [PubMed] 
24. Janssen, Q.P.; O’Reilly, E.M.; Van Eijck, C.H.J.; Koerkamp, B.G. Neoadjuvant Treatment in Patients With Resectable and Borderline Resectable Pancreatic Cancer. Front. Oncol. 2020, 10, 41. [CrossRef]

25. Janssen, Q.P.; for the Dutch Pancreatic Cancer Group; van Dam, J.L.; Bonsing, B.A.; Bos, H.; Bosscha, K.P.; Coene, P.P.L.O.; van Eijck, C.H.J.; de Hingh, I.H.J.T.; Karsten, T.M.; et al. Total neoadjuvant Folfirinox versus neoadjuvant gemcitabine-based chemoradiotherapy and adjuvant gemcitabine for resectable and borderline resectable pancreatic cancer (PREOPANC-2 trial): Study protocol for a nationwide multicenter randomized controlled trial. BMC Cancer 2021, 21, 300. [CrossRef]

26. Wang, Z.J.; Arif-Tiwari, H.; Zaheer, A.; Ameli, S.; Bhosale, P.R.; Do, R.K.; Goenka, A.H.; Guimares, A.R.; Sangster, G.P.; Soloff, E.V.; et al. Therapeutic response assessment in pancreatic ductal adenocarcinoma: Society of abdominal radiology review paper on the role of morphological and functional imaging techniques. Abdom. Radiol. 2020, 45, 4273-4289. [CrossRef]

27. Baliyan, V.; Kordbacheh, H.; Parakh, A.; Kambadakone, A. Response assessment in pancreatic ductal adenocarcinoma: Role of imaging. Abdom. Radiol. 2017, 43, 435-444. [CrossRef]

28. Schwartz, L.H.; Seymour, L.; Litière, S.; Ford, R.; Gwyther, S.; Mandrekar, S.; Shankar, L.; Bogaerts, J.; Chen, A.; Dancey, J.; et al. RECIST 1.1-Standardisation and disease-specific adaptations: Perspectives from the Recist Working Group. Eur. J. Cancer 2016, 62, 138-145. [CrossRef]

29. Perri, G.; Prakash, L.; Qiao, W.; Varadhachary, G.R.; Wolff, R.; Fogelman, D.; Overman, M.; Pant, S.; Javle, M.; Koay, E.J.; et al. Response and Survival Associated With First-line Folfirinox vs Gemcitabine and nab-Paclitaxel Chemotherapy for Localized Pancreatic Ductal Adenocarcinoma. JAMA Surg. 2020, 155, 832-839. [CrossRef]

30. Ahmed, S.A.; Mourad, A.F.; Hassan, R.A.; Ibrahim, M.A.E.; Soliman, A.; Aboeleuon, E.; Elbadee, O.M.A.; Hetta, H.F.; Jabir, M.A. Preoperative CT staging of borderline pancreatic cancer patients after neoadjuvant treatment: Accuracy in the prediction of vascular invasion and resectability. Abdom. Radiol. 2020, 46, 280-289. [CrossRef]

31. Vuijk, F.A.; De Muynck, L.D.A.N.; Franken, L.C.; Busch, O.R.; Wilmink, J.W.; Besselink, M.G.; Bonsing, B.A.; Bhairosingh, S.S.; Kuppen, P.J.K.; Mieog, J.S.D.; et al. Molecular targets for diagnostic and intraoperative imaging of pancreatic ductal adenocarcinoma after neoadjuvant Folfirinox treatment. Sci. Rep. 2020, 10, 16211. [CrossRef]

32. Cassinotto, C.; Cortade, J.; Belleannée, G.; Lapuyade, B.; Terrebonne, E.; Vendrely, V.; Laurent, C.; Cunha, A.S. An evaluation of the accuracy of $\mathrm{CT}$ when determining resectability of pancreatic head adenocarcinoma after neoadjuvant treatment. Eur. J. Radiol. 2013, 82, 589-593. [CrossRef] [PubMed]

33. Ferrone, C.R.; Marchegiani, G.; Hong, T.S.; Ryan, D.P.; Deshpande, V.; McDonnell, E.I.; Sabbatino, F.; Santos, D.D.; Allen, J.N.; Blaszkowsky, L.S.; et al. Radiological and Surgical Implications of Neoadjuvant Treatment With Folfirinox for Locally Advanced and Borderline Resectable Pancreatic Cancer. Ann. Surg. 2015, 261, 12-17. [CrossRef] [PubMed]

34. Tummers, W.S.; Willmann, J.K.; Bonsing, B.A.; Vahrmeijer, A.L.; Gambhir, S.S.; Swijnenburg, R.-J. Advances in Diagnostic and Intraoperative Molecular Imaging of Pancreatic Cancer. Pancreas 2018, 47, 675-689. [CrossRef] [PubMed]

35. Wagner, M.; Antunes, C.; Pietrasz, D.; Cassinotto, C.; Zappa, M.; Cunha, A.S.; Lucidarme, O.; Bachet, J.-B. CT evaluation after neoadjuvant Folfirinox chemotherapy for borderline and locally advanced pancreatic adenocarcinoma. Eur. Radiol. 2016, 27, 3104-3116. [CrossRef] [PubMed]

36. Panda, A.; Garg, I.; Truty, M.J.; Kline, T.L.; Johnson, M.P.; Ehman, E.C.; Suman, G.; Anaam, D.A.; Kemp, B.J.; Johnson, G.B.; et al. Borderline Resectable and Locally Advanced Pancreatic Cancer: FDG PET/MRI and CT Tumor Metrics for Assessment of Pathologic Response to Neoadjuvant Therapy and Prediction of Survival. Am. J. Roentgenol. 2021, 217, 730-740. [CrossRef]

37. Zimmermann, C.; Distler, M.; Jentsch, C.; Blum, S.; Folprecht, G.; Zöphel, K.; Polster, H.; Troost, E.G.C.; Abolmaali, N.; Weitz, J.; et al. Evaluation of response using FDG-PET/CT and diffusion weighted MRI after radiochemotherapy of pancreatic cancer: A non-randomized, monocentric phase II clinical trial-PaCa-DD-041 (Eudra-CT 2009-011968-11). Strahlenther. Onkol. 2020, 197, 19-26. [CrossRef]

38. Ben-Haim, S.; Ell, P. 18F-FDG PET and PET/CT in the Evaluation of Cancer Treatment Response. J. Nucl. Med. 2009, 50, 88-99. [CrossRef]

39. Wang, L.; Dong, P.; Shen, G.; Hou, S.; Zhang, Y.; Liu, X.; Tian, B. 18F-Fluorodeoxyglucose Positron Emission Tomography Predicts Treatment Efficacy and Clinical Outcome for Patients With Pancreatic Carcinoma. Pancreas 2019, 48, 996-1002. [CrossRef]

40. Vahrmeijer, A.L.; Hutteman, M.; Van Der Vorst, J.R.; Van De Velde, C.J.H.; Frangioni, J.V. Image-guided cancer surgery using near-infrared fluorescence. Nat. Rev. Clin. Oncol. 2013, 10, 507-518. [CrossRef]

41. Mieog, J.S.D.; Achterberg, F.B.; Zlitni, A.; Hutteman, M.; Burggraaf, J.; Swijnenburg, R.-J.; Gioux, S.; Vahrmeijer, A.L. Fundamentals and developments in fluorescence-guided cancer surgery. Nat. Rev. Clin. Oncol. 2021, 1-14. [CrossRef]

42. Tummers, W.S.; Farina-Sarasqueta, A.; Boonstra, M.C.; Prevoo, H.A.; Sier, C.F.; Mieog, J.S.; Morreau, J.; Van Eijck, C.H.; Kuppen, P.J.; Van De Velde, C.J.; et al. Selection of optimal molecular targets for tumor-specific imaging in pancreatic ductal adenocarcinoma. Oncotarget 2017, 8, 56816-56828. [CrossRef]

43. Kramer-Marek, G.; Gore, J.; Korc, M. Molecular imaging in pancreatic cancer-A roadmap for therapeutic decisions. Cancer Lett. 2013, 341, 132-138. [CrossRef]

44. De Geus, S.W.L.; Boogerd, L.S.F.; Swijnenburg, R.-J.; Mieog, J.S.D.; Tummers, W.S.F.J.; Prevoo, H.A.J.M.; Sier, C.F.M.; Morreau, H.; Bonsing, B.A.; Van De Velde, C.J.H.; et al. Selecting Tumor-Specific Molecular Targets in Pancreatic Adenocarcinoma: Paving the Way for Image-Guided Pancreatic Surgery. Mol. Imaging Biol. 2016, 18, 807-819. [CrossRef] 
45. Jiao, J.; Zhang, J.; Yang, F.; Song, W.; Han, D.; Wen, W.; Qin, W. Quicker, deeper and stronger imaging: A review of tumor-targeted, near-infrared fluorescent dyes for fluorescence guided surgery in the preclinical and clinical stages. Eur. J. Pharm. Biopharm. 2020, 152, 123-143. [CrossRef]

46. Hernot, S.; van Manen, L.; Debie, P.; Mieog, J.S.D.; Vahrmeijer, A.L. Latest developments in molecular tracers for fluorescence image-guided cancer surgery. Lancet Oncol. 2019, 20, e354-e367. [CrossRef]

47. Cornelissen, B.; Knight, J.C.; Mukherjee, S.; Evangelista, L.; Xavier, C.; Caobelli, F.; Del Vecchio, S.; Rbah-Vidal, L.; Barbet, J.; De Jong, M.; et al. Translational molecular imaging in exocrine pancreatic cancer. Eur. J. Nucl. Med. Mol. Imaging 2018, 45, $2442-2455$. [CrossRef]

48. England, C.G.; Hernandez, R.; Eddine, S.B.Z.; Cai, W. Molecular Imaging of Pancreatic Cancer with Antibodies. Mol. Pharm. 2015, 13, 8-24. [CrossRef]

49. Van Oosten, M.; Crane, L.M.; Bart, J.; van Leeuwen, F.W.; van Dam, G.M. Selecting Potential Targetable Biomarkers for Imaging Purposes in Colorectal Cancer Using TArget Selection Criteria (TASC): A Novel Target Identification Tool. Transl. Oncol. 2011, 4, 71-82. [CrossRef]

50. Blanas, A.; Sahasrabudhe, N.M.; Rodríguez, E.; Van Kooyk, Y.; Van Vliet, S.J. Fucosylated Antigens in Cancer: An Alliance toward Tumor Progression, Metastasis, and Resistance to Chemotherapy. Front. Oncol. 2018, 8, 39. [CrossRef]

51. Poruk, K.E.; Gay, D.Z.; Brown, K.; Mulvihill, J.D.; Boucher, K.M.; Scaife, C.L.; Firpo, M.A.; Mulvihill, S.J. The Clinical Utility of CA 19-9 in Pancreatic Adenocarcinoma: Diagnostic and Prognostic Updates. Curr. Mol. Med. 2013, 13, 340-351. [CrossRef]

52. Ni, X.G.; Bai, X.F.; Mao, Y.L.; Shao, Y.F.; Wu, J.X.; Shan, Y.; Wang, C.F.; Wang, J.; Tian, Y.T.; Liu, Q.; et al. The clinical value of serum CEA, CA19-9, and CA242 in the diagnosis and prognosis of pancreatic cancer. Eur. J. Surg. Oncol. EJSO 2005, 31, 164-169. [CrossRef] [PubMed]

53. Loy, T.S.; Sharp, S.C.; Andershock, C.J.; Craig, S.B. Distribution of CA 19-9 in Adenocarcinomas and Transitional Cell Carcinomas: An Immunohistochemical Study of 527 Cases. Am. J. Clin. Pathol. 1993, 99, 726-728. [CrossRef] [PubMed]

54. Zhou, J.; Hu, L.; Yu, Z.; Zheng, J.; Yang, D.; Bouvet, M.; Hoffman, R.M. Marker Expression in Circulating Cancer Cells of Pancreatic Cancer Patients. J. Surg. Res. 2011, 171, 631-636. [CrossRef] [PubMed]

55. Haglund, C.; Lindgren, J.; Roberts, P.J.; Nordling, S. Gastrointestinal cancer-associated antigen CA 19-9 in histological specimens of pancreatic tumours and pancreatitis. Br. J. Cancer 1986, 53, 189-195. [CrossRef]

56. Houvast, R.D.; Vankemmelbeke, M.; Durrant, L.G.; Wuhrer, M.; Baart, V.M.; Kuppen, P.J.K.; De Geus-Oei, L.-F.; Vahrmeijer, A.L.; Sier, C.F.M. Targeting Glycans and Heavily Glycosylated Proteins for Tumor Imaging. Cancers 2020, 12, 3870. [CrossRef]

57. Pontious, C.; Kaul, S.; Hong, M.; Hart, P.A.; Krishna, S.G.; Lara, L.F.; Conwell, D.L.; Cruz-Monserrate, Z. Cathepsin E expression and activity: Role in the detection and treatment of pancreatic cancer. Pancreatology 2019, 19, 951-956. [CrossRef]

58. Cruz-Monserrate, Z.; Abd-Elgaliel, W.R.; Grote, T.; Deng, D.; Ji, B.; Arumugam, T.; Wang, H.; Tung, C.-H.; Logsdon, C.D. Detection of pancreatic cancer tumours and precursor lesions by cathepsin E activity in mouse models. Gut 2011, 61, 1315-1322. [CrossRef]

59. Li, H.; Li, Y.; Cui, L.; Wang, B.; Cui, W.; Li, M.; Cheng, Y. Monitoring Pancreatic Carcinogenesis by the Molecular Imaging of Cathepsin E In Vivo Using Confocal Laser Endomicroscopy. PLoS ONE 2014, 9, e106566. [CrossRef]

60. Abd-Elgaliel, W.R.; Cruz-Monserrate, Z.; Logsdon, C.D.; Tung, C.-H. Molecular imaging of Cathepsin E-positive tumors in mice using a novel protease-activatable fluorescent probe. Mol. BioSyst. 2011, 7, 3207-3213. [CrossRef]

61. Lwin, T.M.; Hoffman, R.M.; Bouvet, M. The development of fluorescence guided surgery for pancreatic cancer: From bench to clinic. Expert Rev. Anticancer. Ther. 2018, 18, 651-662. [CrossRef]

62. Miyazawa, Y.; Uekita, T.; Hiraoka, N.; Fujii, S.; Kosuge, T.; Kanai, Y.; Nojima, Y.; Sakai, R. CUB Domain-Containing Protein 1, a Prognostic Factor for Human Pancreatic Cancers, Promotes Cell Migration and Extracellular Matrix Degradation. Cancer Res. 2010, 70, 5136-5146. [CrossRef]

63. Moroz, A.; Wang, Y.-H.; Sharib, J.M.; Wei, J.; Zhao, N.; Huang, Y.; Chen, Z.; Martinko, A.J.; Zhuo, J.; Lim, S.A.; et al. Theranostic Targeting of CUB Domain Containing Protein 1 (CDCP1) in Pancreatic Cancer. Clin. Cancer Res. 2020, 26, 3608-3615. [CrossRef]

64. Khan, T.; Kryza, T.; Lyons, N.J.; He, Y.; Hooper, J.D. The CDCP1 Signaling Hub: A Target for Cancer Detection and Therapeutic Intervention. Cancer Res. 2021, 81, 2259-2269. [CrossRef]

65. Yamaguchi, K.; Enjoji, M.; Tsuneyoshi, M. Pancreatoduodenal carcinoma: A clinicopathologic study of 304 patients and immunohistochemical observation for CEA and CA19-9. J. Surg. Oncol. 1991, 47, 148-154. [CrossRef]

66. Lwin, T.M.; Murakami, T.; Miyake, K.; Yazaki, P.J.; Shivley, J.E.; Hoffman, R.M.; Bouvet, M. Tumor-Specific Labeling of Pancreatic Cancer Using a Humanized Anti-CEA Antibody Conjugated to a Near-Infrared Fluorophore. Ann. Surg. Oncol. 2018, 25, 1079-1085. [CrossRef]

67. Bouvet, M.; Hoffman, R.M. Toward Curative Fluorescence-Guided Surgery of Pancreatic Cancer. Hepatogastroenterology 2015, 62, 715-722.

68. Hoogstins, C.E.S.; Boogerd, L.S.F.; Mulder, B.G.S.; Mieog, J.S.D.; Swijnenburg, R.J.; Van De Velde, C.J.H.; Farina Sarasqueta, A.; Bonsing, B.A.; Framery, B.; Pèlegrin, A.; et al. Image-Guided Surgery in Patients with Pancreatic Cancer: First Results of a Clinical Trial Using SGM-101, a Novel Carcinoembryonic Antigen-Targeting, Near-Infrared Fluorescent Agent. Ann. Surg. Oncol. 2018, 25, 3350-3357. [CrossRef]

69. Wong, P.; Li, L.; Chea, J.; Hu, W.; Poku, E.; Ebner, T.; Bowles, N.; Wong, J.Y.C.; Yazaki, P.J.; Sligar, S.G.; et al. Antibody Targeted PET Imaging of 64Cu-DOTA-Anti-CEA PEGylated Lipid Nanodiscs in CEA Positive Tumors. Bioconjugate Chem. 2020, 31, 743-753. [CrossRef] 
70. Boonstra, M.C.; Tolner, B.; Schaafsma, B.E.; Boogerd, L.S.; Prevoo, H.A.; Bhavsar, G.; Kuppen, P.; Sier, C.; Bonsing, B.A.; Frangioni, J.V.; et al. Preclinical evaluation of a novel CEA-targeting near-infrared fluorescent tracer delineating colorectal and pancreatic tumors. Int. J. Cancer 2015, 137, 1910-1920. [CrossRef]

71. Metildi, C.A.; Kaushal, S.; Pu, M.; Messer, K.A.; Luiken, G.A.; Moossa, A.R.; Hoffman, R.M.; Bouvet, M. Fluorescence-guided Surgery with a Fluorophore-conjugated Antibody to Carcinoembryonic Antigen (CEA), that Highlights the Tumor, Improves Surgical Resection and Increases Survival in Orthotopic Mouse Models of Human Pancreatic Cancer. Ann. Surg. Oncol. 2014, 21, 1405-1411. [CrossRef]

72. Nedaeinia, R.; Avan, A.; Manian, M.; Salehi, R.; Ghayour-Mobarhan, M. EGFR as a potential target for the treatment of pancreatic cancer: Dilemma and controversies. Curr. Drug Targets 2014, 15, 1293-1301. [CrossRef]

73. Oliveira-Cunha, M.; Newman, W.G.; Siriwardena, A.K. Epidermal Growth Factor Receptor in Pancreatic Cancer. Cancers 2011, 3, 1513-1526. [CrossRef]

74. Troiani, T.; Martinelli, E.; Capasso, A.; Morgillo, F.; Orditura, M.; De Vita, F.; Ciardiello, F. Targeting EGFR in pancreatic cancer treatment. Curr. Drug Targets 2012, 13, 802-810. [CrossRef]

75. Oliveira, S.; Van Dongen, G.A.; Walsum, M.S.-V.; Roovers, R.; Stam, J.C.; Mali, W.; Van Diest, P.J.; Henegouwen, P.M.V.B.E. Rapid Visualization of Human Tumor Xenografts through Optical Imaging with a Near-Infrared Fluorescent Anti-Epidermal Growth Factor Receptor Nanobody. Mol. Imaging 2012, 11, 33-46. [CrossRef]

76. Duff, S.E.; Li, C.; Garland, J.M.; Kumar, S. CD105 is important for angiogenesis: Evidence and potential applications. FASEB J. 2003, 17, 984-992. [CrossRef]

77. Zhou, L.; Yu, L.; Ding, G.; Chen, W.; Zheng, S.; Cao, L. Overexpressions of DLL4 and CD105 are Associated with Poor Prognosis of Patients with Pancreatic Ductal Adenocarcinoma. Pathol. Oncol. Res. 2015, 21, 1141-1147. [CrossRef]

78. Yoshitomi, H.; Kobayashi, S.; Ohtsuka, M.; Kimura, F.; Shimizu, H.; Yoshidome, H.; Miyazaki, M. Specific Expression of Endoglin (CD105) in Endothelial Cells of Intratumoral Blood and Lymphatic Vessels in Pancreatic Cancer. Pancreas 2008, 37, $275-281$. [CrossRef]

79. Yonaiyama, S.; Toyoki, Y.; Morohashi, S.; Sakuraba, S.; Yoshizawa, T.; Suzuki, T.; Wu, Y.; Kijima, H.; Hakamada, K. Epithelial cell adhesion molecule (EpCAM) overexpression is correlated with malignant potentials of intraductal papillary mucinous neoplasms (IPMNs) of the pancreas. Biomed. Res. 2013, 34, 87-95. [CrossRef]

80. Fong, D.; Steurer, M.; Obrist, P.; Barbieri, V.; Margreiter, R.; Amberger, A.; Laimer, K.; Gastl, G.; Tzankov, A.; Spizzo, G. Ep-CAM expression in pancreatic and ampullary carcinomas: Frequency and prognostic relevance. J. Clin. Pathol. 2007, 61, 31-35. [CrossRef]

81. Boogerd, L.S.; Boonstra, M.C.; Prevoo, H.A.; Handgraaf, H.J.; Kuppen, P.J.; van de Velde, C.J.; Fish, A.; Cordfunke, R.A.; Valentijn, A.R.P.; van Scheltinga, A.T.; et al. Fluorescence-guided tumor detection with a novel anti-EpCAM targeted antibody fragment: Preclinical validation. Surg. Oncol. 2018, 28, 1-8. [CrossRef]

82. Shi, M.; Yu, D.-H.; Chen, Y.; Zhao, C.-Y.; Zhang, J.; Liu, Q.-H.; Ni, C.-R.; Zhu, M.-H. Expression of fibroblast activation protein in human pancreatic adenocarcinoma and its clinicopathological significance. World J. Gastroenterol. 2012, 18, 840-846. [CrossRef] [PubMed]

83. Kratochwil, C.; Flechsig, P.; Lindner, T.; Abderrahim, L.; Altmann, A.; Mier, W.; Adeberg, S.; Rathke, H.; Röhrich, M.; Winter, H.; et al. 68Ga-FAPI PET/CT: Tracer Uptake in 28 Different Kinds of Cancer. J. Nucl. Med. 2019, 60, 801-805. [CrossRef] [PubMed]

84. Hicks, R.J.; Roselt, P.J.; Kallur, K.G.; Tothill, R.W.; Mileshkin, L. FAPI PET/CT: Will It End the Hegemony of 18F-FDG in Oncology? J. Nucl. Med. 2020, 62, 296-302. [CrossRef] [PubMed]

85. Topalovski, M.; Brekken, R.A. Matrix control of pancreatic cancer: New insights into fibronectin signaling. Cancer Lett. 2015, 381, 252-258. [CrossRef]

86. Hu, D.; Ansari, D.; Zhou, Q.; Sasor, A.; Hilmersson, K.S.; Andersson, R. Stromal fibronectin expression in patients with resected pancreatic ductal adenocarcinoma. World J. Surg. Oncol. 2019, 17, 29. [CrossRef]

87. Amrutkar, M.; Aasrum, M.; Verbeke, C.S.; Gladhaug, I.P. Secretion of fibronectin by human pancreatic stellate cells promotes chemoresistance to gemcitabine in pancreatic cancer cells. BMC Cancer 2019, 19, 596. [CrossRef]

88. Dauer, P.; Sharma, N.; Gupta, V.K.; Durden, B.; Hadad, R.; Banerjee, S.; Dudeja, V.; Saluja, A.; Banerjee, S. ER stress sensor, glucose regulatory protein 78 (GRP78) regulates redox status in pancreatic cancer thereby maintaining "stemness". Cell Death Dis. 2019, 10, 132. [CrossRef]

89. Ni, M.; Zhang, Y.; Lee, A.S. Beyond the endoplasmic reticulum: Atypical GRP78 in cell viability, signalling and therapeutic targeting. Biochem. J. 2011, 434, 181-188. [CrossRef]

90. Niu, Z.; Wang, M.; Zhou, L.; Yao, L.; Liao, Q.; Zhao, Y. Elevated GRP78 expression is associated with poor prognosis in patients with pancreatic cancer. Sci. Rep. 2015, 5, 16067. [CrossRef]

91. Sahni, S.; Nahm, C.; Krisp, C.; Molloy, M.P.; Mehta, S.; Maloney, S.; Itchins, M.; Pavlakis, N.; Clarke, S.; Chan, D.; et al. Identification of Novel Biomarkers in Pancreatic Tumor Tissue to Predict Response to Neoadjuvant Chemotherapy. Front. Oncol. 2020, 10, 237. [CrossRef]

92. Wang, H.; Li, D.; Liu, S.; Liu, R.; Yuan, H.; Krasnoperov, V.; Shan, H.; Conti, P.S.; Gill, P.S.; Li, Z. Small-Animal PET Imaging of Pancreatic Cancer Xenografts Using a 64Cu-Labeled Monoclonal Antibody, MAb159. J. Nucl. Med. 2015, 56, 908-913. [CrossRef]

93. Hosotani, R.; Kawaguchi, M.; Masui, T.; Koshiba, T.; Ida, J.; Fujimoto, K.; Wada, M.; Doi, R.; Imamura, M. Expression of Integrin $\alpha \mathrm{V} \beta 3$ in Pancreatic Carcinoma: Relation to MMP-2 Activation and Lymph Node Metastasis. Pancreas 2002, 25, e30-e35. [CrossRef] 
94. Steiger, K.; Schlitter, A.-M.; Weichert, W.; Esposito, I.; Wester, H.-J.; Notni, J. Perspective of $\alpha v \beta 6$-Integrin Imaging for Clinical Management of Pancreatic Carcinoma and Its Precursor Lesions. Mol. Imaging 2017, 16, 1536012117709384. [CrossRef]

95. Feng, X.; Wang, Y.; Lu, D.; Xu, X.; Zhou, X.; Zhang, H.; Zhang, T.; Zhu, H.; Yang, Z.; Wang, F.; et al. Clinical Translation of a 68Ga-Labeled Integrin $\alpha v \beta 6$-Targeting Cyclic Radiotracer for PET Imaging of Pancreatic Cancer. J. Nucl. Med. 2020, 61, 1461-1467. [CrossRef]

96. Reader, C.S.; Vallath, S.; Steele, C.W.; Haider, S.; Brentnall, A.; Desai, A.; Moore, K.M.; Jamieson, N.; Chang, D.; Bailey, P.; et al. The integrin $\alpha \mathrm{v} \beta 6$ drives pancreatic cancer through diverse mechanisms and represents an effective target for therapy. J. Pathol. 2019, 249, 332-342. [CrossRef]

97. Turaga, R.C.; Sharma, M.; Mishra, F.; Krasinskas, A.; Yuan, Y.; Yang, J.J.; Wang, S.; Liu, C.; Li, S.; Liu, Z.-R. Modulation of Cancer-Associated Fibrotic Stroma by An Integrin $\alpha \mathrm{v} \beta 3$ Targeting Protein for Pancreatic Cancer Treatment. Cell. Mol. Gastroenterol. Hepatol. 2020, 11, 161-179. [CrossRef]

98. Sipos, B.; Hahn, D.; Carceller, A.; Piulats, J.; Hedderich, J.; Kalthoff, H.; Goodman, S.L.; Kosmahl, M.; Klöppel, G. Immunohistochemical screening for beta6-integrin subunit expression in adenocarcinomas using a novel monoclonal antibody reveals strong up-regulation in pancreatic ductal adenocarcinomas in vivo and in vitro. Histopathology 2004, 45, 226-236. [CrossRef]

99. Haubner, R.; Maschauer, S.; Prante, O. PET Radiopharmaceuticals for Imaging Integrin Expression: Tracers in Clinical Studies and Recent Developments. BioMed Res. Int. 2014, 2014, 871609. [CrossRef]

100. Kimura, R.H.; Cheng, Z.; Gambhir, S.S.; Cochran, J.R. Engineered Knottin Peptides: A New Class of Agents for Imaging Integrin Expression in Living Subjects. Cancer Res. 2009, 69, 2435-2442. [CrossRef]

101. Gaertner, F.C.; Kessler, H.; Wester, H.-J.; Schwaiger, M.; Beer, A.J. Radiolabelled RGD peptides for imaging and therapy. Eur. J. Nucl. Med. Mol. Imaging 2012, 39 (Suppl. 1), 126-138. [CrossRef]

102. Weidemann, S.; Gagelmann, P.; Gorbokon, N.; Lennartz, M.; Menz, A.; Luebke, A.; Kluth, M.; Hube-Magg, C.; Blessin, N.; Fraune, C.; et al. Mesothelin Expression in Human Tumors: A Tissue Microarray Study on 12,679 Tumors. Biomedicines 2021, 9 , 397. [CrossRef]

103. Le, K.; Wang, J.; Zhang, T.; Guo, Y.; Chang, H.; Wang, S.; Zhu, B. Overexpression of Mesothelin in Pancreatic Ductal Adenocarcinoma (PDAC). Int. J. Med. Sci. 2020, 17, 422-427. [CrossRef]

104. Argani, P.; Iacobuzio-Donahue, C.; Ryu, B.; Rosty, C.; Goggins, M.; E Wilentz, R.; Murugesan, S.R.; Leach, S.D.; Jaffee, E.; Yeo, C.J.; et al. Mesothelin is overexpressed in the vast majority of ductal adenocarcinomas of the pancreas: Identification of a new pancreatic cancer marker by serial analysis of gene expression (SAGE). Clin. Cancer Res. 2001, 7, 3862-3868.

105. Hassan, R.; Laszik, Z.G.; Lerner, M.; Raffeld, M.; Postier, R.; Brackett, D. Mesothelin is overexpressed in pancreaticobiliary adenocarcinomas but not in normal pancreas and chronic pancreatitis. Am. J. Clin. Pathol. 2005, 124, 838-845. [CrossRef]

106. Seiki, M. Membrane-type 1 matrix metalloproteinase: A key enzyme for tumor invasion. Cancer Lett. 2003, 194, 1-11. [CrossRef]

107. Itoh, Y. MT1-MMP: A key regulator of cell migration in tissue. IUBMB Life 2006, 58, 589-596. [CrossRef]

108. Ottaviano, A.J.; Sun, L.; Ananthanarayanan, V.; Munshi, H.G. Extracellular Matrix-Mediated Membrane-Type 1 Matrix Metalloproteinase Expression in Pancreatic Ductal Cells Is Regulated by Transforming Growth Factor- $\beta 1$. Cancer Res. 2006, 66, 7032-7040. [CrossRef]

109. Slapak, E.J.; Duitman, J.; Tekin, C.; Bijlsma, M.F.; Spek, C.A. Matrix Metalloproteases in Pancreatic Ductal Adenocarcinoma: Key Drivers of Disease Progression? Biology 2020, 9, 80. [CrossRef]

110. Suh, H.; Pillai, K.; Morris, D.L. Mucins in pancreatic cancer: Biological role, implications in carcinogenesis and applications in diagnosis and therapy. Am. J. Cancer Res. 2017, 7, 1372-1383.

111. Matsuyama, M.; Kondo, F.; Ishihara, T.; Yamaguchi, T.; Ito, R.; Tsuyuguchi, T.; Tawada, K.; Yokosuka, O. Evaluation of pancreatic intraepithelial neoplasia and mucin expression in normal pancreata. J. Hepato-Biliary-Pancreat. Sci. 2011, 19, 242-248. [CrossRef]

112. Qu, C.F.; Li, Y.; Song, Y.J.; Rizvi, S.M.A.; Raja, C.; Zhang, D.; Samra, J.; Smith, R.; Perkins, A.C.; Apostolidis, C.; et al. MUC1 expression in primary and metastatic pancreatic cancer cells for in vitro treatment by $213 \mathrm{Bi}-\mathrm{C} 595$ radioimmunoconjugate. $\mathrm{Br}$. $\mathrm{J}$. Cancer 2004, 91, 2086-2093. [CrossRef] [PubMed]

113. Lo, S.-T.; Pantazopouos, P.; Medarova, Z.; Moore, A. Presentation of underglycosylated mucin 1 in pancreatic adenocarcinoma (PDAC) at early stages. Am. J. Cancer Res. 2016, 6, 1986-1995. [PubMed]

114. Takahashi, K.; Ehata, S.; Miyauchi, K.; Morishita, Y.; Miyazawa, K.; Miyazono, K. Neurotensin receptor 1 signaling promotes pancreatic cancer progression. Mol. Oncol. 2020, 15, 151-166. [CrossRef] [PubMed]

115. Yin, X.; Wang, M.; Wang, H.; Deng, H.; He, T.; Tan, Y.; Zhu, Z.; Wu, Z.; Hu, S.; Li, Z. Evaluation of neurotensin receptor 1 as a potential imaging target in pancreatic ductal adenocarcinoma. Amino Acids 2017, 49, 1325-1335. [CrossRef] [PubMed]

116. Prignon, A.; Provost, C.; Alshoukr, F.; Wendum, D.; Couvelard, A.; Barbet, J.; Forgez, P.; Talbot, J.-N.; Gruaz-Guyon, A. Preclinical Evaluation of 68Ga-DOTA-NT-20.3: A Promising PET Imaging Probe To Discriminate Human Pancreatic Ductal Adenocarcinoma from Pancreatitis. Mol. Pharm. 2019, 16, 2776-2784. [CrossRef] [PubMed]

117. Renard, E.; Dancer, P.-A.; Portal, C.; Denat, F.; Prignon, A.; Goncalves, V. Design of Bimodal Ligands of Neurotensin Receptor 1 for Positron Emission Tomography Imaging and Fluorescence-Guided Surgery of Pancreatic Cancer. J. Med. Chem. 2019, 63, 2426-2433. [CrossRef] [PubMed]

118. Hodolic, M.; Wu, W.-Y.; Zhao, Z.; Yu, F.; Virgolini, I.; Wang, F. Safety and tolerability of 68Ga-NT-20.3, a radiopharmaceutical for targeting neurotensin receptors, in patients with pancreatic ductal adenocarcinoma: The first in-human use. Eur. J. Nucl. Med. Mol. Imaging 2020, 48, 1229-1234. [CrossRef] 
119. Stock, K.; Steinestel, K.; Wiesch, R.; Mikesch, J.-H.; Hansmeier, A.; Trautmann, M.; Beller, N.; Rehkämper, J.; Wardelmann, E.; Heitkötter, B.; et al. Neovascular Prostate-Specific Membrane Antigen Expression Is Associated with Improved Overall Survival under Palliative Chemotherapy in Patients with Pancreatic Ductal Adenocarcinoma. BioMed Res. Int. 2017, $2017,2847303$. [CrossRef]

120. Ren, H.; Zhang, H.; Wang, X.; Liu, J.; Yuan, Z.; Hao, J. Prostate-specific membrane antigen as a marker of pancreatic cancer cells. Med. Oncol. 2014, 31, 857. [CrossRef]

121. Chang, S.S.; E Reuter, V.; Heston, W.D.; Bander, N.H.; Grauer, L.S.; Gaudin, P.B. Five different anti-prostate-specific membrane antigen (PSMA) antibodies confirm PSMA expression in tumor-associated neovasculature. Cancer Res. 1999, 59, 3192-3198.

122. Afshar-Oromieh, A.; Babich, J.W.; Kratochwil, C.; Giesel, F.L.; Eisenhut, M.; Kopka, K.; Haberkorn, U. The Rise of PSMA Ligands for Diagnosis and Therapy of Prostate Cancer. J. Nucl. Med. 2016, 57, 79S-89S. [CrossRef]

123. Lütje, S.; Heskamp, S.; Cornelissen, A.S.; Poeppel, T.D.; Broek, S.A.M.W.V.D.; Rosenbaum-Krumme, S.; Bockisch, A.; Gotthardt, M.; Rijpkema, M.; Boerman, O.C. PSMA Ligands for Radionuclide Imaging and Therapy of Prostate Cancer: Clinical Status. Theranostics 2015, 5, 1388-1401. [CrossRef]

124. Krishnaraju, V.S.; Kumar, R.; Mittal, B.R.; Sharma, V.; Singh, H.; Nada, R.; Bal, A.; Rohilla, M.; Singh, H.; Rana, S.S. Differentiating benign and malignant pancreatic masses: Ga-68 PSMA PET/CT as a new diagnostic avenue. Eur. Radiol. 2020, 31, 2199-2208. [CrossRef]

125. Fragomeni, R.A.S.; Amir, T.; Sheikhbahaei, S.; Harvey, S.C.; Javadi, M.S.; Solnes, L.B.; Kiess, A.P.; Allaf, M.E.; Pomper, M.G.; Gorin, M.A.; et al. Imaging of Nonprostate Cancers Using PSMA-Targeted Radiotracers: Rationale, Current State of the Field, and a Call to Arms. J. Nucl. Med. 2018, 59, 871-877. [CrossRef]

126. Derks, Y.H.; Löwik, D.W.P.M.; Sedelaar, J.P.M.; Gotthardt, M.; Boerman, O.C.; Rijpkema, M.; Lütje, S.; Heskamp, S. PSMA-targeting agents for radio- and fluorescence-guided prostate cancer surgery. Theranostics 2019, 9, 6824-6839. [CrossRef]

127. Haas, S.L.; Jesnowski, R.; Steiner, M.; Hummel, F.; Ringel, J.; Burstein, C.; Nizze, H.; Liebe, S.; Löhr, J.M. Expression of tissue factor in pancreatic adenocarcinoma is associated with activation of coagulation. World J. Gastroenterol. 2006, 12, 4843-4849. [CrossRef]

128. Khorana, A.A.; Ahrendt, S.; Ryan, C.K.; Francis, C.W.; Hruban, R.H.; Hu, Y.C.; Hostetter, G.; Harvey, J.; Taubman, M.B. Tissue Factor Expression, Angiogenesis, and Thrombosis in Pancreatic Cancer. Clin. Cancer Res. 2007, 13, 2870-2875. [CrossRef]

129. Kakkar, A.K.; Lemoine, N.R.; Scully, M.F.; Tebbutt, S.; Williamson, R.C.N. Tissue factor expression correlates with histological grade in human pancreatic cancer. BJS 1995, 82, 1101-1104. [CrossRef]

130. Hong, H.; Zhang, Y.; Nayak, T.R.; Engle, J.W.; Wong, H.C.; Liu, B.; Barnhart, T.E.; Cai, W. Immuno-PET of Tissue Factor in Pancreatic Cancer. J. Nucl. Med. 2012, 53, 1748-1754. [CrossRef]

131. Nielsen, C.H.; Jeppesen, T.E.; Kristensen, L.K.; Jensen, M.M.; El Ali, H.H.; Madsen, J.; Wiinberg, B.; Petersen, L.C.; Kjaer, A. PET Imaging of Tissue Factor in Pancreatic Cancer Using 64Cu-Labeled Active Site-Inhibited Factor VII. J. Nucl. Med. 2016, 57, 1112-1119. [CrossRef]

132. Hernandez, R.; England, C.G.; Yang, Y.; Valdovinos, H.; Liu, B.; Wong, H.C.; Barnhart, T.E.; Cai, W. ImmunoPET imaging of tissue factor expression in pancreatic cancer with 89Zr-Df-ALT-836. J. Control. Release 2017, 264, 160-168. [CrossRef] [PubMed]

133. Daniels, T.R.; Delgado, T.; Helguera, G.; Penichet, M.L. The transferrin receptor part II: Targeted delivery of therapeutic agents into cancer cells. Clin. Immunol. 2006, 121, 159-176. [CrossRef] [PubMed]

134. Daniels, T.R.; Delgado, T.; Rodriguez, J.A.; Helguera, G.; Penichet, M.L. The transferrin receptor part I: Biology and targeting with cytotoxic antibodies for the treatment of cancer. Clin. Immunol. 2006, 121, 144-158. [CrossRef] [PubMed]

135. Gatter, K.C.; Brown, G.; Trowbridge, I.S.; Woolston, R.E.; Mason, D.Y. Transferrin receptors in human tissues: Their distribution and possible clinical relevance. J. Clin. Pathol. 1983, 36, 539-545. [CrossRef] [PubMed]

136. Jeong, S.M.; Hwang, S.; Seong, R. Transferrin receptor regulates pancreatic cancer growth by modulating mitochondrial respiration and ROS generation. Biochem. Biophys. Res. Commun. 2016, 471, 373-379. [CrossRef]

137. Ryschich, E.; Huszty, G.; Knaebel, H.; Hartel, M.; Büchler, M.; Schmidt, J. Transferrin receptor is a marker of malignant phenotype in human pancreatic cancer and in neuroendocrine carcinoma of the pancreas. Eur. J. Cancer 2004, 40, 1418-1422. [CrossRef]

138. Di Mauro, C.; Pesapane, A.; Formisano, L.; Rosa, R.; D’Amato, V.; Ciciola, P.; Servetto, A.; Marciano, R.; Orsini, R.C.; Monteleone, F.; et al. Urokinase-type plasminogen activator receptor (uPAR) expression enhances invasion and metastasis in RAS mutated tumors. Sci. Rep. 2017, 7, 9388. [CrossRef]

139. De Geus, S.W.; Baart, V.M.; Boonstra, M.C.; Kuppen, P.J.; Prevoo, H.A.; Mazar, A.P.; Bonsing, B.A.; Morreau, H.; Van De Velde, C.J.; Vahrmeijer, A.L.; et al. Prognostic Impact of Urokinase Plasminogen Activator Receptor Expression in Pancreatic Cancer: Malignant Versus Stromal Cells. Biomark. Insights 2017, 12, 1177271917715443. [CrossRef]

140. Hildenbrand, R.; Niedergethmann, M.; Marx, A.; Belharazem, D.; Allgayer, H.; Schleger, C.; Ströbel, P. Amplification of the Urokinase-Type Plasminogen Activator Receptor (uPAR) Gene in Ductal Pancreatic Carcinomas Identifies a Clinically High-Risk Group. Am. J. Pathol. 2009, 174, 2246-2253. [CrossRef]

141. Costache, M.; Ioana, M.; Iordache, S.; Ene, D.; Costache, C.A.; Săftoiu, A. VEGF expression in pancreatic cancer and other malignancies: A review of the literature. Rom. J. Intern. Med. 2015, 53, 199-208. [CrossRef]

142. Hicklin, D.J.; Ellis, L.M. Role of the Vascular Endothelial Growth Factor Pathway in Tumor Growth and Angiogenesis. J. Clin. Oncol. 2005, 23, 1011-1027. [CrossRef]

143. Liang, Q.-L.; Wang, B.-R.; Chen, G.-Q.; Li, G.-H.; Xu, Y.-Y. Clinical significance of vascular endothelial growth factor and connexin43 for predicting pancreatic cancer clinicopathologic parameters. Med. Oncol. 2009, 27, 1164-1170. [CrossRef] 
144. Cannon, A.; Thompson, C.; Hall, B.R.; Jain, M.; Kumar, S.; Batra, S.K. Desmoplasia in pancreatic ductal adenocarcinoma: Insight into pathological function and therapeutic potential. Genes Cancer 2018, 9, 78-86. [CrossRef]

145. Wood, L.D.; Hruban, R.H. Pathology and Molecular Genetics of Pancreatic Neoplasms. Cancer J. 2012, 18, 492-501. [CrossRef]

146. Kryza, T.; Khan, T.; Puttick, S.; Li, C.; Sokolowski, K.A.; Tse, B.W.; Cuda, T.; Lyons, N.; Gough, M.; Yin, J.; et al. Effective targeting of intact and proteolysed CDCP1 for imaging and treatment of pancreatic ductal adenocarcinoma. Theranostics 2020, 10, 4116-4133 [CrossRef]

147. Allum, W.H.; Stokes, H.J.; Macdonald, F.; Fielding, J.W. Demonstration of carcinoembryonic antigen (CEA) expression in normal, chronically inflamed, and malignant pancreatic tissue by immunohistochemistry. J. Clin. Pathol. 1986, 39, 610-614. [CrossRef]

148. Seeberger, K.L.; Eshpeter, A.; Rajotte, R.V.; Korbutt, G.S. Epithelial cells within the human pancreas do not coexpress mesenchymal antigens: Epithelial-mesenchymal transition is an artifact of cell culture. Lab. Investig. 2008, 89, 110-121. [CrossRef]

149. Hsing, J.; McConkey, D.; Logsdon, C. GRP78 and HSP90 are overexpressed in pancreatic cancer. In Proceedings of the 98th AACR Annual Meeting, Los Angeles, CA, USA, 14-18 April 2007; Volume 67, p. 708.

150. Ellenrieder, V.; Alber, B.; Lacher, U.; Hendler, S.F.; Menke, A.; Boeck, W.; Wagner, M.; Wilda, M.; Friess, H.; Büchler, M.; et al. Role of MT-MMPs and MMP-2 in pancreatic cancer progression. Int. J. Cancer 1999, 85, 14-20. [CrossRef]

151. Nagata, K.; Horinouchi, M.; Saitou, M.; Higashi, M.; Nomoto, M.; Goto, M.; Yonezawa, S. Mucin expression profile in pancreatic cancer and the precursor lesions. J. Hepato-Biliary-Pancreat. Surg. 2007, 14, 243-254. [CrossRef]

152. Saftoiu, A.; Angelescu, R.; Burada, F.; Angelescu, C.; Gheonea, D.; Iordache, S.; Mixich, F.; Ioana, M. Expression of vascular endothelial growth factor and epidermal growth factor receptor in pancreatic ductal adenocarcinomas, neuroendocrine tumours and chronic pancreatitis. Endosc. Ultrasound 2013, 2, 86-91. [CrossRef]

153. Arnone, A.; Laudicella, R.; Caobelli, F.; Guglielmo, P.; Spallino, M.; Abenavoli, E.; Martini, A.L.; Filice, R.; Comis, A.D.; Cuzzocrea, M.; et al. Clinical Impact of ${ }^{18}$ F-FDG PET/CT in the Diagnostic Workup of Pancreatic Ductal Adenocarcinoma: A Systematic Review. Diagnostics 2020, 10, 1042. [CrossRef]

154. Ghaneh, P.; Hanson, R.; Titman, A.; Lancaster, G.; Plumpton, C.; Lloyd-Williams, H.; Yeo, S.T.; Edwards, R.T.; Johnson, C.; Abu Hilal, M.; et al. PET-PANC: Multicentre prospective diagnostic accuracy and health economic analysis study of the impact of combined modality 18fluorine-2-fluoro-2-deoxy-d-glucose positron emission tomography with computed tomography scanning in the diagnosis and management of pancreatic cancer. Health Technol. Assess. 2018, 22, 1-114. [CrossRef]

155. Yeh, R.; Dercle, L.; Garg, I.; Wang, Z.J.; Hough, D.M.; Goenka, A.H. The Role of 18F-FDG PET/CT and PET/MRI in Pancreatic Ductal Adenocarcinoma. Abdom. Radiol. 2018, 43, 415-434. [CrossRef]

156. Yokose, T.; Kitago, M.; Matsusaka, Y.; Masugi, Y.; Shinoda, M.; Yagi, H.; Abe, Y.; Oshima, G.; Hori, S.; Endo, Y.; et al. Usefulness of18F-fluorodeoxyglucose positron emission tomography/computed tomography for predicting the prognosis and treatment response of neoadjuvant therapy for pancreatic ductal adenocarcinoma. Cancer Med. 2020, 9, 4059-4068. [CrossRef]

157. Dalah, E.; Tai, A.; Oshima, K.; A Hall, W.; Erickson, B.; Li, X.A. PET-based Treatment Response Assessment for Neoadjuvant Chemoradiation in Pancreatic Adenocarcinoma: An Exploratory Study. Transl. Oncol. 2018, 11, 1104-1109. [CrossRef]

158. Heinrich, S.; Schäfer, M.; Weber, A.; Hany, T.F.; Bhure, U.; Pestalozzi, B.C.; Clavien, P.-A. Neoadjuvant Chemotherapy Generates a Significant Tumor Response in Resectable Pancreatic Cancer Without Increasing Morbidity. Ann. Surg. 2008, 248, 1014-1022. [CrossRef]

159. Yoshioka, M.; Sato, T.; Furuya, T.; Shibata, S.; Andoh, H.; Asanuma, Y.; Hatazawa, J.; Shimosegawa, E.; Koyama, K.; Yamamoto, Y. Role of positron emission tomography with 2-deoxy-2-[18 F]fluoro-d-glucose in evaluating the effects of arterial infusion chemotherapy and radiotherapy on pancreatic cancer. J. Gastroenterol. 2004, 39, 50-55. [CrossRef]

160. Quon, A.; Chang, S.T.; Chin, F.; Kamaya, A.; Dick, D.W.; Loo, B.W.; Gambhir, S.S.; Koong, A.C. Initial evaluation of 18Ffluorothymidine (FLT) PET/CT scanning for primary pancreatic cancer. Eur. J. Nucl. Med. Mol. Imaging 2008, 35, 527-531. [CrossRef]

161. Wieder, H.; Beer, A.J.; Siveke, J.; Schuster, T.; Buck, A.K.; Herrmann, K.; Stollfuss, J.C. 18F-fluorothymidine PET for predicting survival in patients with resectable pancreatic cancer. Oncotarget 2018, 9, 10128-10134. [CrossRef]

162. Segard, T.; Robins, P.D.; Yusoff, I.F.; Ee, H.; Morandeau, L.; Campbell, E.M.; Francis, R.J. Detection of Hypoxia With 18FFluoromisonidazole (18F-FMISO) PET/CT in Suspected or Proven Pancreatic Cancer. Clin. Nucl. Med. 2013, 38, 1-6. [CrossRef]

163. Yamane, T.; Aikawa, M.; Yasuda, M.; Fukushima, K.; Seto, A.; Okamoto, K.; Koyama, I.; Kuji, I. [18F]FMISO PET/CT as a preoperative prognostic factor in patients with pancreatic cancer. EJNMMI Res. 2019, 9, 39. [CrossRef] [PubMed]

164. Metran-Nascente, C.; Yeung, I.; Vines, D.C.; Metser, U.; Dhani, N.C.; Green, D.; Milosevic, M.; Jaffray, D.; Hedley, D. Measurement of Tumor Hypoxia in Patients with Advanced Pancreatic Cancer Based on 18F-Fluoroazomyin Arabinoside Uptake. J. Nucl. Med. 2016, 57, 361-366. [CrossRef] [PubMed]

165. Lohrmann, C.; O’Reilly, E.M.; O’Donoghue, J.A.; Pandit-Taskar, N.; Carrasquillo, J.A.; Lyashchenko, S.K.; Ruan, S.; Teng, R.; Scholz, W.; Maffuid, P.W.; et al. Retooling a blood-based biomarker: Phase I assessment of the high-affinity CA19-9 antibody HuMAB-5B1 for immuno-PET imaging of pancreatic cancer. Clin. Cancer Res. 2019, 25, 7014-7023. [CrossRef] [PubMed]

166. Houghton, J.L.; Zeglis, B.M.; Abdel-Atti, D.; Aggeler, R.; Sawada, R.; Agnew, B.J.; Scholz, W.W.; Lewis, J.S. Site-specifically labeled CA19.9-targeted immunoconjugates for the PET, NIRF, and multimodal PET/NIRF imaging of pancreatic cancer. Proc. Natl. Acad. Sci. USA 2015, 112, 15850-15855. [CrossRef] 
167. Röhrich, M.; Naumann, P.; Giesel, F.L.; Choyke, P.L.; Staudinger, F.; Wefers, A.; Liew, D.P.; Kratochwil, C.; Rathke, H.; Liermann, J.; et al. Impact of 68Ga-FAPI PET/CT Imaging on the Therapeutic Management of Primary and Recurrent Pancreatic Ductal Adenocarcinomas. J. Nucl. Med. 2020, 62, 779-786. [CrossRef]

168. Liermann, J.; Syed, M.; Ben-Josef, E.; Schubert, K.; Schlampp, I.; Sprengel, S.D.; Ristau, J.; Weykamp, F.; Röhrich, M.; Koerber, S.A.; et al. Impact of FAPI-PET/CT on Target Volume Definition in Radiation Therapy of Locally Recurrent Pancreatic Cancer. Cancers 2021, 13, 796. [CrossRef]

169. Liu, Y.; Watabe, T.; Kaneda-Nakashima, K.; Shirakami, Y.; Naka, S.; Ooe, K.; Toyoshima, A.; Nagata, K.; Haberkorn, U.; Kratochwil, C.; et al. Fibroblast activation protein targeted therapy using [177Lu]FAPI-46 compared with [225Ac]FAPI-46 in a pancreatic cancer model. Eur. J. Nucl. Med. Mol. Imaging 2021, 1-9. [CrossRef]

170. Kimura, R.H.; Wang, L.; Shen, B.; Huo, L.; Tummers, W.; Filipp, F.V.; Guo, H.H.; Haywood, T.; Abou-Elkacem, L.; Baratto, L.; et al. Evaluation of integrin $\alpha \mathrm{v} \beta 6$ cystine knot PET tracers to detect cancer and idiopathic pulmonary fibrosis. Nat. Commun. 2019, 10, 4673. [CrossRef]

171. Nakamoto, R.; Duan, H.; Ferri, V.; HATAMI, N.; Goel, M.; Kimura, R.; Wardak, M.; Haywood, T.; Shen, B.; Park, W.; et al. Biodistribution and Safety of 18-F-FP-R01-MG-F2 Knottin PET Tracer in Patients with Pancreatic Cancer. J. Nucl. Med. 2021, 62,1008 .

172. Trajkovic-Arsic, M.; Mohajerani, P.; Sarantopoulos, A.; Kalideris, E.; Steiger, K.; Esposito, I.; Ma, X.; Themelis, G.; Burton, N.; Michalski, C.W.; et al. Multimodal Molecular Imaging of Integrin $\alpha v \beta 3$ for In Vivo Detection of Pancreatic Cancer. J. Nucl. Med. 2014, 55, 446-451. [CrossRef]

173. Boyle, A.; Cao, P.-J.; Hedley, D.; Sidhu, S.S.; Winnik, M.A.; Reilly, R.M. MicroPET/CT imaging of patient-derived pancreatic cancer xenografts implanted subcutaneously or orthotopically in NOD-scid mice using 64Cu-NOTA-panitumumab F(ab')2 fragments. Nucl. Med. Biol. 2015, 42, 71-77. [CrossRef]

174. Yang, D.; Severin, G.W.; Dougherty, C.A.; Lombardi, R.; Chen, D.; Van Dort, M.E.; Barnhart, T.E.; Ross, B.D.; Mazar, A.P.; Hong, H. Antibody-based PET of uPA/uPAR signaling with broad applicability for cancer imaging. Oncotarget 2016, 7, 73912-73924. [CrossRef]

175. Verbeek, F.P.R.; van der Vorst, J.R.; Schaafsma, B.E.; Hutteman, M.; Bonsing, B.A.; van Leeuwen, F.W.B.; Frangioni, J.V.; van de Velde, C.J.H.; Swijnenburg, R.-J.; Vahrmeijer, A.L. Image-guided hepatopancreatobiliary surgery using near-infrared fluorescent light. J. Hepato-Biliary-Pancreat. Sci. 2012, 19, 626-637. [CrossRef]

176. Lwin, T.M.; Hoffman, R.M.; Bouvet, M. The future of tumour-specific fluorescence-guided surgery for pancreatic cancer. Lancet Gastroenterol. Hepatol. 2020, 5, 715-717. [CrossRef]

177. Li, C.; Chen, G.; Zhang, Y.; Wu, F.; Wang, Q. Advanced Fluorescence Imaging Technology in the Near-Infrared-II Window for Biomedical Applications. J. Am. Chem. Soc. 2020, 142, 35. [CrossRef]

178. Frangioni, J.V. In vivo near-infrared fluorescence imaging. Curr. Opin. Chem. Biol. 2003, 7, 626-634. [CrossRef]

179. Shi, Y.; Van Der Meel, R.; Chen, X.; Lammers, T. The EPR effect and beyond: Strategies to improve tumor targeting and cancer nanomedicine treatment efficacy. Theranostics 2020, 10, 7921-7924. [CrossRef]

180. Hutteman, M.; Van Der Vorst, J.; Mieog, J.; Bonsing, B.; Hartgrink, H.; Kuppen, P.; Löwik, C.; Frangioni, J.; Van De Velde, C.; Vahrmeijer, A. Near-Infrared Fluorescence Imaging in Patients Undergoing Pancreaticoduodenectomy. Eur. Surg. Res. 2011, 47, 90-97. [CrossRef]

181. Van Der Vorst, J.R.; Vahrmeijer, A.L.; Hutteman, M.; Bosse, T.; Smit, V.T.H.B.M.; Van De Velde, C.J.H.; Frangioni, J.V.; A Bonsing, B. Near-infrared fluorescence imaging of a solitary fibrous tumor of the pancreas using methylene blue. World J. Gastrointest. Surg. 2012, 4, 180-184. [CrossRef]

182. Majlesara, A.; Golriz, M.; Hafezi, M.; Saffari, A.; Stenau, E.; Maier-Hein, L.; Müller-Stich, B.P.; Mehrabi, A. Indocyanine green fluorescence imaging in hepatobiliary surgery. Photodiagn. Photodyn. Ther. 2017, 17, 208-215. [CrossRef]

183. Girgis, M.D.; Olafsen, T.; Kenanova, V.; E McCabe, K.; Wu, A.M.; Tomlinson, J.S. Targeting CEA in Pancreas Cancer Xenografts with a Mutated scFv-Fc Antibody Fragment. EJNMMI Res. 2011, 1, 24. [CrossRef]

184. Rosenthal, E.L.; Kulbersh, B.D.; King, T.; Chaudhuri, T.R.; Zinn, K. Use of fluorescent labeled anti-epidermal growth factor receptor antibody to image head and neck squamous cell carcinoma xenografts. Mol. Cancer Ther. 2007, 6, 1230-1238. [CrossRef] [PubMed]

185. Tummers, W.S.; Miller, S.E.; Teraphongphom, N.T.; Gomez, A.; Steinberg, I.; Huland, D.M.; Hong, S.; Kothapalli, S.-R.; Hasan, A.; Ertsey, R.; et al. Intraoperative Pancreatic Cancer Detection using Tumor-Specific Multimodality Molecular Imaging. Ann. Surg. Oncol. 2018, 25, 1880-1888. [CrossRef] [PubMed]

186. Tummers, W.S.; Miller, S.E.; Teraphongphom, N.T.; Berg, N.S.V.D.; Hasan, A.; Longacre, T.A.; Fisher, G.A.; Bonsing, B.A.; Vahrmeijer, A.L.; Gambhir, S.S.; et al. Detection of visually occult metastatic lymph nodes using molecularly targeted fluorescent imaging during surgical resection of pancreatic cancer. HPB 2019, 21, 883-890. [CrossRef] [PubMed]

187. Lu, G.; van den Berg, N.S.; Martin, B.A.; Nishio, N.; Hart, Z.P.; van Keulen, S.; Fakurnejad, S.; Chirita, S.U.; Raymundo, R.C.; Yi, G.; et al. Tumour-specific fluorescence-guided surgery for pancreatic cancer using panitumumab-IRDye800CW: A phase 1 single-centre, open-label, single-arm, dose-escalation study. Lancet Gastroenterol. Hepatol. 2020, 5, 753-764. [CrossRef]

188. Harlaar, N.J.; Koller, M.; de Jongh, S.J.; van Leeuwen, B.; Hemmer, P.H.; Kruijff, S.; van Ginkel, R.J.; Been, L.B.; de Jong, J.S.; Kats-Ugurlu, G.; et al. Molecular fluorescence-guided surgery of peritoneal carcinomatosis of colorectal origin: A single-centre feasibility study. Lancet Gastroenterol. Hepatol. 2016, 1, 283-290. [CrossRef] 
189. Lamberts, L.E.; Koch, M.; De Jong, J.S.; Adams, A.L.L.; Glatz, J.; Kranendonk, M.E.G.; Van Scheltinga, A.G.T.; Jansen, L.; De Vries, J.; Hooge, M.N.L.-D.; et al. Tumor-Specific Uptake of Fluorescent Bevacizumab-IRDye800CW Microdosing in Patients with Primary Breast Cancer: A Phase I Feasibility Study. Clin. Cancer Res. 2017, 23, 2730-2741. [CrossRef]

190. Handgraaf, H.; Boonstra, M.C.; Prevoo, H.A.; Kuil, J.; Bordo, M.W.; Boogerd, L.S.; Mulder, B.G.S.; Sier, C.; Slooten, M.L.V.-V.; Valentijn, A.R.P.; et al. Real-time near-infrared fluorescence imaging using cRGD-ZW800-1 for intraoperative visualization of multiple cancer types. Oncotarget 2017, 8, 21054-21066. [CrossRef]

191. De Valk, K.S.; Deken, M.M.; Handgraaf, H.J.M.; Bhairosingh, S.S.; Bijlstra, O.D.; Van Esdonk, M.J.; Van Scheltinga, A.G.T.; Valentijn, A.R.P.; March, T.L.; Vuijk, J.; et al. First-in-Human Assessment of cRGD-ZW800-1, a Zwitterionic, Integrin-Targeted, Near-Infrared Fluorescent Peptide in Colon Carcinoma. Clin. Cancer Res. 2020, 26, 3990-3998. [CrossRef]

192. Tummers, W.S.; Kimura, R.H.; Abou-Elkacem, L.; Beinat, C.; Vahrmeijer, A.L.; Swijnenburg, R.-J.; Willmann, J.K.; Gambhir, S.S. Development and Preclinical Validation of a Cysteine Knottin Peptide Targeting Integrin $\alpha \mathrm{v} \beta 6$ for Near-infrared Fluorescentguided Surgery in Pancreatic Cancer. Clin. Cancer Res. 2018, 24, 1667-1676. [CrossRef]

193. Juhl, K.; Christensen, A.; Rubek, N.; Karnov, K.K.S.; Von Buchwald, C.; Kjaer, A. Improved surgical resection of metastatic pancreatic cancer using UPAR targeted in vivo fluorescent guidance: Comparison with traditional white light surgery. Oncotarget 2019, 10, 6308-6316. [CrossRef]

194. Zettlitz, K.A.; Tsai, W.-T.K.; Knowles, S.M.; Kobayashi, N.; Donahue, T.R.; Reiter, R.E.; Wu, A.M. Dual-Modality Immuno-PET and Near-Infrared Fluorescence Imaging of Pancreatic Cancer Using an Anti-Prostate Stem Cell Antigen Cys-Diabody. J. Nucl. Med. 2018, 59, 1398-1405. [CrossRef]

195. Ehlerding, E.B.; Sun, L.; Lan, X.; Zeng, D.; Cai, W. Dual-Targeted Molecular Imaging of Cancer. J. Nucl. Med. 2018, 59, 390-395. [CrossRef]

196. Wang, Q.; Yan, H.; Wang, Z.; Li, Z.; Li, D.; Li, Z.; Wang, K.; Tian, J.; Zhao, X. Construction of a novel bispecific fusion protein to enhance targeting for pancreatic cancer imaging. Biomaterials 2020, 255, 120161. [CrossRef]

197. Luo, H.; England, C.G.; Shi, S.; Graves, S.A.; Hernandez, R.; Liu, B.; Theuer, C.P.; Wong, H.C.; Nickles, R.J.; Cai, W. Dual Targeting of Tissue Factor and CD105 for Preclinical PET Imaging of Pancreatic Cancer. Clin. Cancer Res. 2016, 22, 3821-3830. [CrossRef]

198. Altai, M.; Membreno, R.; Cook, B.; Tolmachev, V.; Zeglis, B.M. Pretargeted Imaging and Therapy. J. Nucl. Med. 2017, 58, 1553-1559. [CrossRef]

199. Bailly, C.; Bodet-Milin, C.; Rousseau, C.; Faivre-Chauvet, A.; Kraeber-Bodéré, F.; Barbet, J. Pretargeting for imaging and therapy in oncological nuclear medicine. EJNMMI Radiopharm. Chem. 2017, 2, 6. [CrossRef]

200. Houghton, J.L.; Zeglis, B.M.; Abdel-Atti, D.; Sawada, R.; Scholz, W.W.; Lewis, J.S. Pretargeted Immuno-PET of Pancreatic Cancer: Overcoming Circulating Antigen and Internalized Antibody to Reduce Radiation Doses. J. Nucl. Med. 2015, 57, 453-459. [CrossRef]

201. Du, J.; Gu, J.; Li, J. Mechanisms of drug resistance of pancreatic ductal adenocarcinoma at different levels. Biosci. Rep. 2020, 40. [CrossRef]

202. Mucciolo, G.; Roux, C.; Scagliotti, A.; Brugiapaglia, S.; Novelli, F.; Cappello, P. The dark side of immunotherapy: Pancreatic cancer. Cancer Drug Resist. 2020, 3, 419-520. [CrossRef]

203. Yang, E.; Shah, K. Nanobodies: Next Generation of Cancer Diagnostics and Therapeutics. Front. Oncol. 2020, 10, 1182. [CrossRef]

204. Caputo, D.; Pozzi, D.; Farolfi, T.; Passa, R.; Coppola, R.; Caracciolo, G. Nanotechnology and pancreatic cancer management: State of the art and further perspectives. World J. Gastrointest. Oncol. 2021, 13, 231-237. [CrossRef]

205. Wei, Q.-Y.; Xu, Y.-M.; Lau, A.T.Y. Recent Progress of Nanocarrier-Based Therapy for Solid Malignancies. Cancers 2020, $12,2783$. [CrossRef]

206. Stumpp, M.T.; Dawson, K.M.; Binz, H.K. Beyond Antibodies: The DARPin ${ }^{\circledR}$ Drug Platform. BioDrugs 2020, $34,423-433$. [CrossRef]

207. Shilova, O.N.; Deyev, S.M. DARPins: Promising Scaffolds for Theranostics. Acta Nat. 2019, 11, 42-53. [CrossRef]

208. Attia, A.B.E.; Balasundaram, G.; Moothanchery, M.; Dinish, U.; Bi, R.; Ntziachristos, V.; Olivo, M. A review of clinical photoacoustic imaging: Current and future trends. Photoacoustics 2019, 16, 100144. [CrossRef]

209. Beard, P. Biomedical photoacoustic imaging. Interface Focus 2011, 1, 602-631. [CrossRef]

210. Zhao, Y.; Ye, F.; Brismar, T.B.; Li, X.; He, R.; Heuchel, R.; El-Sayed, R.; Feliu, N.; Zheng, W.; Oerther, S.; et al. Multimodal Imaging of Pancreatic Ductal Adenocarcinoma Using Multifunctional Nanoparticles as Contrast Agents. ACS Appl. Mater. Interfaces 2020, 12, 53665-53681. [CrossRef]

211. Gomes Marin, J.F.; Nunes, R.F.; Coutinho, A.M.; Zaniboni, E.C.; Costa, L.B.; Barbosa, F.G.; Queiroz, M.A.; Cerri, G.G.; Buchpiguel, C.A. Theranostics in Nuclear Medicine: Emerging and Re-emerging Integrated Imaging and Therapies in the Era of Precision Oncology. Radiographics 2020, 40, 1715-1740. [CrossRef]

212. Montemagno, C.; Cassim, S.; De Leiris, N.; Durivault, J.; Faraggi, M.; Pagès, G. Pancreatic Ductal Adenocarcinoma: The Dawn of the Era of Nuclear Medicine? Int. J. Mol. Sci. 2021, 22, 6413. [CrossRef]

213. Watabe, T.; Liu, Y.; Kaneda-Nakashima, K.; Shirakami, Y.; Lindner, T.; Ooe, K.; Toyoshima, A.; Nagata, K.; Shimosegawa, E.; Haberkorn, U.; et al. Theranostics Targeting Fibroblast Activation Protein in the Tumor Stroma: 64Cu- and 225Ac-Labeled FAPI-04 in Pancreatic Cancer Xenograft Mouse Models. J. Nucl. Med. 2020, 61, 563-569. [CrossRef] [PubMed] 
214. Lamberts, L.E.; Menke-van der Houven, C.W.; ter Weele, E.J.; Bensch, F.; Smeenk, M.M.; Voortman, J.; Hoekstra, O.S.; Williams, S.P.; Fine, B.M.; Maslyar, D.; et al. ImmunoPET with Anti-Mesothelin Antibody in Patients with Pancreatic and Ovarian Cancer before Anti-Mesothelin Antibody-Drug Conjugate Treatment. Clin. Cancer Res. 2016, 22, 1642-1652. [CrossRef] [PubMed]

215. McElroy, M.; Kaushal, S.; Luiken, G.A.; Talamini, M.A.; Moossa, A.R.; Hoffman, R.M.; Bouvet, M. Imaging of Primary and Metastatic Pancreatic Cancer Using a Fluorophore-Conjugated Anti-CA19-9 Antibody for Surgical Navigation. World J. Surg. 2008, 32, 1057-1066. [CrossRef] [PubMed]

216. Girgis, M.D.; Kenanova, V.; Olafsen, T.; McCabe, K.E.; Wu, A.M.; Tomlinson, J.S. Anti-CA19-9 Diabody as a PET Imaging Probe for Pancreas Cancer. J. Surg. Res. 2011, 170, 169-178. [CrossRef] [PubMed]

217. Girgis, M.D.; Federman, N.; Rochefort, M.M.; McCabe, K.E.; Wu, A.M.; Nagy, J.O.; Denny, C.; Tomlinson, J.S. An engineered anti-CA19-9 cys-diabody for positron emission tomography imaging of pancreatic cancer and targeting of polymerized liposomal nanoparticles. J. Surg. Res. 2013, 185, 45-55. [CrossRef] [PubMed]

218. Kaushal, S.; McElroy, M.K.; Luiken, G.A.; Talamini, M.A.; Moossa, A.R.; Hoffman, R.M.; Bouvet, M. Fluorophore-conjugated anti-CEA antibody for the intraoperative imaging of pancreatic and colorectal cancer. J. Gastrointest. Surg. 2008, 12, 1938-1950. [CrossRef] [PubMed]

219. Gao, S.; Qin, J.; Sergeeva, O.; Sergeev, M.; Qiao, P.; Roelle, S.; Avril, N.; Lee, Z.; Li, Y.; Lu, Z. Synthesis and assessment of ZD2-(68Ga-NOTA) specific to extradomain B fibronectin in tumor microenvironment for PET imaging of pancreatic cancer. Am. J. Nucl. Med. Mol. Imaging 2019, 9, 216-229.

220. Jailkhani, N.; Ingram, J.R.; Rashidian, M.; Rickelt, S.; Tian, C.; Mak, H.; Jiang, Z.; Ploegh, H.L.; Hynes, R.O. Noninvasive imaging of tumor progression, metastasis, and fibrosis using a nanobody targeting the extracellular matrix. Proc. Natl. Acad. Sci. USA 2019, 116, 14181-14190. [CrossRef]

221. Müller, M.; Altmann, A.; Sauter, M.; Lindner, T.; Jäger, D.; Rathke, H.; Herold-Mende, C.; Marmé, F.; Babich, J.; Mier, W.; et al. Preclinical evaluation of peptide-based radiotracers for integrin $\alpha \mathrm{v} \beta 6$-positive pancreatic carcinoma. Nuklearmedizin 2019, 58, 309-318. [CrossRef]

222. Morcillo, M.Á.; de Lucas, G.; Oteo, M.; Romero, E.; Magro, N.; Ibañez, M.; Martinez, A.; Garaulet, G.; Arroyo, A.G.; Lopez-Casas, P.P.; et al. MT1-MMP as a PET imaging biomarker for pancreas cancer management. Contrast Media Mol. Imaging 2018, 2018, 8382148. [CrossRef]

223. Park, J.Y.; Hiroshima, Y.; Lee, J.Y.; Maawy, A.A.; Hoffman, R.M.; Bouvet, M. MUC1 Selectively Targets Human Pancreatic Cancer in Orthotopic Nude Mouse Models. PLoS ONE 2015, 10, e0122100. [CrossRef]

224. Sugyo, A.; Tsuji, A.B.; Sudo, H.; Nagatsu, K.; Koizumi, M.; Ukai, Y.; Kurosawa, G.; Zhang, M.-R.; Kurosawa, Y.; Saga, T. Preclinical evaluation of $89 \mathrm{Zr}$-labeled human antitransferrin receptor monoclonal antibody as a PET probe using a pancreatic cancer mouse model. Nucl. Med. Commun. 2015, 36, 286-294. [CrossRef] 